\title{
Expected Benefits of Federally-Funded Thermal Energy Storage Research
}

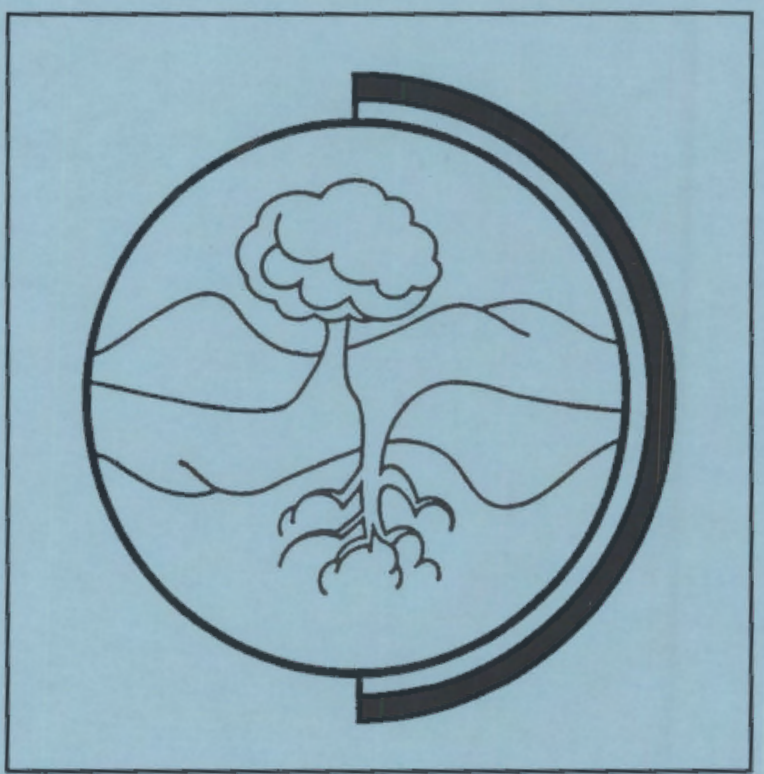

September 1992

Prepared for the U.S. Department of Energy Contract DE-AC06-76RLO 1830

Pacific Northwest Laboratory Operated for the U.S. Department of Energy by Battelle Memorial Institute 


\section{DISCLAIMER}

This report was prepared as an account of work sponsored by an agency of the United States Government. Neither the United States Government nor any agency thereof, nor Battelle Memorial institute, nor any of their employees, makes any warranty, expressed or implied, or assumes any legal liability or responsibility for the accuracy, completeness, or usefulness of any information, apparatus, product, or process disclosed, or represents that its use would not infringe privately owned rights. Reference herein to any specific commercial product, process, or service by trade name, trademark, manufacturer, or otherwise does not necessarily constitute or imply its endorsement, recommendation, or favoring by the United States Government or any agency thereof, or Battelle Memorial institute. The views and opinions of authors expressed herein do not necessarily state or reflect those of the United States Government or any agency thereof.

\section{PACIFIC NORTHWEST LABORATORY operated by \\ BATTELLE MEMORIAL INSTITUTE for the \\ UNITED STATES DEPARTMENT OF ENERGY under Contract DE-AC06-76RLO 1830}

Printed in the United States of America

Available to DOE and DOE contractors from the Office of Scientific and Technical Information, P.O. Box 62, Oak Ridge, TN 37831; prices available from (615) 576-8401. FTS 626-8401.

Available to the public from the National Technical Information Service, U.S. Department of Commerce, 5285 Port Royal Rd., Springfieid, VA 22161. 
PNL -8290

UC -202

EXPECTED BENEFITS OF FEDERALLY-FUNDED THERMAL ENERGY STORAGE RESEARCH
G. E. Spanner
K. K. Daellenbach
K. R. Hughes
D. R. Brown
M. K. Drost

September 1992

Prepared for the U.S. Department of Energy under Contract DE-ACO6-76RLO 1830

Pacific Northwest Laboratory

Richland, Washington 99352 



\section{EXECUTIVE SUMMARY}

Pacific Northwest Laboratory (PNL) conducted this study for the office of Advanced Utility Concepts of the U.S. Department of Energy (DOE). The objective of this study was to develop a series of graphs that depict the long-term benefits of continuing DOE's thermal energy storage (TES) research program in four sectors: building heating, building cooling, utility power production, and transportation.

The study was conducted in three steps. The first step was to assess the maximum possible benefits technically achievable in each sector. In some sectors, the maximum benefit was determined by a "supply side" limitation, and in other sectors, the maximum benefit is determined by a "demand side" limitation. The second step was to appiy economic cost and diffusion models to estimate the benefits that are likely to be achieved by TES under two scenarios: 1) with continuing DOE funding of TES research, and 2) without continued funding. The models ail cover the 20-year period from 1990 to 2010 . The third step was to prepare graphs that show the maximum technical benefits achievable, the estimated benefits with TES research funding, and the estimated benefits in the absence of TES research funding.

The benefits of federally-funded TES research are largely in four areas: displacement of primary energy, displacement of oil and natural gas, reduction in peak electric loads, and emissions reductions. 



\section{CONTENTS}

EXECUTIVE SUMMARY ............................ ...

1.0 INTRODUCTION . . . . . . . . . . . . . . . . . . . . . . . . . . . 1.1

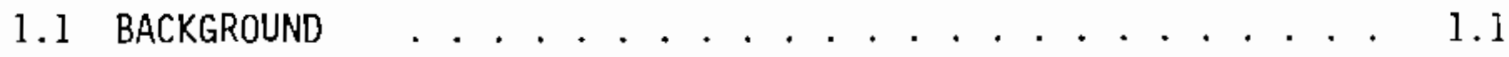

I.2 OBJECTIVE . . . . . . . . . . . . . . . . . . 1.1

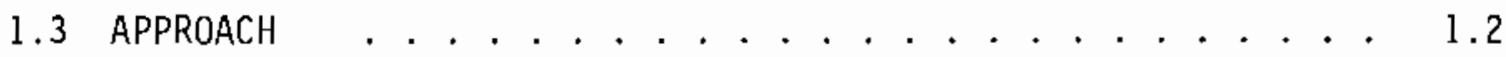

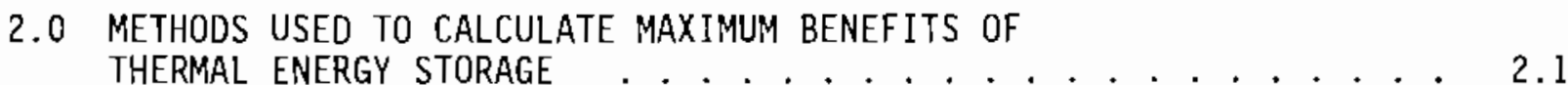

3.0 DESCRIPTION OF THE ECONOMIC COST AND DIFFUSION MODELS $\ldots . . . .3 .1$

3.1 BACKGROUND . . . . . . . . . . . . . . . . . . . . . 3.1

3.1.1 Economic Cost Models . . . . . . . . . . . 3.1

3.1.2 Diffusion Models . . . . . . . . . . . . 3.2

3.2 METHOD . . . . . . . . . . . . . . . . . . 3.3

3.2.1 General .................. 3.3

3.2.2 Model Determination and Assumptions . . . . . . . 3.4

4.0 BENEFITS OF THERMAL ENERGY STORAGE RESEARCH . . . . . . . . . . . . 4.1

4.1 TES PROGRAM tOTAL BENEFITS . . . . . . . . . . . . 4.2

4.2 TES PROGRAM BENEFITS BY SECTOR . . . . . . . . . . . . . . 4.10

4.2.1 Building Sector Heating .............. 4.10

4.2.2 Building Sector Cooling ............. 4.15

4.2.3 Utility Sector ............... 4.20

4.2.4 Transportation Sector ............ 4.24

4.3 GRAPHS SUPPORTING TES BENEFITS RESULTS . . . . . . . . . . . . 4.26

4.3.1 Building Sector Heating .............. 4.26

4.3.2 Bujlding Sector Cooling ............ 4.30

4.3.3 Utility Sector ................. 4.33 
4.3.4 Industrial Sector ............... 4.33

5.0 REFERENCES ........................... . . . . . . . . . . .

6.0 BIBLIOGRAPHY . . . . . . . . . . . . . . . . . . . . . . . . 6.1

APPENDIX A - KEY ASSUMPTIONS AND DATA SOURCES FOR THE BENEFITS GRAPHS ................... A.1

APPENDIX B - KEY ASSUMPTIONS AND DATA SOURCES FOR THE SUPPORTING GRAPHS .................... B.I 


\section{FIGURES}

4.1 Total Benefits: Primary Energy Displaced by A1.1 TES . . . . . . 4.3

4.2 Total Benefits: $\mathrm{CO}_{2}$ Emissions Reduction Due to TES . . . . . . . 4.4

4.3 Total Benefits: So Emissions Reduction Due to TES . . . . . . 4.5

4.4 Total Benefits: N0 Emissions Reduced Due to TES . . . . . . . . 4.6

4.5 Total Benefits: Avoid Generating Capacity by all TES . . . . . 4.7

4.6 Total Benefits: $0 i 1$ and Gas Displacement by Utility TES . . . 4.8

4.7 Total Benefits: Electric Energy Reduction by TES . . . . . . 4.9

4.8 Seasonal TES: Building Sector Heating Primary Energy Displaced by STES Technology ............... . 4.10

4.9 Seasonal TES: Building Sector Heating Energy Displaced by STES (Industrial Waste Heat) . . . . . . . . . . . . 4.11

4.10 Seasonal TES: Building Sector Heating Energy Displaced by STES (Solar Heat) .................. 4.12

4.11 Building Sector Heating: $\mathrm{CO}_{2}$ Emissions Reduction Due to TES . . 4.13

4.12 Building Sector Heating SO Emissions Reduction Due to TES * . 4 4.14

4.13 Building Sector Heating NO Emissions Reduction Due to TES • • 4.15

4.14 Seasonal TES: Building Sector Cooling Primary Energy Displaced . 4.16

4.15 Building Sector Cooling: Avoided Generating Capacity by Diurnal TES . . . . . . . . . . . . . . . . 4.17

4.16 Building Sector Cooling: $\mathrm{CO}_{2}$ Emissions Reduction Due to TES . . 4.18

4.17 Building Sector Cooling: SO Emissions Reduction Due to TES . . 4.19

4.18 Building Sector Cooling: $\mathrm{NO}_{x}$ Emissions Reduction Due to TES . . 4.20

4.19 Utility Sector: $0 i 1$ and Gas Displacement by Utility TES . . . . 4.21

4.20 Utility Sector: Avoided Capacity by UTES-Gas Turbine Inlet Cooling .................. 4.22

4.21 Utility Sector: Avoided Capacity by UTES-Cogeneration . . . . . 4.23

4.22 Utility Sector: Total Avoided New Capacity A11 UTES . . . . . 4.24 
4.23 Transportation Sector: NO Emissions Reduction by TES (Catalytic Preheat)

4.24 Building Sector Heating: Seasonal Thermal Primary

Power Demand

4.25 Seasonal Solar Heat Supply (U.S. excluding Alaska) . . . . . . 4.27

4.26 Building Sector Heating: Diurnal Thermal Primary Power Demand for January . . . . . . . . . . . . . 4.28

4.27 Diurnal Solar Heat Suppiy: December (U.S. excluding Alaska) • . 4.29

4.28 Building Sector Heating: Total Primary Energy Heat Demand . . 4.29

4.29 Total Solar Heat Available: (U.S. excluding Alaska) . . . . . 4.30

4.30 Building Sector Cooling: Annual Cooling Load (Primary Energy) . 4.31

4.31 Bujlding Sector Cooling: Peak Electric Cooling Demand . . . . 4.31

4.32 Building Sector Cooling: Seasonal Primary Electric Energy Demand ................... . . 4.32

4.33 Building Sector Cooling: Diurnal Cooling Primary Energy Demand for July .................. 4.32

4.34 Utility Sector: Electricity Generating Costs . . . . . . . 4.33

4.35 Industria] Sector: Total Waste Heat Supply . . . . . . . . 4.34

4.36 Industrial Sector: Seasonal Waste Heat Supply . . . . . . . . 4.34

\section{$\underline{\text { TABLES }}$}

4.1 Expected Derivative Benefits of the TES Program by Sector . . . 4.2 


\subsection{INTRODUCTION}

\subsection{BACKGROUND}

Thermal energy storage (TES) technologies, if implemented to the maximum extent possible, are expected to yield significant benefits in a number of areas. For example, TES implementation can result in primary energy savings by using industrial waste heat and solar heat to heat buildings. Peak electricity demand can be reduced in the building cooling sector by saving energy produced during off-peak periods and using the energy to cool buildings during periods of peak demand. Reliance on natural gas and oil can be reduced by storing energy from coal plants during off-peak periods and then using the energy during periods of peak demand instead of burning the premium fuels. Emissions can be reduced by storing solar energy and industrial waste heat so that building heat can be provided at the appropriate time without having to burn fossil fuels. Emissions can also be reduced in the transportation sector by preheating engines and catalytic converters so that excess pollution ordinarily produced by automobiles during warmup is eliminated.

A federally-funded TES research program can be expected to increase implementation of TES technologies and thereby increase the benefits derived. Important questions to ask are: what are the potential benefits of TES technologies and how much can TES research increase TES implementation? The goal of this project was to answer these questions in graphical form.

\subsection{OBJECTIVE}

The specific objective of this research was to develop a series of graphs that depict the long-term benefits of continuing the U.S. Department of Energy's (DOE's) TES research program. In particular, the graphs show how achieving the benefits of TES is affected by continuing TES research in four sectors: building heating, building cooling, utility power production, and transportation. For each benefit in each sector, the graphs are to show the maximum level of TES benefit technically achievable in the sector, as well as the benefit likely to be achieved if DOE funding of TES research continues at 
the current funding level of $\$ 5 \mathrm{million} / \mathrm{yr}$, and if it does not. These graphs can then be used to guide decisions about where TES research funding should be focused.

\subsection{APPROACH}

The first step in developing the graphs was to assess the maximum possible benefits technically achievable in each sector. In some sectors, the maximum benefit was determined by a "supply side" limitation. For instance, the maximum amount of industrial waste heat that can be stored and used to displace primary energy in the building heating sector is limited by the amount of waste heat available. For other sectors, the maximum benefit is determined by a "demand side" Jimitation. An exampie of this type of maximum benefit is also in the building heating sector, except that the stored energy is obtained from solar heat. In this case, there is far more solar heat avajlable than can be used by the sector, so the maximum benefit is limited by demand for building heating. Several graphs were prepared that illustrate the maximum benefits determinations .

The next step was to apply economic cost and diffusion models to estimate the benefits that are likely to be achieved by TES under two scenarios: with continuing DOE funding of TES research, and without continued funding. The models all cover the 20-year period from 1990 to 2010 . For each sector, a graph was prepared that shows the maximum technical benefits achievabie, the estimated benefits with TES research funding, and the estimated benefits in the absence of TES research funding. The benefits are iargely in four areas: displacement of primary energy, displacement of oil and naturat gas, reduction in peak electric loads, and emissions reductions.

The final step in this research was to develop simpiified graphs that, in addition to showing the benefits over time, also show in iconic form some particularly significant benefit for each sector. For example, in the building heating sector, DOE funding of TES research will avoid enough $\mathrm{SO}_{\mathrm{x}}$ emissions to fill Lake Superior with acid rain to a depth of 1200 feet (as shown in Figure 4.12). 
This report is organized as follows. Chapter 2.0 describes in detail how the maximum benefits were calculated for each sector. Chapter 3.0 provides a description of the economic cost and diffusion models, and iists the overall assumptions involved in the models. Chapter 4.0 presents the simplified graphs that illustrate the benefits to be expected from implementing TES in each sector. A brief explanation is provided for each graph. Appendix A lists the key assumptions, data sources, and limitations for the benefits graphs in Sections 4.1 and 4.2. In Appendix B, key assumptions, data sources, and limitations are presented for each of the supporting graphs in Section 4.3. 



\subsection{METHODS USED TO CALCULATE MAXIMUM BENEFITS OF THERMAL ENERGY STORAGE}

The following narrative describes the general method used to determine inputs for the maximum potential benefit curves. These curves, represented by the top curve in each figure, indicate the total potential for energy savings or reduced emissions for the following four sectors: building sector heating which includes industrial process heat, building sector cooling, utility sector, and transportation sector. Total benefit graphs combine the results from appropriate sectors to display aggregate energy savings, avoided capacity, or reduced emissions. The final group of graphs is the single-curve figures that provide useful supporting information on both energy sources and energy use.

Building sector heating curves include figures 4.8 through 4.13 . The potential energy savings curves on the building sector heating figures were based primarily on energy consumption projections in the 1991 EIA Annual Energy Outlook with Projections to 2010 (1991). Primary end-use patterns found in EIA: Annual Energy Review (1990), National Energy Strategy (1991), and the Analysis and Technology Transfer Report, 1989 and 1990 - Building Technologies (1991) recorded percentage of space heating for various fuel types. Seasonal thermal energy storage (STES) would utilize available solar heat and/or industrial waste heat to offset the primary energy used in the building sector for space heating. The available solar heat (see figure 4.29) could easily of fset the amount of primary energy needed in building sector heating while the availabie industrial waste heat would be limited to five Quad Btu per year during the 20-year period from 1990 to 2010 (see Figure 4.35).

The potential $\mathrm{CO}_{2}, \mathrm{SO}_{\mathrm{x}}$, and $\mathrm{NO}$ emissions reduction curves on the building sector heating figures were based on emission guidelines in an Environmenta 1 Protection Agency (EPA) document (AP-42 1985). This EPA document, along with predictions based on stoichiometric calculations, provided uncontrolled emission factors by fuel type. It al so included emission regulation standards by fuel type for the various fuel-firing configurations. By coupling the predicted emission levels by fuel type with the total potential primary building sector heating energy (Figures 4.8 and 4.28 ), total emission 
values were determined. Because there is more energy available from solar heat and industrial waste heat than the projected heating needs for the 20 year period between 1990 and 2010, the total emission levels also represent the potential for emission reductions. Unlike the potential energy savings curves, top curves for emission reductions are not linear, indicating the changing ratio between fuel types between 1990 and 2010 .

Building sector cooling curves include figures 4.14 through 4.18 . The potential energy savings curves in the building sector cooling shown in Figure 4.14, like the preceding building sector heating figures, were based primarily on energy consumption projections in the 1991 EIA Annual Energy Outlook with Projections to 2010 (1991). Primary end-use patterns found in EIA: Annual Energy Review (1990), National Eneroy Strategy (1991), and the Analysis and Technology Transfer Report, 1989 and 1990 - Building Technologies (1991) recorded percentage of space cooiing for various fuel types. With the abundant supply of solar energy, applying STES technology to the primary energy needed for building sector cooling has the potential to offset all cooling requirements. The potentjal capacity reduction in Figure 4.15 was based on the projected total electric energy demand for space cooling (1991 EIA Annual Energy Outlook with Projections to 2010 [1991]) and an electric load factor of $61.6 \%$ (Statistical Yearbook of the Electric Industry/1990 [1991]).

Determination of the potential $\mathrm{CO}_{2}, \mathrm{SO}_{x}$, and $\mathrm{NO}_{x}$ emission reduction curves followed the method outlined above for the building sector heating. The difference between the two sectors is the smaller amount of primary energy needed in the building cooling sector and, therefore, the potential emissions reduction will be less.

The utility sector curves include Figures 4.19 through 4.22 . The potential oil and gas displacement by a less expensive fuel such as coal includes the projected demand for $0 i 7$ and gas by electric utilities for the 20-year period between 1990 and 2010 (EIA 1991). The top curves for Figures 4:20 and 4.21 with the aggregate of the two displayed in Figure 4.22 are based on the projected total electric energy demand for space cooling (1991 EIA Annual Energy Outlook with Projections to 2010 [1991]) and an eiectric load factor of $61.6 \%$ (Statistical Yearbook of the Electric Industry/1990 [1991]). The curves 
represent the potential for avoided capacity by applying utility thermal energy storage (UTES) technology to gas turbine inlet cooling temperatures and cogeneration.

The transportation sector curve includes Figure 4.23. Thermal energy storage technology used to preheat automobile catalytic converters could reduce the $\mathrm{NO}_{x}$ emitted during the engine's cold start. The reduction of $\mathrm{NO}_{x}$ emitted could amount to a $75 \%$ reduction of the total $\mathrm{NO}_{\mathrm{x}}$ emissions for an average trip of 9.2 miles. The technology will only be applied to new cars with no retrofitting of old cars. It is believed that once the technology is proven (starting in 1995 with TES research and 2000 without TES research), the EPA will mandate its use on all new automobiles.

The total benefits curves include Figures 4.1 through 4.8 and represent an aggregate of energy savings and reduced emission potential. The curves present an overall view of the impact of TES technology. The inputs to these aggregate figures are derived from the four sectors described above.

The single-curve figures include Figures 4.24 through 4.36 and provide useful background for the understanding and development of the more complex three-curve figures. Thermal primary power demand is shown for the 20-year period between 1990 and 2010 (Figure 4.28), seasonally (Figure 4.24), and diurnally for the month of January (Figure 4.26). Building sector cooling is shown for the 20-year period between 1990 and 2010 (Figure 4.31), seasonally (Figure 4.32), and diurnally for the month of July (Figure 4.33). Solar heat supply is likewise shown as total supply (Figure 4.29), seasonal supply (Figure 4.25), and diurnally (4.27). Finally, industrial waste heat supply is shown for the 20-year period between 1990 and 2010 (Figure 4.35) and seasonally (Figure 4.35). 



\subsection{DESCRIPIION OF THE ECONOMIC COST AND DIFFUSION MODELS}

The following section outlines the method employed to predict the diffusion of the TES technologies in the various sectors analyzed. Detailed information on the sources of the various parameters and on the market data employed appears in Section 3.2.2.

\subsection{BACKGROUND}

The development of diffusion models dates back to the early work of Fourt and Woodlock (1960), Mansfield (1961), and Bass (1969). Of the models developed by these three, the Bass model has received the most widespread use and attention and, as a result, is the most refined in terms of assumptions and areas of applicability. Specific diffusion models have been developed to represent new product or technology diffusion in many areas including those of consumer goods, agricultural innovations, industrial innovations, medical innovations, and telecommunication innovations (Mahajan et a1. 1990). A model developed by the Stanford Research Institute (SRI) and reported by Teotia and Raju (1986) has been designed specifically to model the diffusion of energyefficient innovations (such as energy-efficient solar technologies, energyefficient electric motors, and gas turbines, etc.). The present study employs this model, as well as the method developed by Teotia and Raju (1986). The following paragraphs describe this model as well as the method used.

\subsubsection{Economic Cost Models}

Economic cost models predict market share at a given time based on the economic attractiveness of the new product or technology. When employing this approach, one first identifies a competing technology that is currently employed. Next, one determines the cost of switching to the new technology. This cost includes setup costs as well as operation and maintenance costs. These costs are converted to a levelized yearly cost (an annuity). Finally, the model predicts that all users who would realize a net economic gain from switching to the new technology (as occurs when the levelized cost of using the new technology is less than the levelized cost of using the existing technology) will, in fact, adopt it. For these individuals, the ratio of the 
levelized cost of the new technology to that of the existing technology (ca)led the Economic Cost Ratio, or ECR) is less than one. The ratio of the number of individuals for whom the technology is attractive $(E C R<1)$ to the total market is referred to as the Economic Market Ratio (EMR).

\subsubsection{Diffusion Models}

The economic cost model makes the assumption that once an alternative is economically attractive, it will be immediately adopted. This is usually not the case. Diffusion of new products or of new technologies is characterized by, first, the initial adoption by innovators, followed by the eariy adopters, the early and late majorities, and finally, those adopters who lag far behind the majority in terms of time of adoption (Rogers 1962, Rogers and Shoemaker 1971). The diffusion models referred to in the previous section attempt to mode1 this phenomenon.

The SRI model (Teotia et a). 1981) was developed especially for energyefficient innovations. It is an S-shaped (logistic) behavioral lag function governed by the following expression:

$$
Y(k)=\frac{1}{1+\left(\frac{h}{k}\right)^{\alpha}}
$$

where $Y(k)=$ market penetration fraction

$$
\begin{aligned}
& h=\text { years to capture } 50 \% \text { of the market (half-life) } \\
& \alpha=\text { a response parameter } \\
& k=\text { number of years beyond assumed base year. }
\end{aligned}
$$

As such, it is similar to a diffusion model for a pure imitative process (e.g., it does not contain a constant of innovation, as is found in the Bass model) (Warren 1980). The parameter $h$ controls the location of the inflection point of the graph (the point at which the rate of incremental adoptions begins to decrease). The parameter $\alpha$ controls the amount of curvature in the 
function, with low values of $\alpha$ generating a more linear, ramp-type curve, and high values of $\alpha$ generating exaggerated $S$-shaped curves.

\subsection{METHOD}

The following sections describe the general method employed in the generation of the market penetration curves, as well as assumptions relating to the use and specification of the diffusion model.

\subsubsection{General}

Teotia and Raju (1986) recommend a four-step, combined economic cost and diffusion model approach to predicting market response to technological innovations. They recommend that researchers in this area employ the following approach:

1. Define the new technology and specify the end-use market segments.

2. Estimate the total potential market for the new technology and its competitors in the end-use market segments.

3. Estimate the economic market for the new technology in the end-use market segments (using the economic cost model).

4. Estimate the market penetration of the new technology in the end-use market segments (using the diffusion model).

In Step 1, the new technology is operationally defined in order to determine what technology or technologies it is likely to compete against, and to determine the end-use market segments that the technology is likely to be employed in, based on different industries or on different uses of the technology.

In Step 2, the total potential market $P(t)$ is determined. This may be accomplished by summing the end-use segments that could potentially adopt the new technology.

In Step 3, the economic market $E(t)$ is estimated using the economic cost model approach described in the previous section. The economic market is that 
portion of the total market for which the new technology is more attractive economically than the existing technology. It may be found as the product of $P(t) \star E M R$.

In Step 4, the diffusion model developed by SRI (discussed above) is applied to calculate the total market penetration of the new technology as a function of time. The total number of sales is determined by the product of $Y(t) * E(t)$.

This four-step approach has been implemented successfully by Teotia and Raju (1986) in the description of district heating cogeneration energy systems and energy-efficient motors.

The following section describes the specific parameters employed in the calculating the diffusion of TES technologies in this study.

\subsubsection{Mode] Determination and Assumptions}

This section describes the parameters employed in the specification of the diffusion model, lists certain assumptions that have been made to use the economic cost and diffusion models, and provides typical calculations employed in determining the 20-year diffusion curves.

\section{Model Determination}

Given either the EMR or $E(t)$ for each TES technology, one must determine the product of $E(t) \star Y(t)$. This equals $M(t)$, the total number of adoptions of the TES technology at time $t$. The principal task involved in doing this is to determine the values of $h$ (half-life) and $\alpha$ (the diffusion rate parameter).

These values may be determined statistically if market penetration data exist for a number of previous periods. If such data are available, the parameters of $Y(t)$ may be determined (perhaps through least squares analysis) and future sales/adoptions predicted. However, if $Y(t)$ is to be determined without any prior adoption data (as is the case with TES technologies), the values of $h$ and $\alpha$ must be estimated by analogy (Mahajan et a]. 1990).

Teotia and Raju (1986) report success using an $h$ equal to 12 years and an $\alpha$ equal to 4.0 for energy-efficient technological innovations, based on the work of SRI (Teotia et a1. 1981). Hence, these values for $h$ and $\alpha$ were 
employed in the specification of $Y(t)$. Once $Y(t)$ was determined, the total number of adoptions as a function of time $M(t)$ could be found from the product of $Y(t)$ and $E(t)$.

\section{Model Assumptions}

A number of assumptions implicit to the economic cost and diffusion models are presented below.

1. The model assumes a dynamic logistic growth. Logistic refers to the log-linear, S-shape of the diffusion curve, while dynamic refers to the ability of the market of potential adopters to change over time. This is necessary to account for the delayed nature of product adoption, which must be considered to not overestimate the total number of sales.

2. The model assumes the technologies will be feasible/available. Should they not be ready for market, adoption cannot begin.

3. The modei assumes that homogeneous TES benefits are realized within a given sector. This assumption implies that the same benefits will accrue to any consumer as a result of the adoption of TES technology. It, therefore, does not account for unique variation among adopters in terms of how much energy savings (or other benefit) each can realize, as this information is unavailable.

4. A rate parameter $\alpha$ is assumed. This parameter controls the initial and final rates of adoption. It has been estimated in this study from analogous forecasts of the diffusion of energy-efficient electric motors, district heating cogeneration, and solar energy innovations (Teotia et a1. 1981).

5. A half-life $h$ is assumed. This value sets the point in time during the diffusion cycle at which the adoption rate is greatest. It has been estimated here from the same data used to estimate the rate parameter.

6. The energy consumption rate is assumed. This value controls the rate at which the demand for energy will increase over the adoption period.

7. The energy cost rate is assumed. This parameter estimates the rate at which the cost of competing technology use (such as use of public electric utility power) will increase.

8. A standard installation capital cost is assumed. The cost of installing a "TES technology package" has been set to a constant value, because the actual variation in the cost of TES technology adoption, which can vary from individual to individual based on what they install, cannot be forecast. 
9. The ECR dictates adoption of the technology. This implies that if the TES technology is more economically attractive than is the status quo, that adopter will enter the total economic market.

10. Diffusion of TES technology is independent of all other innovations. This assumption implies that if a new and better (e.g., more energy efficient) technology is developed, its presence will not affect the TES technology adoption curve. This assumption is required as future breakthroughs cannot be readily predicted. Future breakthroughs could reduce the total number of adoptions.

11. The geographic nature of the adopters is independent of the innovation pattern (e.g., word of mouth networks that are stronger in some areas and weaker in others are not accounted for, etc.), as the impact of these influences is not documented.

12. The diffusion process is binary: either a potential adopter adopts or he/she does not, based on whether his or her ECR is less than or greater than one (respectively). The mental stage in the potential adopter's decision-making process cannot be modeled on an aggregate basis.

13. The diffusion process is not influenced by marketing strategies. That is, the effects of varying distribution channels, customer arrangements, promotional pricing decisions, advertising, etc., is not modeled, as these are not foreseeable.

14. There are no repeat adoptions. Additional purchases beyond the initial purchase are not considered. Such purchases would increase the total number of adoptions.

15. The beginning of 1990 was assumed to be the base year for the adoption process, while the numbers shown for the year represent end-of-year figures. 


\section{Iypical Marketing Calculations}

The calculation of the 20-year diffusion curves, for both with and without funding, was facilitated by equations resembling the following for each such graph.

$$
\begin{gathered}
P(t)=P_{c}(t)+P_{r}(t) \\
E_{R}(t)=\left[P_{c}(t)\right]\left[E C R_{R c}(t)\right]+\left[P_{r}(t)\right]\left[E_{R r}(t)\right] \\
Y(k)=\frac{1}{1+\left(\frac{h}{k}\right)^{\alpha}} \\
M_{R}(t)=E_{R}(t) * Y(t)
\end{gathered}
$$

where $P(t)=$ total potential market at time $t$

$$
\begin{aligned}
P_{r}(t)= & \text { total potential market in the residential sector at } \\
& \text { time } t \\
P_{c}(t)= & \text { total potential market in the commercial sector at } \\
& \text { time } t \\
E_{R}(t)= & \text { total economic market with TES research at time } t \\
E R_{R C}(t)= & \text { economic cost ratio with research in the commercial } \\
& \text { sector at time } t \\
E R_{R r}(t)= & \text { economic cost ratio with research in the residential } \\
& \text { sector at time } t \\
Y(k)= & \text { diffusion model fraction at time } k \\
h= & \text { diffusion model half-life } \\
\alpha= & \text { diffusion model rate parameter } \\
k= & \text { current year - base year (1990) } \\
M_{R}(t)= & \text { actual penetrated market with TES research at time } t .
\end{aligned}
$$





\subsection{BENEFITS OF THERMAL ENERGY STORAGE RESEARCH}

The predicted benefits from the TES research program are presented in graphical and text form in this chapter. Section 4.1 contains graphs indicating overall (across sector) TES research program benefits. These benefits are aggregated across the building sector (heating and cooling), the transportation sector, and the utility sector. Section 4.2 shows graphs dealing with the same predicted TES benefits, but broken down across those sectors in which said benefits are expected to accrue. Section 4.3 provides graphs that support and form the basis for those graphs that appear in Sections 4.1 and 4.2. A description of what the graph shows as well as the key points of the graph is provided in each case. Appendixes A and B provide detailed background information for each graph (e.g., references, assumptions, sample calculations).

The market response to each technology in both the funded and the unfunded scenarios has been modeled both by economic cost and by diffusion models. These models account for the economic attractiveness of the TES technology as well as for dynamic, overall customer reaction to the technology.

The benefits of the TES program may be categorized as follows:

- Primary Energy Displacement - This benefit will reduce primary energy consumption by the U.S. economy regardless of fuel type.

- Emissions Reductions - The displacement of primary energy noted in the first benefit will also result in a reduction in the emissions of $\mathrm{NO}_{x}, \mathrm{SO}_{x}$, and $\mathrm{CO}_{2}$.

- Reduction in Requirements for New Electric Generating Capacity Use of TES technologies will provide enough supplemental power for utilities to avoid having to construct new peaking power plants. This benefit can be achieved by either reducing daily variations in end-use demand for electricity or by increasing the peak output of existing power plants.

- Reductions in Premium Fuel Use - Utility TES allows the use of base load coal-firing technologies to reduce the consumption of premium fuels (oil and natural gas) used for generating electric power. 
The benefits expected to acrue from each sector by type of TES technology are summarized in Table 4.1.

TABLE 4.1. Expected Derivative Benefits of the TES Program by Sector

\begin{tabular}{|c|c|c|c|c|c|}
\hline \multirow[b]{2}{*}{ Benefit } & \multicolumn{5}{|c|}{ TES Technology } \\
\hline & UTES & $\begin{array}{l}\text { STES } \\
\text { Chilt } \\
\text { (Buitding) } \\
\end{array}$ & $\begin{array}{r}\text { STES } \\
\text { Heat } \\
\text { (Building) } \\
\end{array}$ & $\begin{array}{r}\text { Diurnal } \\
\text { (Building) }\end{array}$ & Iransportation \\
\hline $\begin{array}{l}\text { Primary Energy } \\
\text { Displacenent }\end{array}$ & & $x$ & $x$ & & \\
\hline Emissions Reductions & & $x$ & $x$ & & $x$ \\
\hline $\begin{array}{l}\text { Reduction in Requirements } \\
\text { for New Generating } \\
\text { Capacity }\end{array}$ & $x$ & & & $x$ & \\
\hline $\begin{array}{l}\text { Reductions in Premiun } \\
\text { Fuel Use }\end{array}$ & $x$ & & & & \\
\hline
\end{tabular}

\subsection{TES PROGRAM TOTAL BENEFITS}

The following graphs illustrate the estimated benefits of TES from all four sectors combined. 

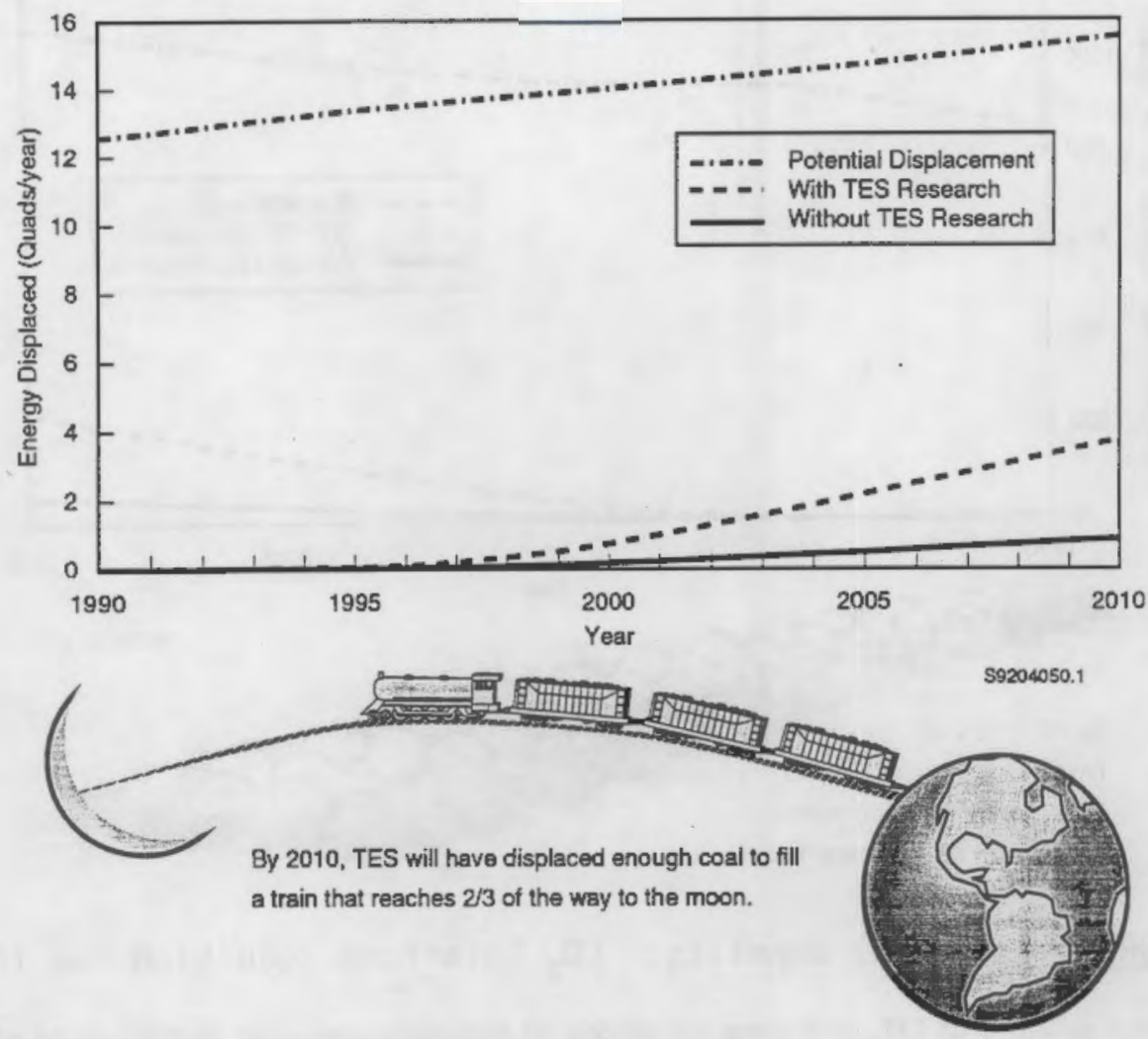

\section{FIGURE 4.1. Total Benefits: Primary Energy Displaced by All TES}

Shown: The total amount of primary energy savings in quads occurring over the next 20 years as a result of TES technology (building space heating and building space cooling). The top curve shows the maximum predicted potential primary energy savings that TES technology could achieve. The middle curve indicates predicted energy savings should TES research continue, while the bottom curve shows predicted savings without DOE-funded TES research.

\section{Key Points:}

- The maximum potential primary energy displacement resulting from the use of TES technologies is between 13 and 15 quads per year. (1 quad $=10^{15}$ Btu)

- With a DOE-funded research program in TES, primary energy displacement resulting from the use of TES technologies will be 3.7 quads per year by the year 2010 .

- Over the next 20 years, DOE funding of TES is predicted to result in a savings of 19.7 quads (cumulative) of primary energy. 


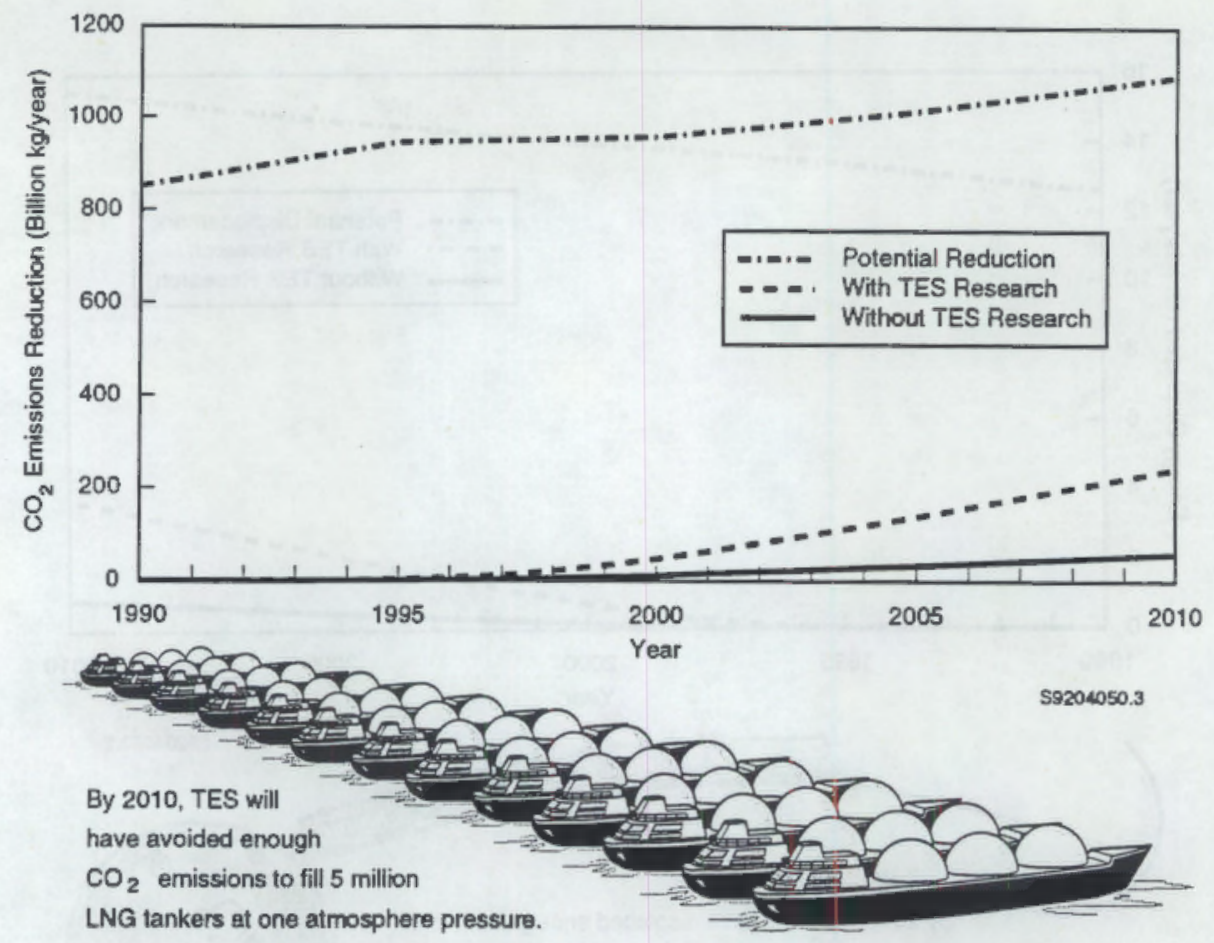

\section{FIGURE 4.2. Total Benefits: $\mathrm{CO}_{2}$ Emissions Reduction Due to TES}

Shown: The total quantity of $\mathrm{CO}_{2}$ emissions (in billions of kilograms per year) that could be obviated over the next 20 years through the application of TES technology (building space heating and building space cooling). The top curve shows the predicted potential quantity of $\mathrm{CO}_{2}$ emissions that could be eliminated by TES technology. The middle curve indicates those emissions predicted to be prevented if TES research continues (at an assumed rate of $\$ 5$ million/ $/ \mathrm{r}$ ), while the bottom curve shows predicted emissions reductions without DOE-funded TES research.

\section{Key Points:}

- The maximum potential reductions in $\mathrm{CO}_{2}$ emissions resulting from the use of TES technologies is between 800 and 1100 billion $\mathrm{kg} / \mathrm{yr}$.

- With a DOE-funded research program in TES, reductions in $\mathrm{CO}_{2}$ emissions resulting from the use of TES technologies will be 250 billion $\mathrm{kg} / \mathrm{yr}$ by the year 2010 .

- Over the next 20 years, DOE funding of TES is predicted to result in a 1,232 billion kilogram (cumulative) reduction of $\mathrm{CO}_{2}$ emissions. 


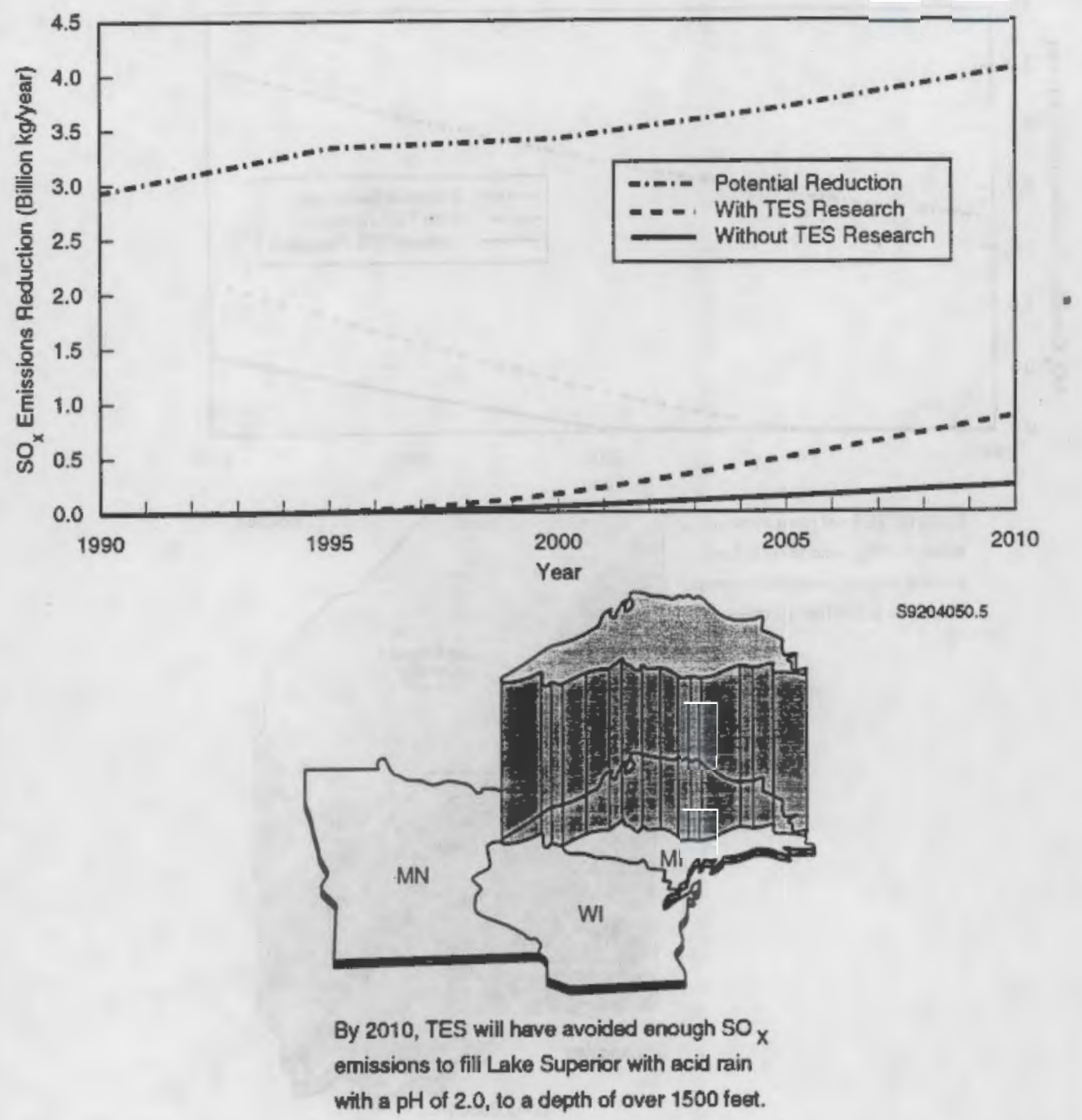

\section{FIGURE 4.3. Total Benefits: SO Emissions Reduction Due to TES}

Shown: The total quantity of $\mathrm{SO}_{x}$ emissions (in billions of kilograms per year) that could be obviated over the next 20 years through the application of TES technology (in building space heating and building space cooling). The top curve shows the predicted potential quantity of $\mathrm{SO}_{x}$ emissions that could be eliminated by TES technology. The middle curve indicates those emissions predicted to be prevented if TES research continues (at current funding levels, assumed to be $\$ 5$ million/yr), while the bottom curve shows predicted emissions reductions without DOE-funded TES research.

\section{Key Points:}

- The maximum potential reductions in $\mathrm{SO}_{\mathrm{x}}$ emissions resulting from the use of TES technologies is between 2.9 and 4.1 billion $\mathrm{kg} / \mathrm{yr}$.

- With a DOE-funded research program in TES, reductions in $\mathrm{SO}_{x}$ emissions resulting from the use of TES technologies will be 0.64 billion $\mathrm{kg} / \mathrm{yr}$ by the year 2010 .

- Over the next 20 years, DOE funding of TES is predicted to result in a 4.2 billion kilogram (cumulative) reduction of $\mathrm{SO}_{x}$ emissions. 

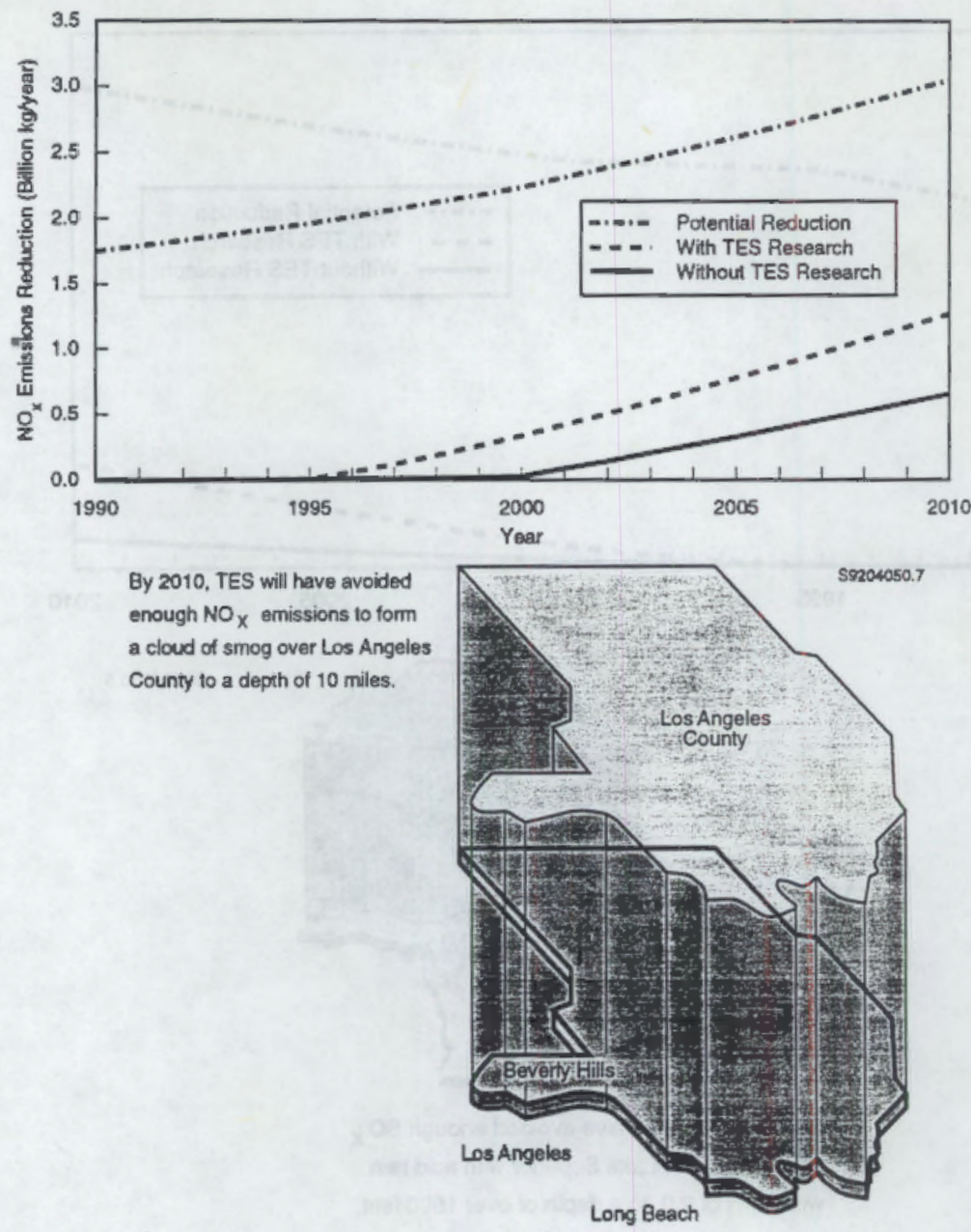

\section{FIGURE 4.4. Total Benefits: NO Emissions Reduced Due to TES}

Shown: The total quantity of $\mathrm{NO}_{x}$ emissions (in billions of kilograms per year that could be obviated over the next 20 years through the application of TES technology (building space heating, building space cooling, and transportation). The top curve shows the predicted potential quantity of $\mathrm{NO}_{\mathrm{x}}$ emissions that could be eliminated by TES technology. The middle curve indicates those emissions predicted to be prevented if TES research continues, while the bottom curve shows predicted emissions reductions without DOE-funded TES research.

\section{Key Points:}

- The maximum potential reduction in $\mathrm{NO}_{x}$ emissions resulting from the use of TES technologies is between 1.7 and 3.1 billion $\mathrm{kg} / \mathrm{yr}$.

- With a DOE-funded research program in TES, reductions in $\mathrm{NO}_{x}$ emissions resulting from the use of TES technologies will be 0.61 billion $\mathrm{kg} / \mathrm{yr}$ by the year 2010 .

- Over the next 20 years, DOE funding of TES is predicted to result in a 5.6 bilion kilogram (cumulative) reduction of $\mathrm{NO}_{x}$ emissions. 


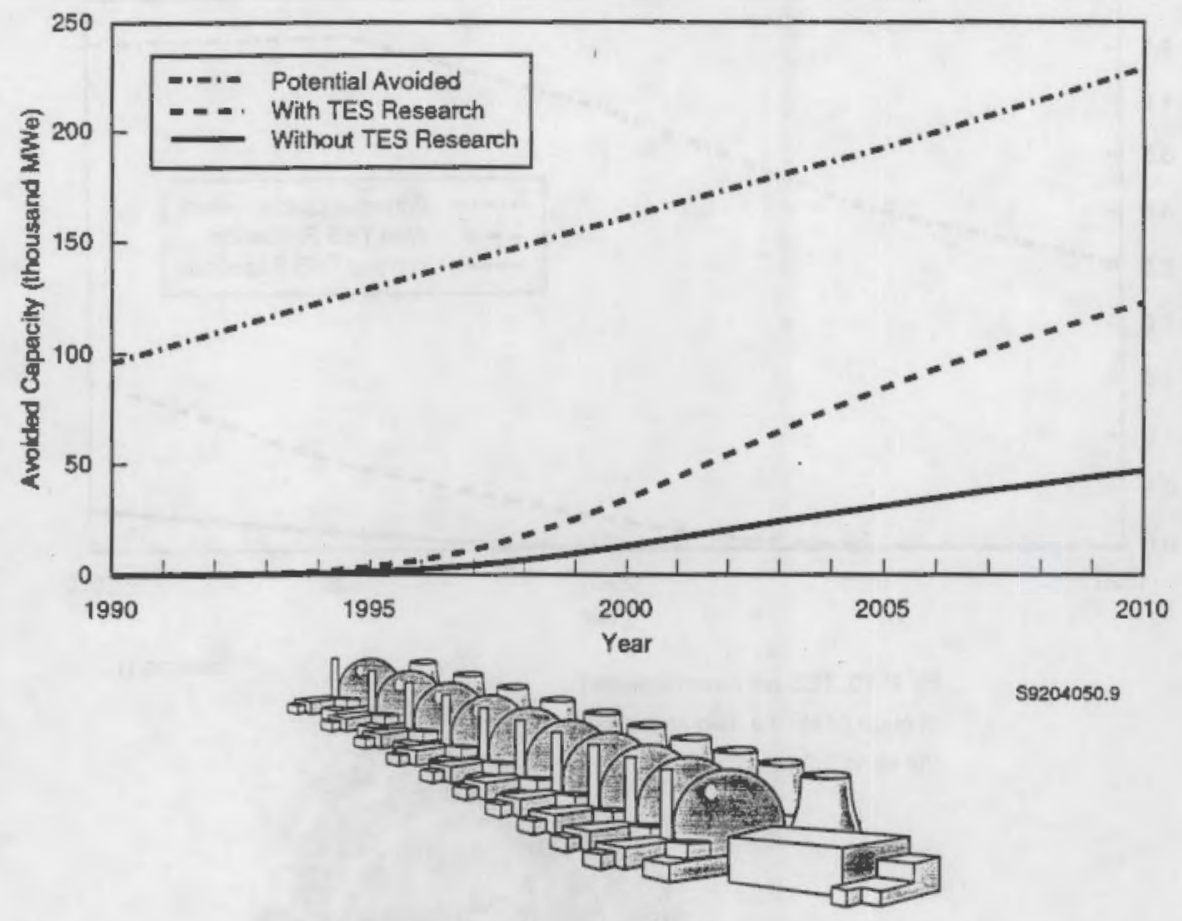

In 2010, TES could avoid the need for 75 large power plants.

\section{FIGURE 4.5. Total Benefits: Avoided Generating Capacity by all TES}

Shown: The amount of peak electric generating capacity (in thousands of MWe) that can be reduced over the next 20 years through TES technology. The top curve indicates the predicted potential peak capacity reduction, the middle curve indicates the predicted capacity that can be avoided if research continues, and the bottom curve indicates the predicted peak capacity reduction without DOE-funded TES research.

\section{Key Points:}

- The maximum potential reduction in required new generating capacity attributable to the use of TES technologies is between $96,000 \mathrm{MWe}$ and 230,000 MWe.

- With a DOE-funded research program in TES, required new generating capacity by 2010 will be 75,000 MWe less than the capacity required without a DOE-funded research program. 


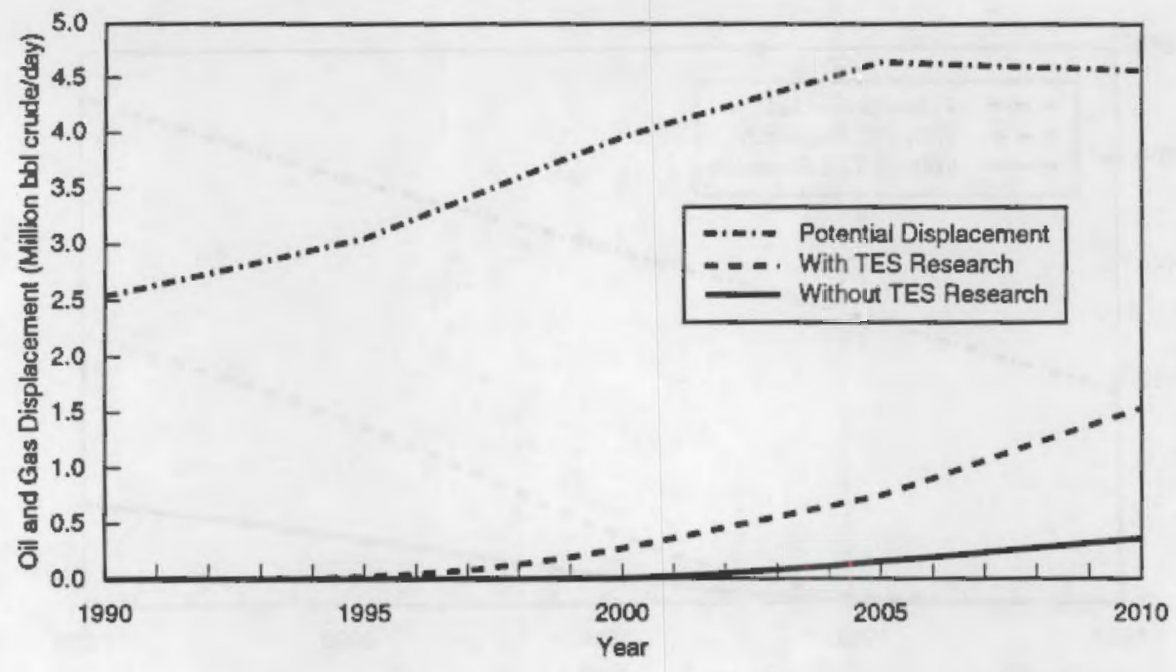

By 2010, TES will have displaced enough oil to fill a train encircling the earth 2.2 times.

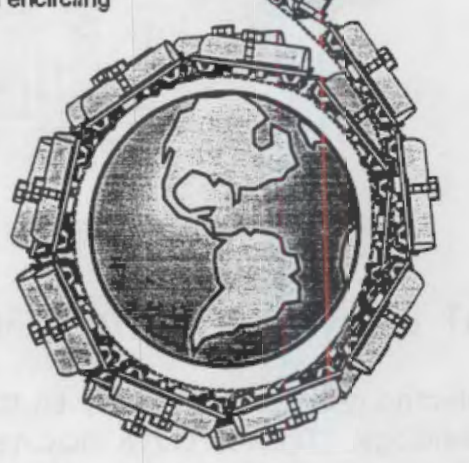

\section{FIGURE 4.6. Total Benefits: $0 i 1$ and Gas Displacement by Utility TES}

Shown: The total potential displacement of more expensive oil and gas fuel sources by coal that can occur over the next 20 years (measured in million barrels of crude oil per day that can be displaced) through the application of TES technology. The top curve shows the predicted potential replacement, the middle curve shows predicted savings if TES research continues, and the bottom curve shows predicted savings without DOE-funded TES research.

\section{Key Points:}

- Over the next 20 years, DOE funding of TES is predicted to result in a savings of 2,858 million barrels (cumulative) of crude oil. 


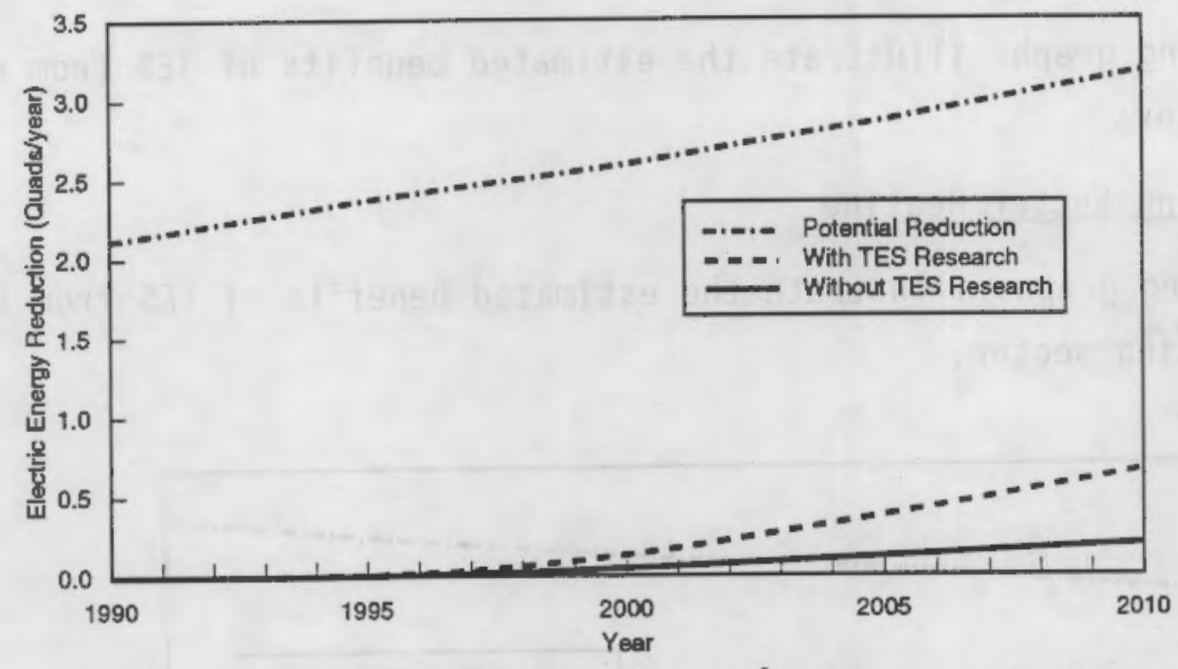

By 2010, TES will have displaced enough coal to fill a train encircling the earth 3 times.

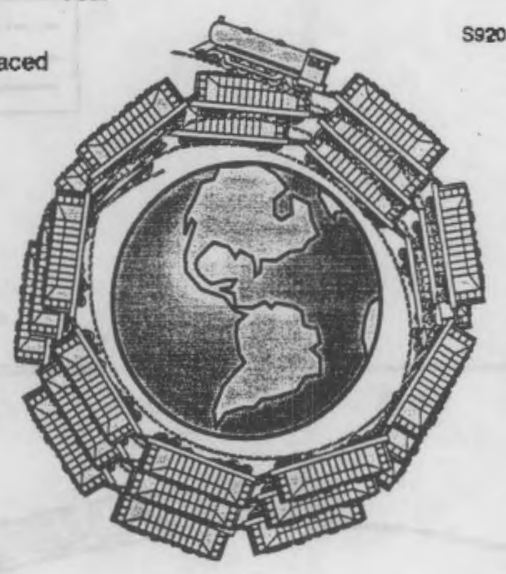

\section{FIGURE 4.7. Total Benefits: Electric Energy Reduction by TES}

Shown: The total amount of primary energy (in quads) used to produce electricity that could be saved over the next 20 years as a result of TES technology. The top curve shows the potential primary energy savings due to TES, the middle curve indicates the predicted savings if TES research continues, and the bottom curve indicates predicted savings without DOE-funded TES research.

\section{Key Points:}

- Over the next 20 years, DOE funding of TES is predicted to result in a savings of 8.0 quads (cumulative) of primary energy employed in the generation of electricity. 


\subsection{TES PROGRAM BENEFITS BY SECTOR}

The following graphs illustrate the estimated benefits of TES from each of the four sectors.

\subsubsection{Building Sector Heating}

The following graphs illustrate the estimated benefits of TES from the building heating sector.

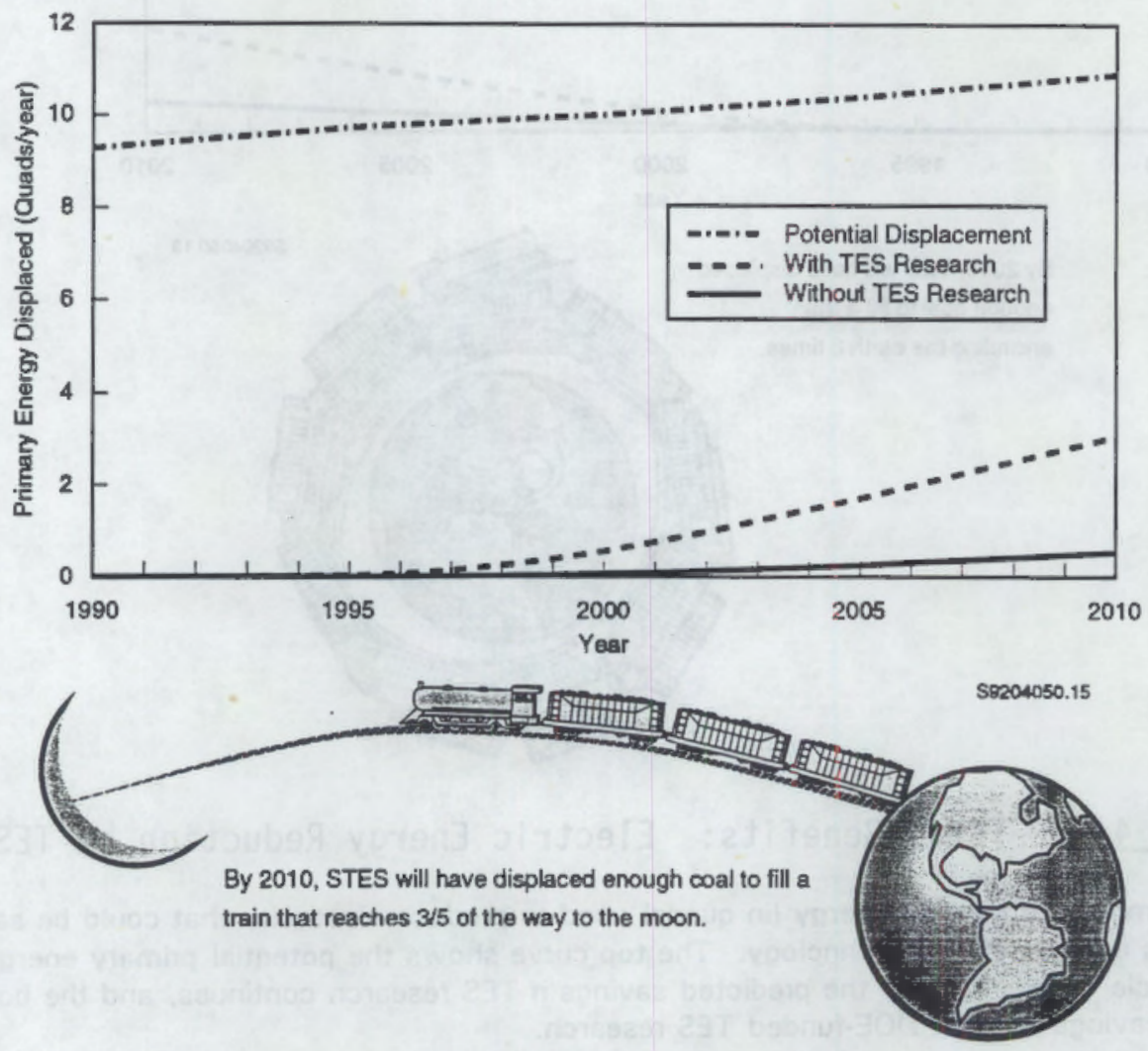

\section{FIGURE 4.8. Seasonal TES: Building Sector Heating Primary Energy Displaced by STES Technology}

Shown: The amount of energy in quads that can be saved over the next 20 years for heating in the building sector as a result of seasonal STES technology employing both solar energy and industrial waste heat. The top curve shows the predicted potential energy savings based on energy demand for heating in this sector. The middle curve shows predicted savings if TES research continues at current funding levels while the bottom curve shows predicted savings without DOE-funded TES research.

\section{Key Points:}

- Over the next 20 years, DOE funding of TES is predicted to result in an energy savings in building sector heating of 17 quads (cumulative). 

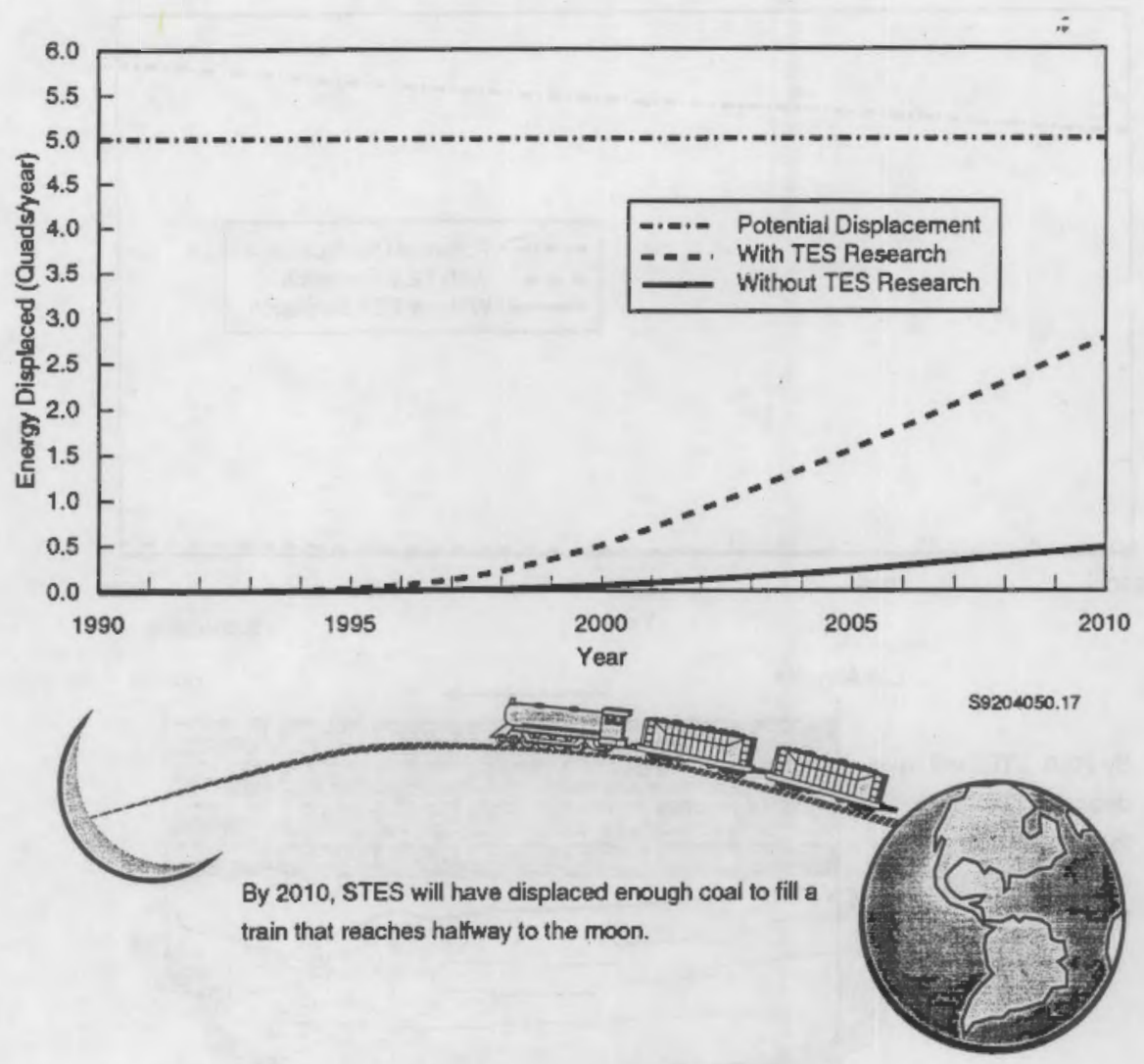

\section{FIGURE 4.9. Seasonal TES: Building Sector Heating Energy Displaced by STES (Industrial Waste Heat)}

Shown: The amount of energy in quads that can be saved over the next 20 years for heating in the building sector as a result of TES technology employing industrial waste heat only. The top curve shows the predicted potential energy savings based on the supply of industrial waste heat. The middle curve shows predicted savings if TES research continues, while the bottom curve shows predicted savings without DOE-funded TES research.

\section{Key Points:}

- Over the next 20 years, DOE funding of TES is predicted to result in an energy savings in building sector heating of $\mathbf{1 5 . 5}$ quads (cumulative) using industrial waste heat. 

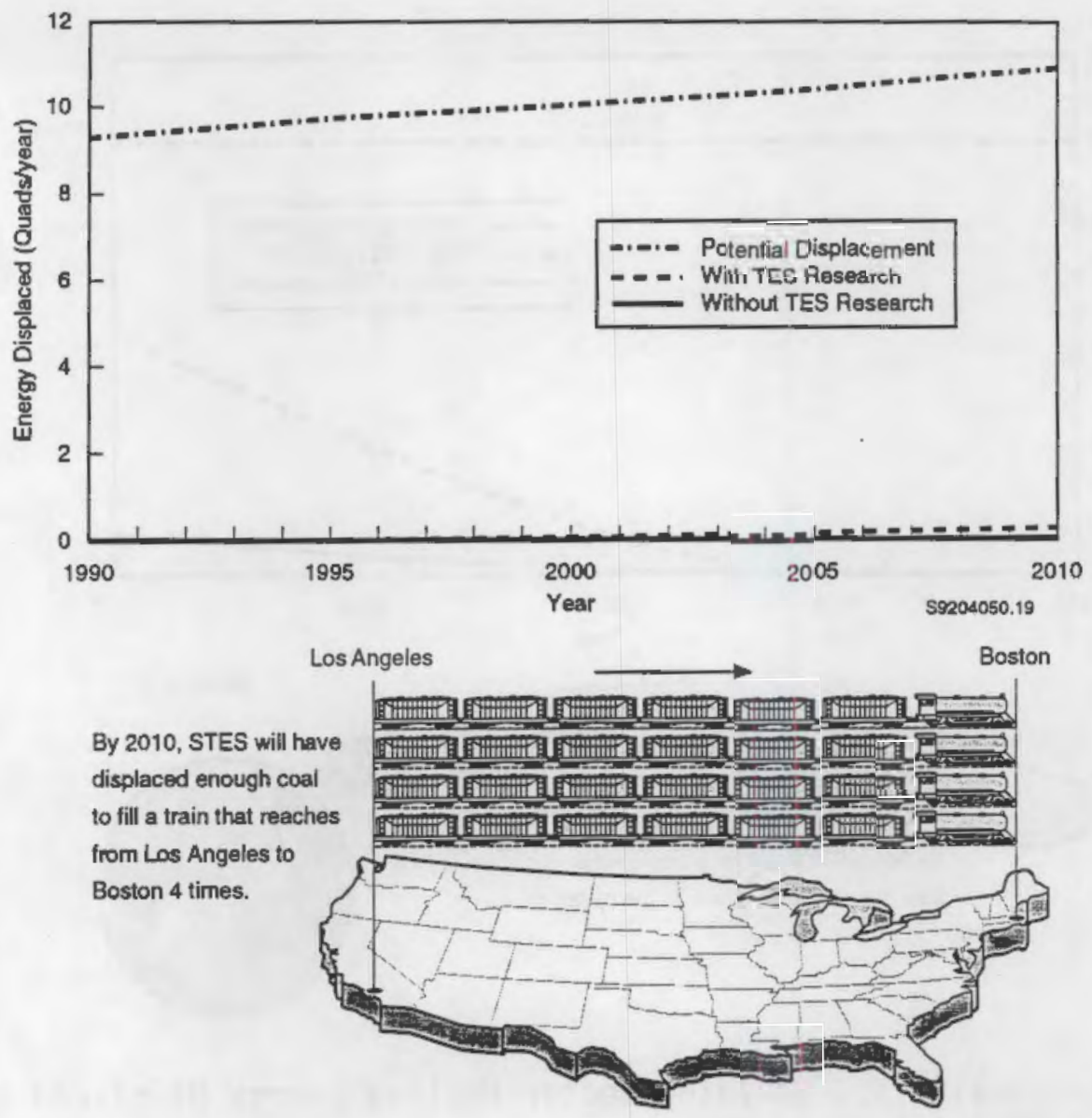

\section{FIGURE 4.10. Seasonal TES: Building Sector Heating Energy Displaced by STES (Solar Heat)}

Shown: The amount of energy in Quads that can be saved over the next 20 years for heating in the building sector as a result of TES technology employing solar energy. The top curve shows the predicted potential energy savings based on energy demand for heating in this sector. The middle curve shows predicted savings if TES research continues, while the bottom curve shows predicted savings without DOE-funded TES research.

\section{Key Points:}

- Over the next 20 years, DOE funding of TES is predicted to result in an energy savings in building sector heating of 1.5 quads (cumulative) using solar heat. 


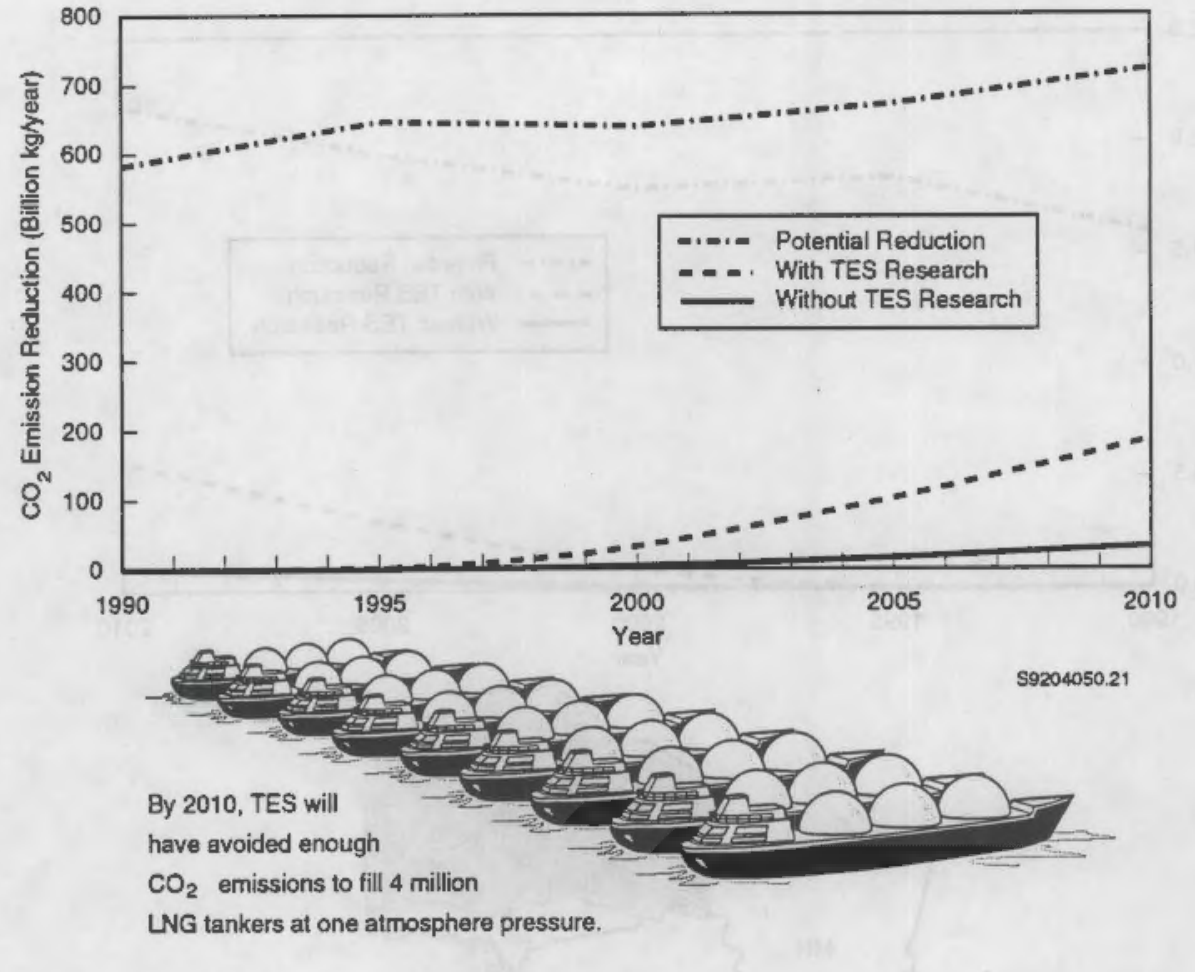

FIGURE 4.11. Building Sector Heating: $\mathrm{CO}_{2}$ Emissions Reduction Due to TES

Shown: The quantity of $\mathrm{CO}_{2}$ emissions from heating in the building sector (in billions of kilograms/year) that can be reduced over the next 20 years as a result of TES technology. The top curve shows the predicted potential $\mathrm{CO}_{2}$ emissions reduction based on the quantity of $\mathrm{CO}_{2}$ emissions that heating in the building sector produces. The middle curve shows predicted savings if TES research continues, while the bottom curve shows predicted savings without DOE-funded TES research.

\section{Key Points:}

- Over the next 20 years, DOE funding of TES is predicted to result in a savings of 1,020 billion kilograms (cumulative) in $\mathrm{CO}_{2}$ emissions produced as a result of heating in the building sector. 


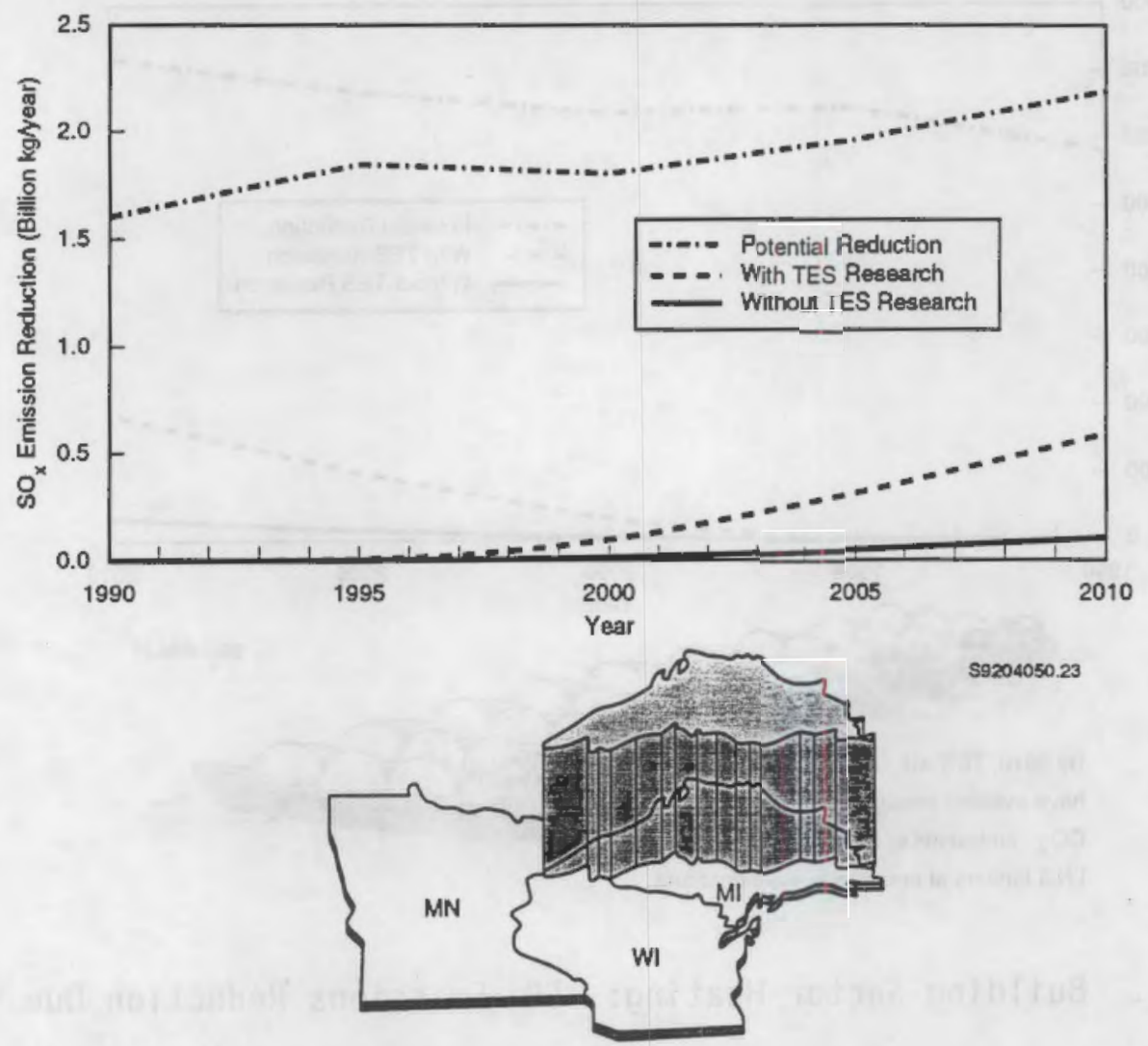

By 2010, TES will have avoided enough $\mathrm{SO}_{X}$ emissions to fill Lake Superior with acid rain with a pH of 2.0, to a dapth of 1200 feet.

\section{FIGURE 4.12. Building Sector Heating SO Emissions Reduction Due to TES}

Shown: The quantity of $\mathrm{SO}_{x}$ emissions from heating in the building sector (in billions of kilograms/Year) that can be reduced over the next 20 years as a result of TES technology. The top curve shows the predicted potential $\mathrm{SO}_{\mathrm{x}}$ emissions reduction based on the quantity of $\mathrm{SO}_{x}$ emissions that heating in the building sector produces. The middle curve shows predicted savings if TES research continues, while the bottom curve shows predicted savings without DOE-funded TES research.

Key Points:

- Over the next 20 years, DOE funding of TES is predicted to result in a savings of 3.1 billion kilograms (cumulative) in $\mathrm{SO}_{\mathrm{x}}$ emissions produced as a result of heating in the building sector. 

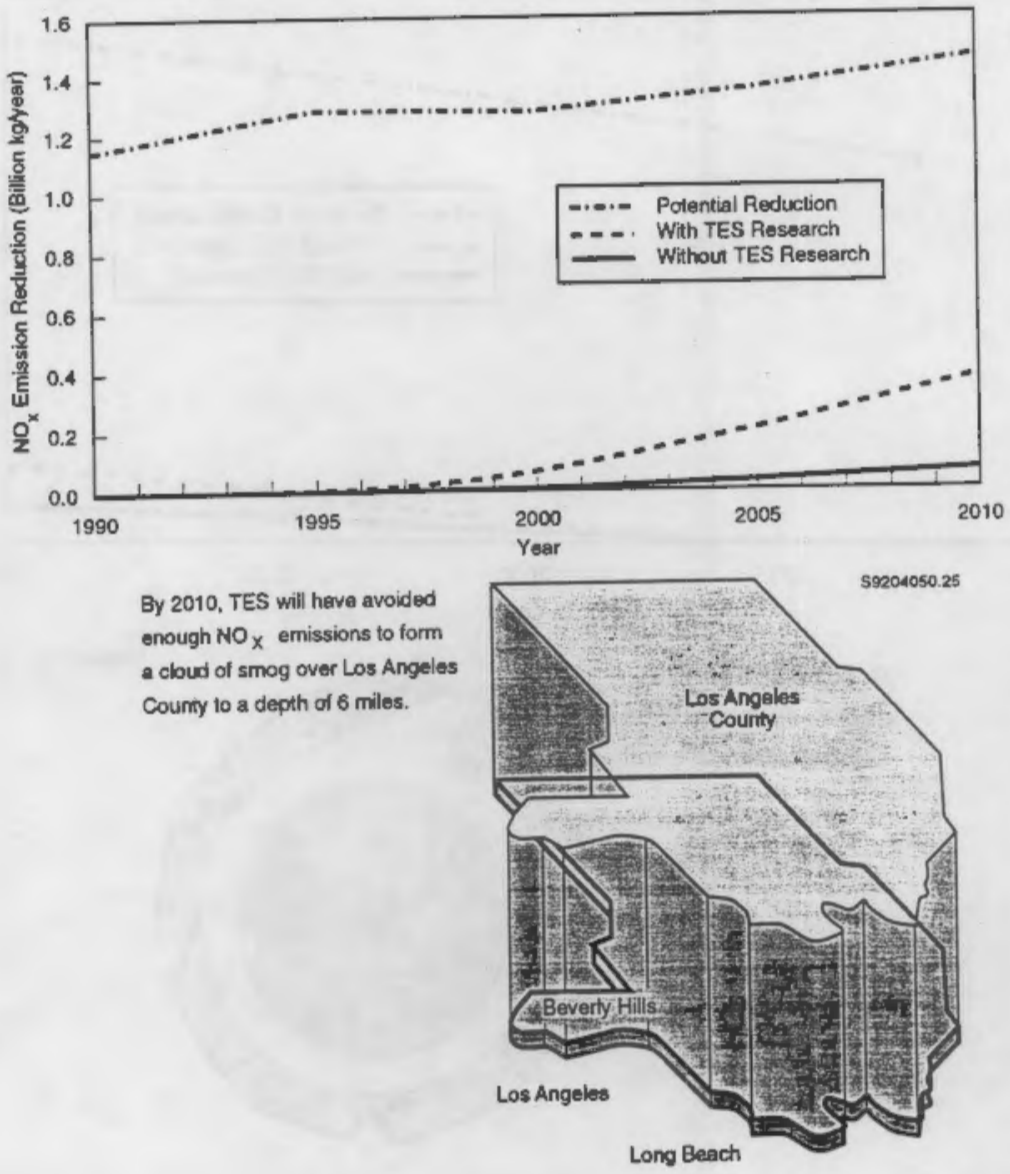

\section{FIGURE 4.13. Building Sector Heating NO Emissions Reduction Due to TES}

Shown: The quantity of $\mathrm{NO}_{x}$ emissions from heating in the building sector (in billions of kilograms/year) that can be reduced over the next 20 years as a result of TES technology. The top curve shows the predicted potential $\mathrm{NO}_{\mathrm{x}}$ emissions reduction based on the quantity of $\mathrm{NO}_{\mathrm{x}}$ emissions that heating in the building sector produces. The middle curve shows predicted savings if TES research continues, while the bottom curve shows predicted savings without DOE-funded TES research.

\section{Key Points:}

- Over the next 20 years, DOE funding of TES is predicted to resuit in a savings of 2.1 billion kilograms (cumulative) in $\mathrm{NO}_{\mathrm{x}}$ emissions produced as a result of heating in the building sector.

\subsubsection{Building Sector Cooling}

The following graphs illustrate the estimated benefits of TES from the building cooling sector. 

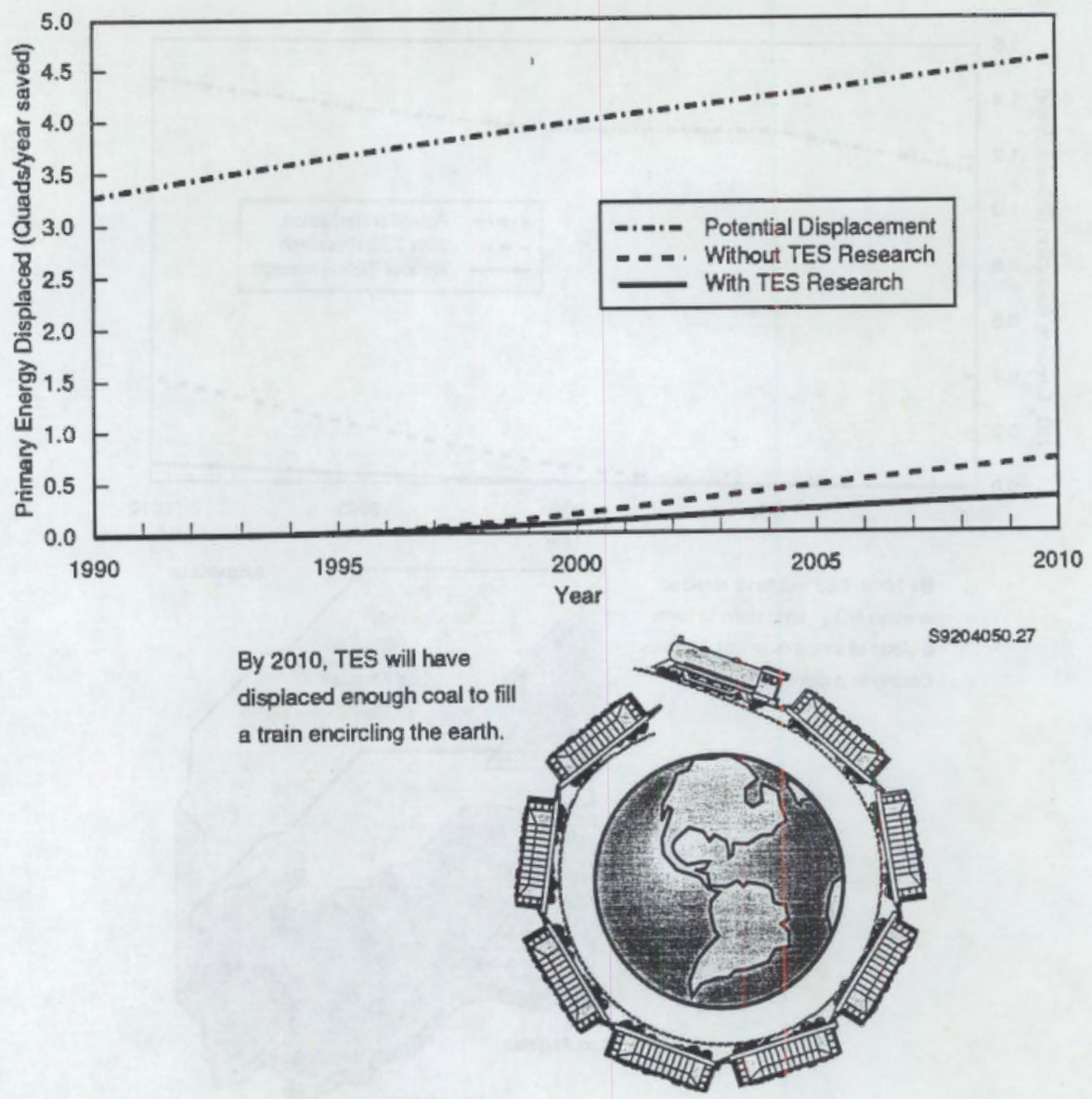

\section{FIGURE 4.14. Seasonal TES: Building Sector Cooling Primary Energy Displaced}

Shown: The amount of primary energy (in quads) used to generate electricity that can be saved over the next 20 years that would otherwise be used for cooling in the building sector. The top curve shows predicted energy savings based on the demand for electricity for cooling in this sector. The middle curve shows predicted savings if TES research continues, while the bottom curve shows predicted savings without DOEfunded TES research.

\section{Key Points:}

- The maximum potential primary energy displacement from building space cooling is between 3.0 and 4.5 quads/yr.

- With a DOE-funded research program in TES, primary energy displacement from building space cooling resulting from the use of TES technologies will be 0.7 quads by the year 2010 .

- Over the next 20 years, DOE funding of TES is predicted to result in a savings of 2.7 quads (cumulative) that would otherwise have been expended in the electrical cooling of the building sector. 

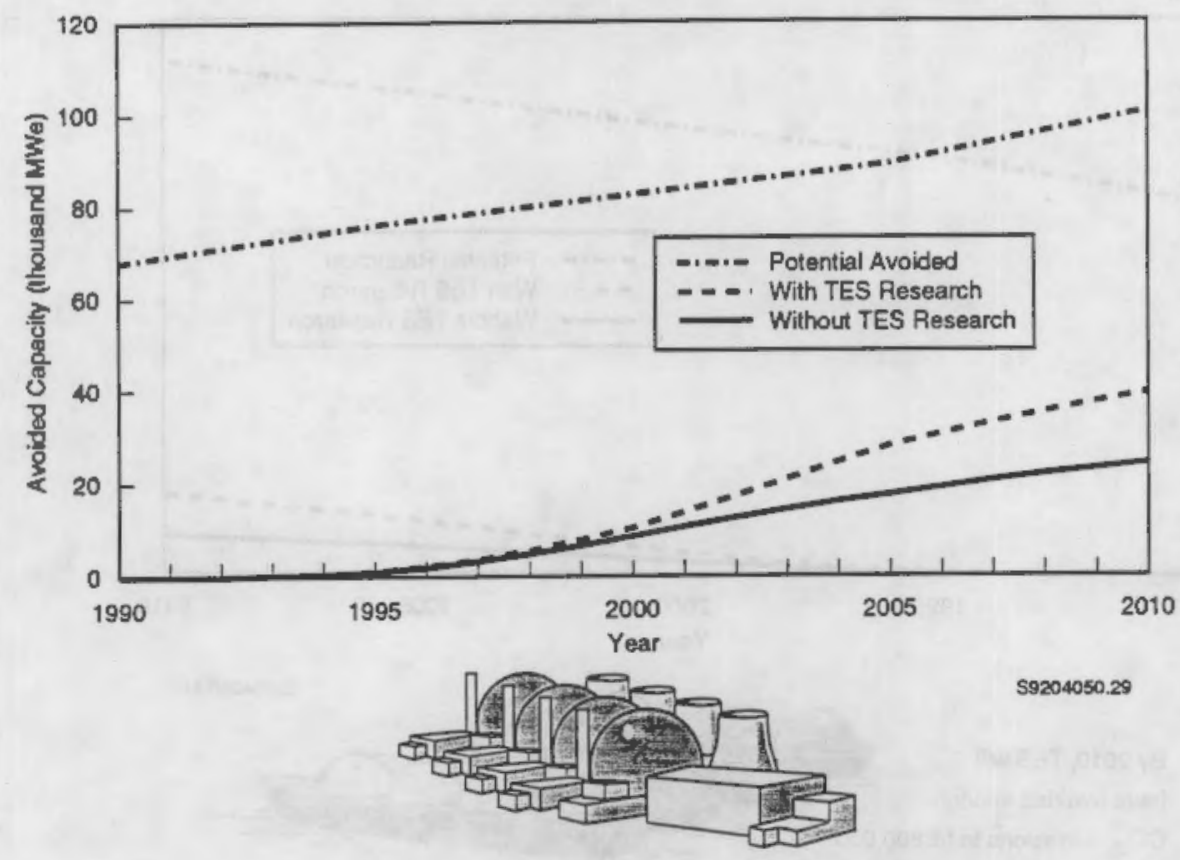

59204050.29

In 2010, TES could avoid the need for 15 large power plants.

\section{FIGURE 4.15. Building Sector Cooling: Avoided Generating Capacity by Diurnal TES}

Shown: The amount of peak electric generating capacity (in thousands of MWe) that can be reduced over the next 20 years through the application of diurnal TES technology. The top curve indicates the predicted potential peak capacity reduction, the middle curve indicates the predicted capacity that can be reduced if research continues at current funding levels (assumed to be approximately $\$ 5$ million/yr), and the bottom curve indicates the predicted peak capacity reduction without DOE-funded TES research.

\section{Key Points:}

- The maximum potential reduction in required new generating capacity attributable to the use of diurnal technologies is between 68,000 MWe and 100,000 MWe.

- With a DOE-funded research program in diurnal TES, required new generating capacity will be $15,000 \mathrm{MWe}$ less than the capacity required without a DOE-funded research program. 


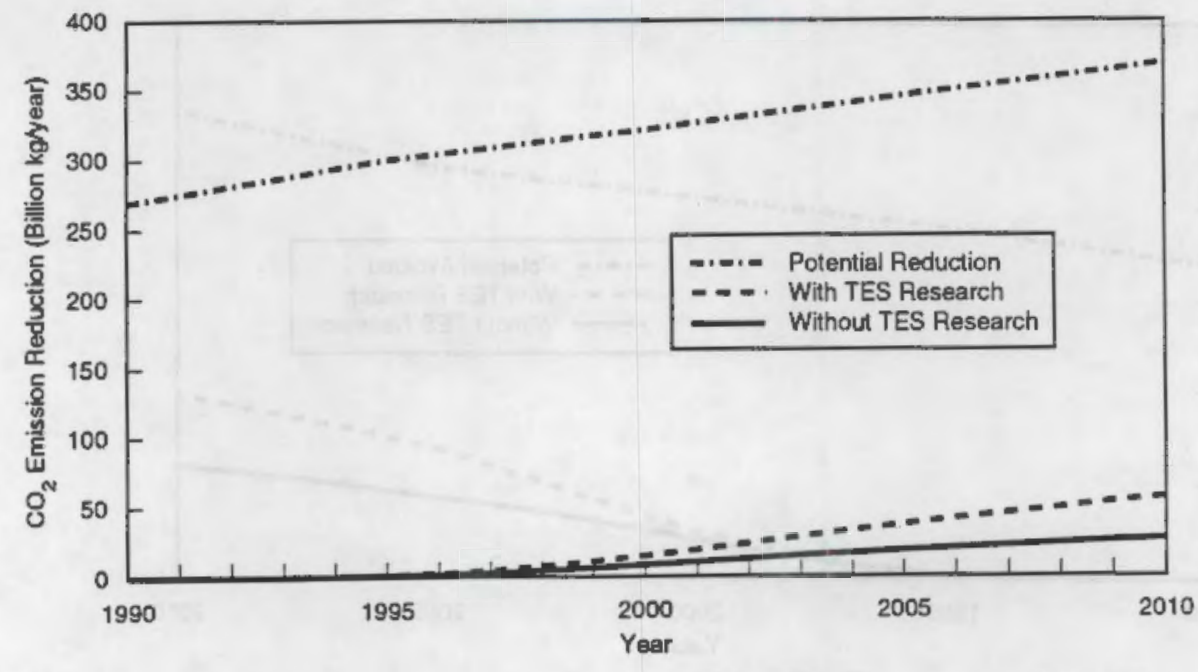

By 2010, TES will have avoided enough $\mathrm{CO}_{2}$ emissions to fill 800,000

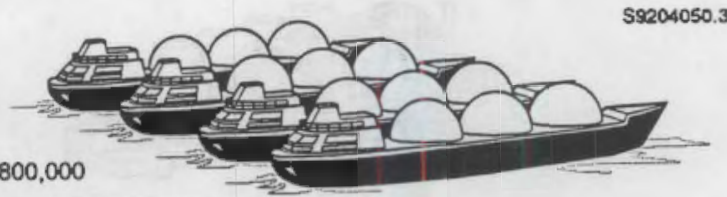

LNG tankers at one atmosphere pressure.

\section{FIGURE 4.16. Building Sector Cooling: $\mathrm{CO}_{2}$ Emissions Reduction Due to TES}

Shown: The quantity of $\mathrm{CO}_{2}$ emissions from cooling in the building sector (in billions of kilograms/year) that can be reduced over the next 20 years as a result of TES technology. The top curve shows the predicted potential $\mathrm{CO}_{2}$ emissions reduction based on the quantity of $\mathrm{CO}_{2}$ emissions that cooling in the building sector produces. The middle curve shows predicted savings if TES research continues, while the bottom curve shows predicted savings without DOE-funded TES research.

\section{Key Points:}

- Over the next 20 years, DOE funding of TES is predicted to result in a savings of 213 billion kilograms (cumulative) in $\mathrm{CO}_{2}$ emissions produced as a result of cooling in the building sector. 


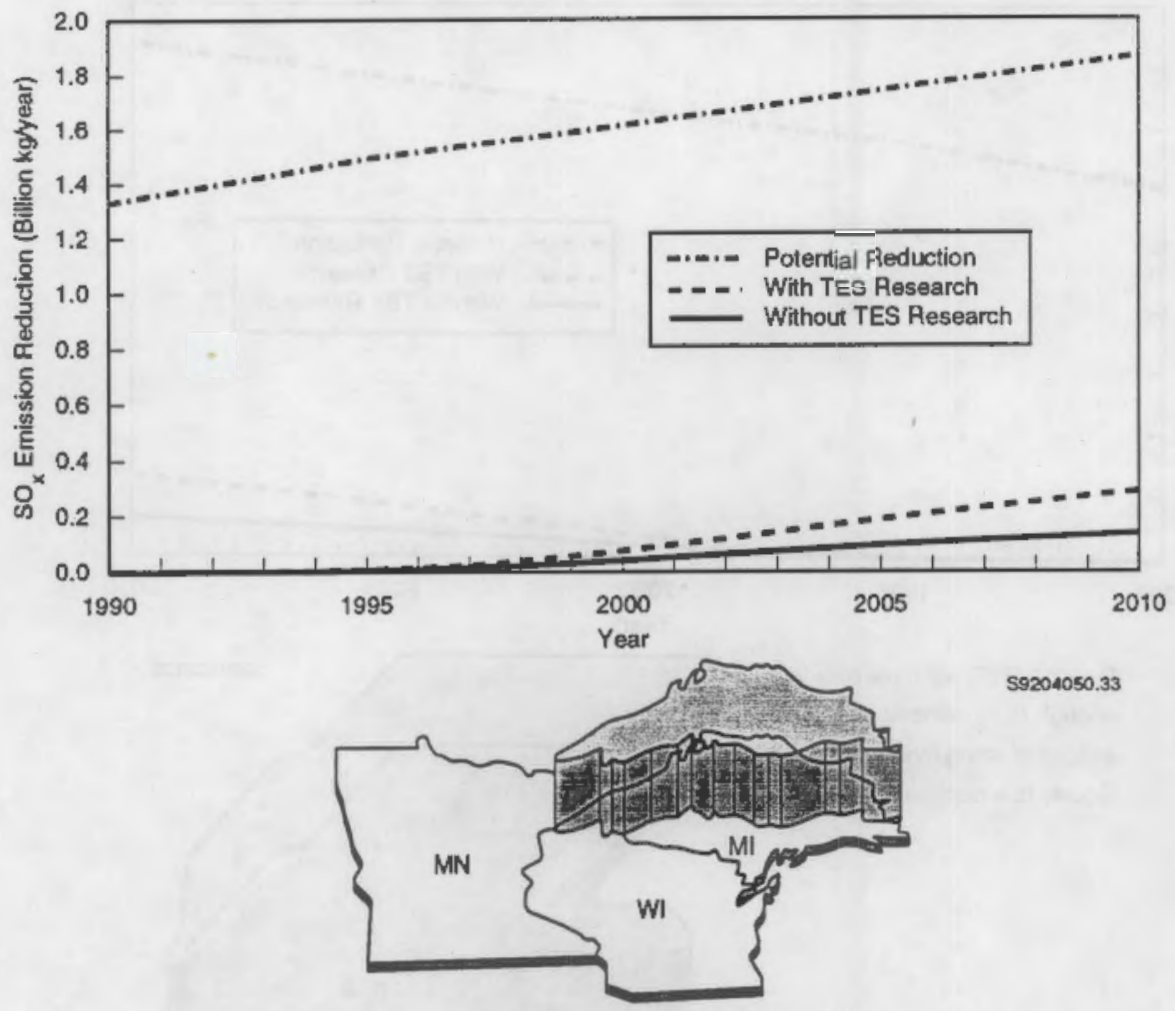

By 2010, TES will have avoided enough $\mathrm{SO}_{x}$ emissions to fill Lake Superior with acid rain with a pH of 2.0, to a depth of 420 feet.

\section{FIGURE 4.17. Building Sector Cooling: SO Emissions Reduction Due to TES}

Shown: The quantity of $\mathrm{SO}_{\mathrm{x}}$ emissions from cooling in the building sector (in billions of kilograms/year) that can be reduced over the next 20 years as a result of TES technology. The top curve shows the predicted potential $\mathrm{SO}_{x}$ emissions reduction based on the quantity of $\mathrm{SO}_{x}$ emissions that cooling in the building sector produces. The middle curve shows predicted savings if TES research continues, while the bottom curve shows predicted savings without DOE-funded TES research.

\section{Key Points:}

- Over the next 20 years, DOE funding of TES is predicted to result in a savings of 1.08 billion kilograms (cumulative) in $\mathrm{SO}_{x}$ emissions produced as a result of cooling in the building sector. 


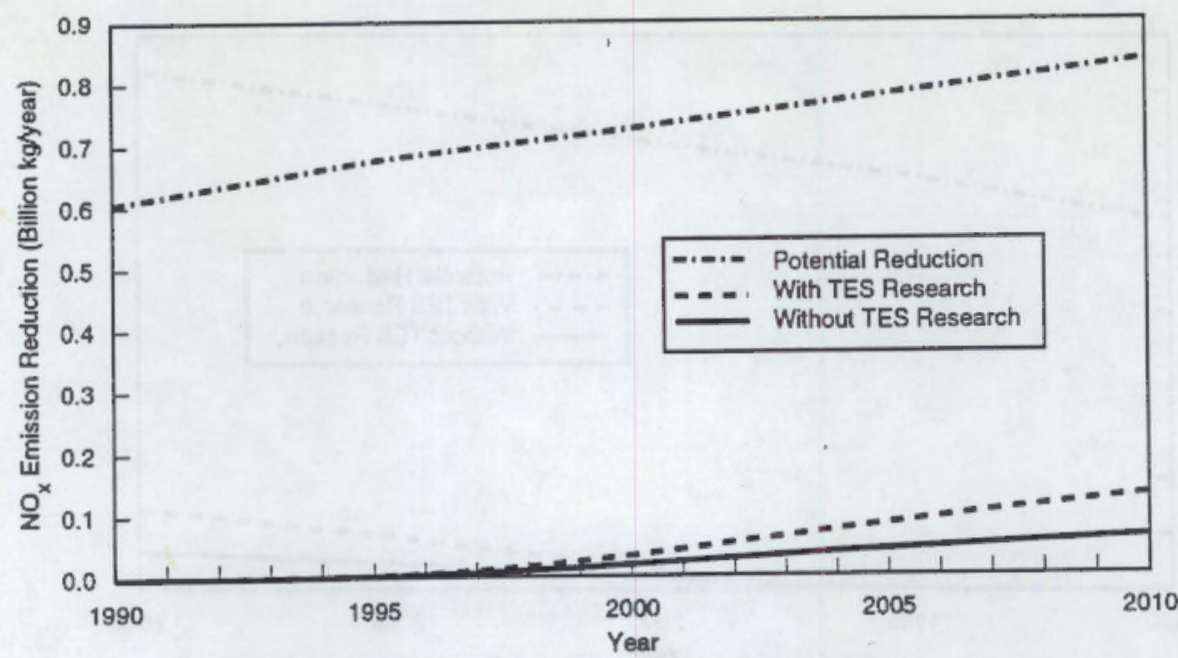

By 2010, TES will have avoided enough $\mathrm{NO}_{X}$ ernissions to form a cloud of smog over Los Angeles County to a depth of 1 mile.

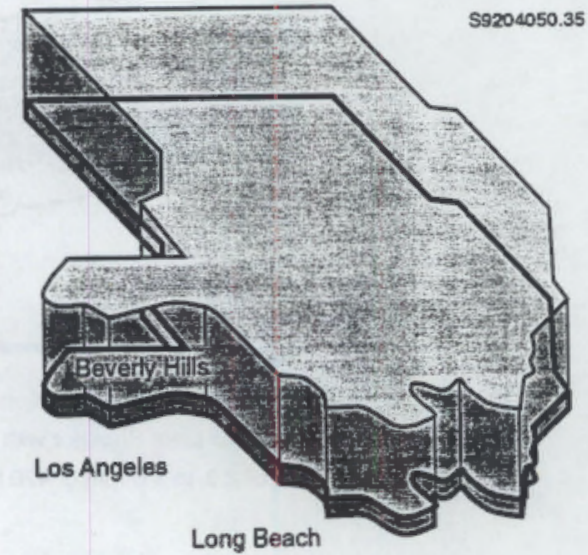

\section{FIGURE 4.18. Building Sector Cooling: NO Emissions Reduction Due to TES}

Shown: The quantity of $\mathrm{NO}_{x}$ emissions from cooling in the building sector (in billions of kilograms/year) that can be reduced over the next 20 years as a result of TES technology. The top curve shows the predicted potential $\mathrm{NO}_{x}$ emissions reduction based on the quantity of $\mathrm{NO}_{x}$ emissions that cooling in the building sector produces. The middle curve shows predicted savings if TES research continues, while the bottorn curve shows predicted savings without DOE-funded TES research.

\section{Key Points:}

- Over the next 20 years, DOE funding of TES is predicted to result in a savings of 0.48 billion kilograms (cumulative) in $\mathrm{NO}_{x}$ emissions produced as a result of cooling in the building sector.

\subsubsection{Utility Sector}

The following graphs illustrate the estimated benefits of TES from the utility sector. 

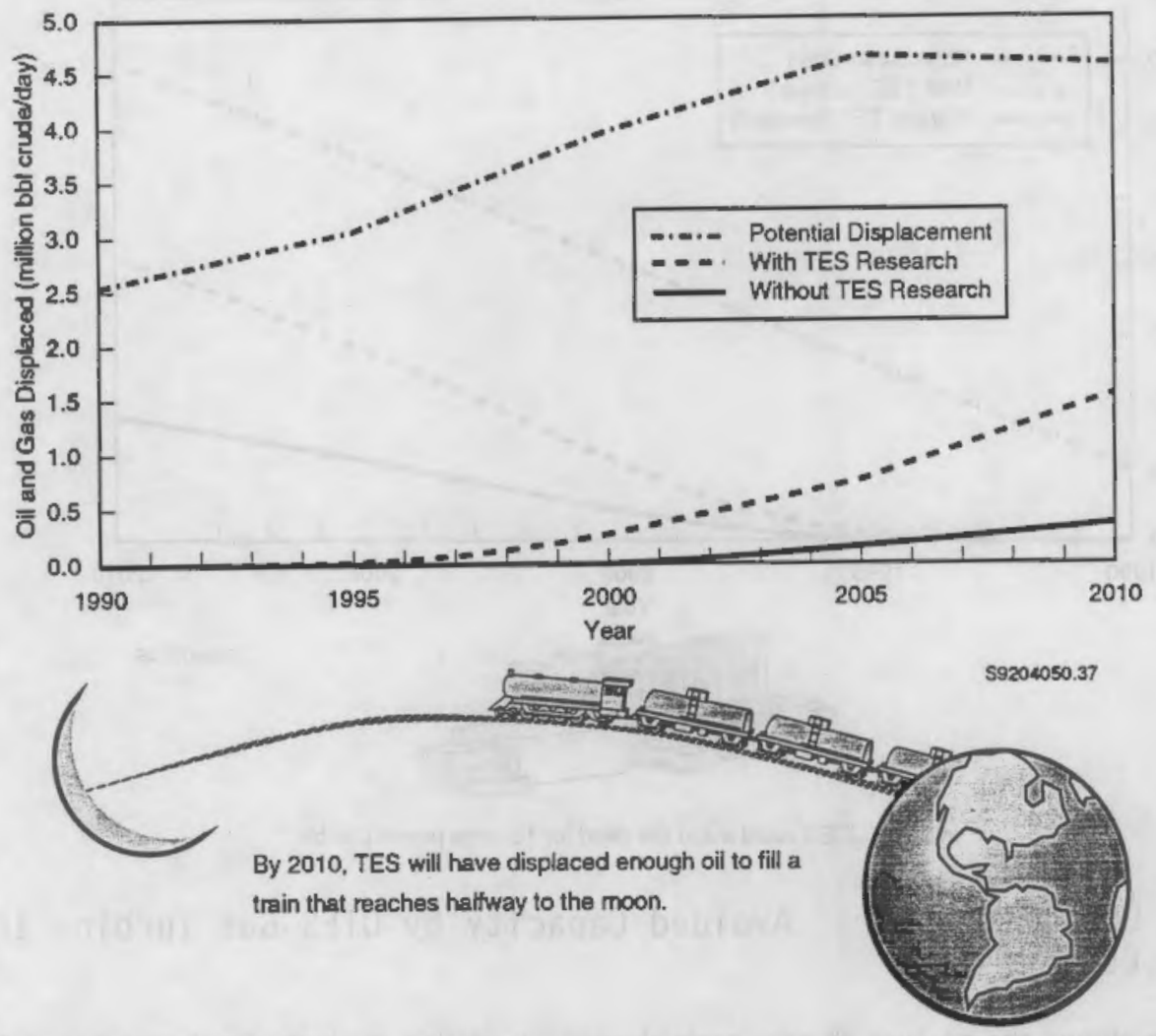

\section{FIGURE 4.19. Utility Sector: $0 i 1$ and Gas Displacement by Utility TES}

Shown: The potential displacement of more expensive oil and gas fuel sources by coal that can occur over the next 20 years made possible by the use of UTES technologies, which would otherwise be employed in power generation by the utility sector (measured in million barrels of crude oil per day that can be displaced). The top curve shows the predicted potential replacement based on oil and gas consumption in this sector. The middle curve shows predicted savings if TES research continues at current funding levels lassumed to be approximately $\$ 5$ million/yr), while the bottom curve shows predicted savings without DOE-funded TES research.

\section{Key Points:}

- The maximum potential displacement of premium fuels for power generation applications is between 2.5 and 4.5 million barrels/day/year.

- With a DOE-funded research program in utility TES, the displacement of premium fuels will be 1.5 million barreis/day/year by the year 2010.

- Over the next 20 years, DOE funding of TES is predicted to result in a savings of 2,858 million barrels (cumulative) of crude oil that would otherwise have been used for power generation by the utility sector. 


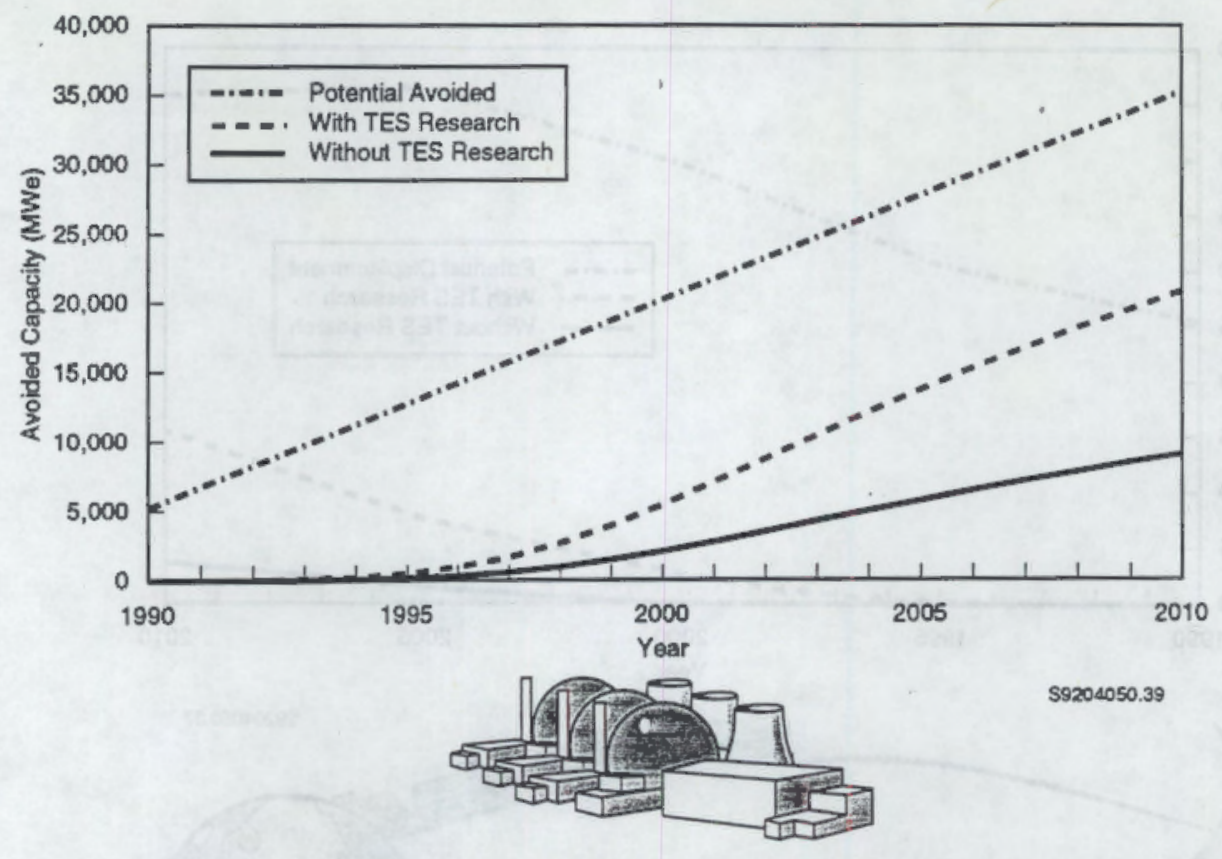

In 2010, UTES could avoid the need for 13 large power plants.

\section{FIGURE 4.20. Utility Sector: Avoided Capacity by UTES-Gas Turbine Inlet Cooling}

Shown: This figure shows the amount of new peak electric generating capacity (in thousands of MWe) that can be avoided over the next 20 years through the application of UTES technology to gas turbine inlet air cooling. The top curve shows the maximum (predicted) potential peak capacity reduction, the middle curve shows the predicted capacity reduction attainable if TES research continues at current funding levels (assumed to be approximately $\$ 5$ million/yr), and the bottom curve indicates the predicted peak capacity reduction attainable without DOE-funded TES research.

\section{Key Points:}

- The maximum potential reduction in required new generating capacity attributable to diurnal technologies is between $5000 \mathrm{MWe}$ and 35,000 MWe.

- With a DOE-funded research program in UTES, required new generating capacity will be $13,000 \mathrm{MWe}$ less than the capacity required without a DOE-funded research program. 


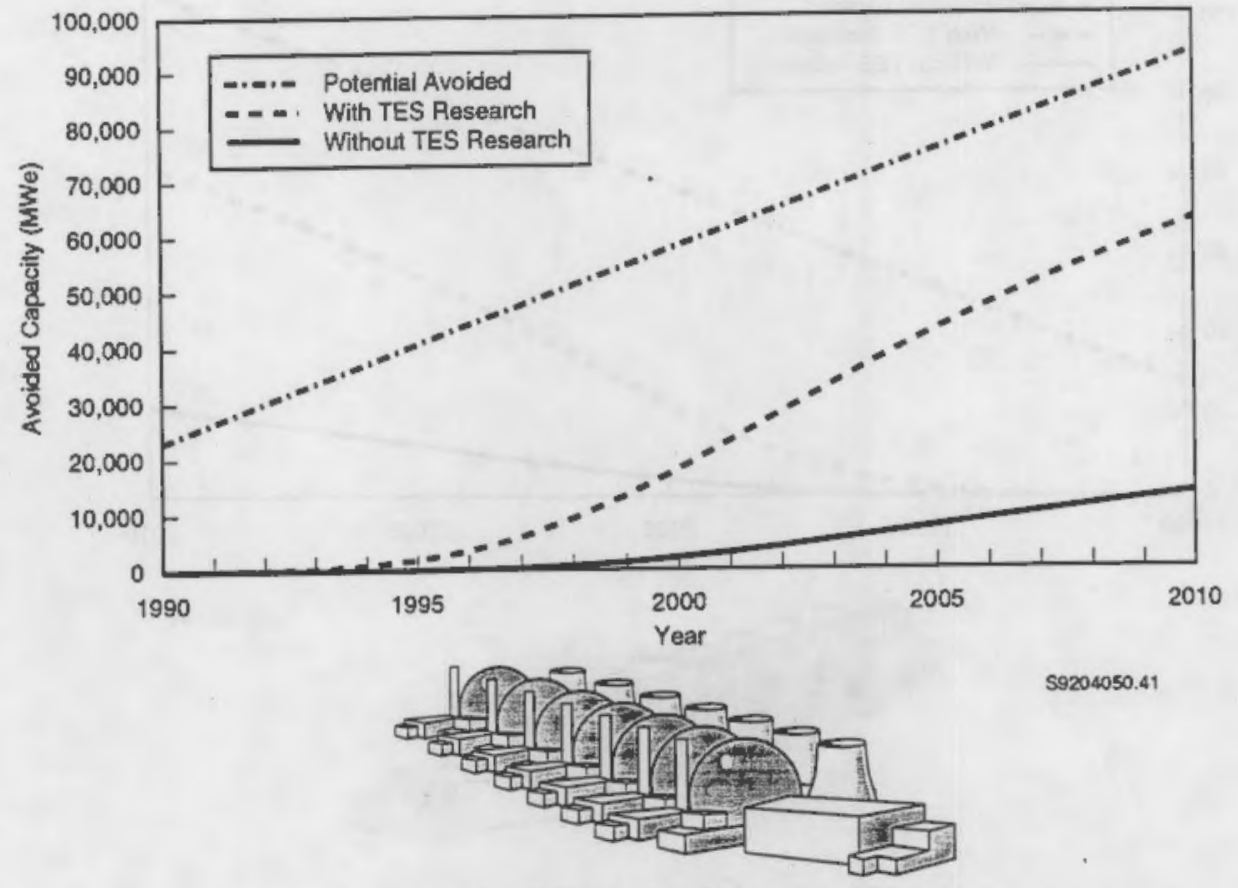

In 2010. TES could avoid the need for 47 large power plants.

\section{FIGURE 4.21. Utility Sector: Avoided Capacity by UTES-Cogeneration}

Shown: This figure shows the amount of new peak electric generating capacity (in thousands of MWe) that can be avoided over the next 20 years through the application of UTES technology to cogeneration. The top curve shows the maximum (predicted) potential peak capacity reduction, the middle curve shows the predicted capacity reduction attainable if TES research continues at current funding levels (assumed to be approximately $\$ 5$ million/yr), and the bottom curve indicates the predicted peak capacity reduction attainable without DDEfunded TES research.

\section{Key Points:}

- The maximum potential reduction in required new generating capacity attributable to diurnal technologies is between 22,000 MWe and 93,000 MWe.

- With a DOE-funded research program in UTES, required new generating capacity will be $47,000 \mathrm{MWe}$ less than the capacity required without a DOE-funded research program. 


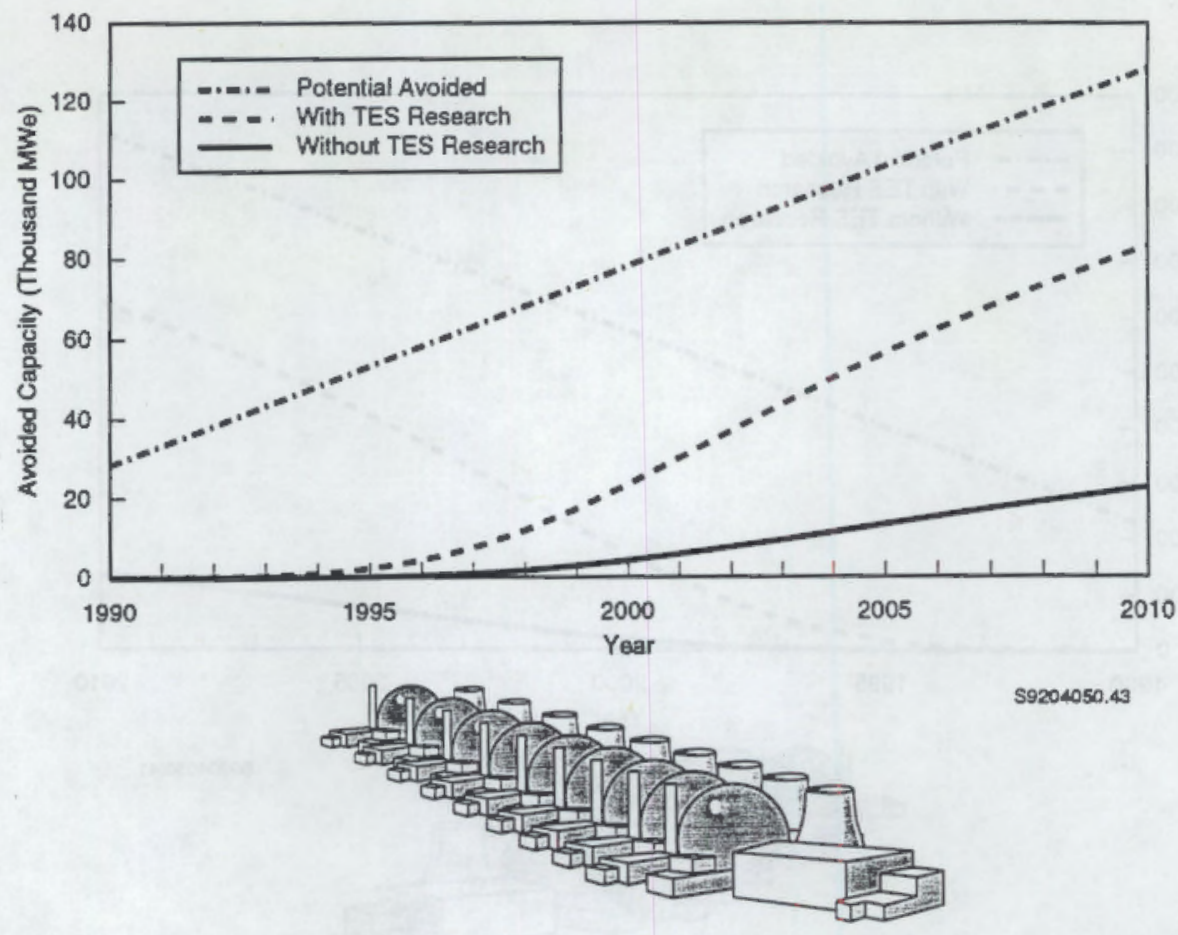

In 2010, TES could avoid the need for 60 large power plants.

\section{FIGURE 4.22. Utility Sector: Total Avoided New Capacity All UTES}

Shown: This figure shows the amount of new peak electric generating capacity (in thousands of MWe) that can be avoided over the next 20 years through the application of UTES technology to gas turbine inlet air cooling and to cogeneration. The top curve shows the maximum (predicted) potential peak capacity reduction, the middle curve shows the predicted capacity reduction attainable if TES research continues at current funding levels (assumed to be approximately $\$ 5 \mathrm{million} / \mathrm{yr}$ ), and the bottom curve indicates the predicted peak capacity reduction attainable without DOE-funded TES research.

Key Points:

- The maximum potential reduction in required new generating capacity attributable to diurnal technologies is between $28,000 \mathrm{MWe}$ and $128,000 \mathrm{MWe}$.

- With a DOE-funded research program in UTES, required new generating capacity will be 61,000 MWe less than the capacity required without a DOE-funded research program.

\subsubsection{Transportation Sector}

The following graph illustrates the estimated benefits of TES from the transportation sector. 

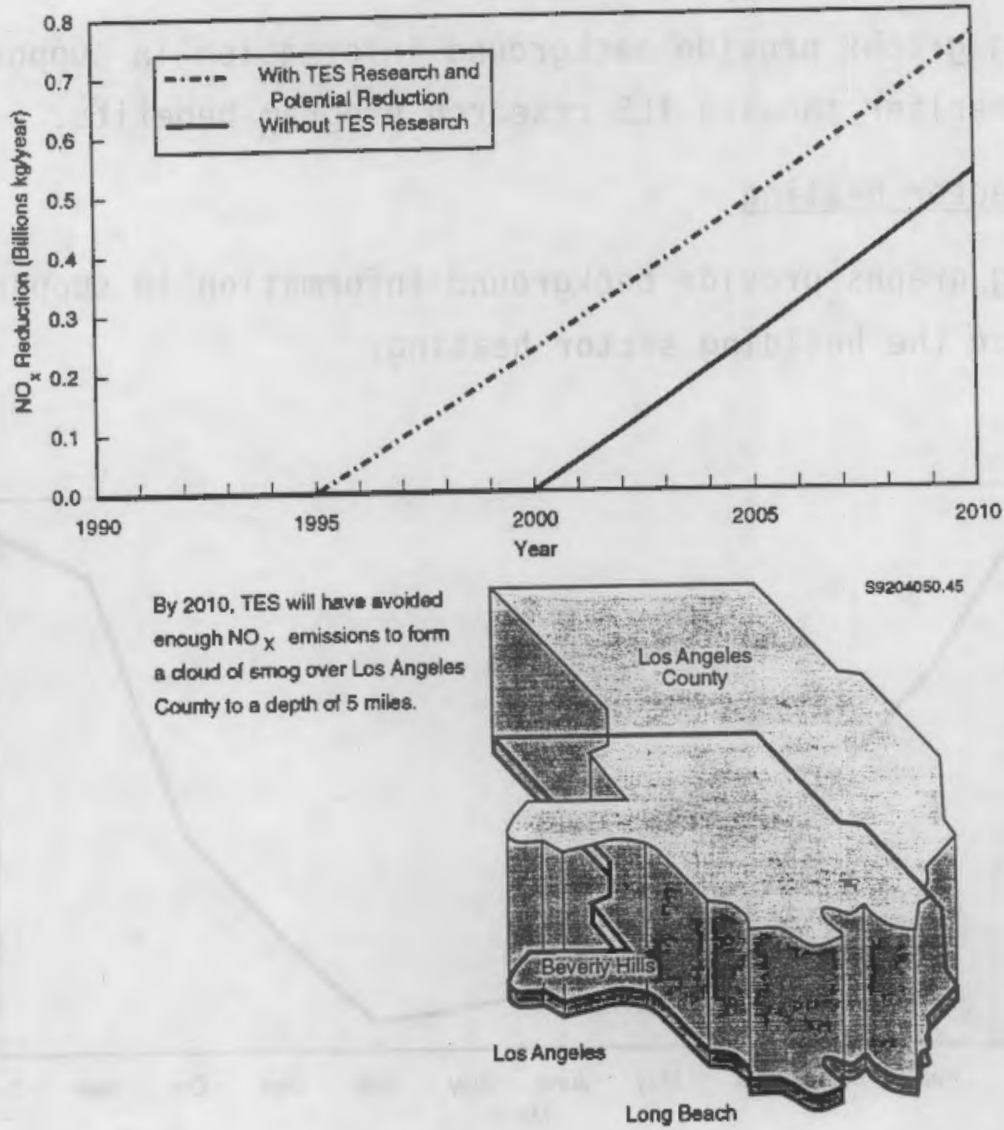

\section{FIGURE 4.23. Transportation Sector: NO Emissions Reduction by TES (Catalytic Preheat)}

Shown: The quantity of $\mathrm{NO}_{x}$ emissions from the transportation sector (in billions of kilograms/year) that can be reduced over the next 20 years as a result of TES technology (specifically, catalytic preheating). The top curve shows the predicted potential $\mathrm{NO}_{\mathrm{x}}$ emissions reduction based on the quantity of $\mathrm{NO}_{\mathrm{x}}$ emissions produced by this sector, which is equal to the predicted savings if TES research continues at current funding levels (assumed to be approximately $\$ 5$ million $/ \mathrm{yr}$ ). The bottom curve shows predicted savings without DOE-funded TES research.

\section{Key Points:}

- With a DOE-funded research program in TES, reductions in $\mathrm{NO}_{x}$ emissions resulting from the use of TES technologies will be 0.8 billion $\mathbf{k g} / \mathrm{yr}$ by the year 2010 .

- Over the next 20 years, DOE funding of TES is predicted to result in a reduction of 2.5 billion kilograms (cumulative) in $\mathrm{NO}_{x}$ emissions produced by the transportation sector. 


\subsection{GRAPHS SUPPORTING TES BENEFITS RESULTS}

The following graphs provide background information in support of the graphs presented earlier showing TES research program benefits.

\subsubsection{Building Sector Heating}

The following graphs provide background information in support of the benefits graphs for the building sector heating.

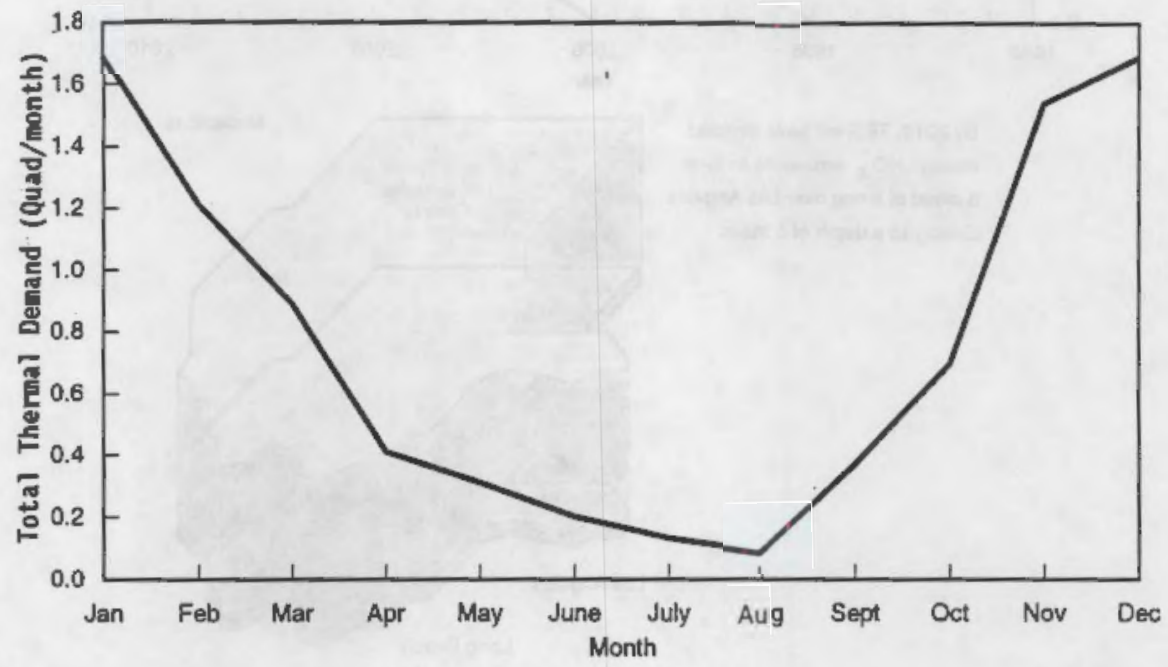

53204050.47

FIGURE 4.24. Building Sector Heating: Seasonal Thermal Primary Power Demand

Shown: This graph illustrates the amount of primary energy in quad per month used for space heating in the building sector during 1990 . The peak demand occurring in December and January is 1.69 quad/mo, and the minimum demand of 0.09 quad/mo occurs in August. 


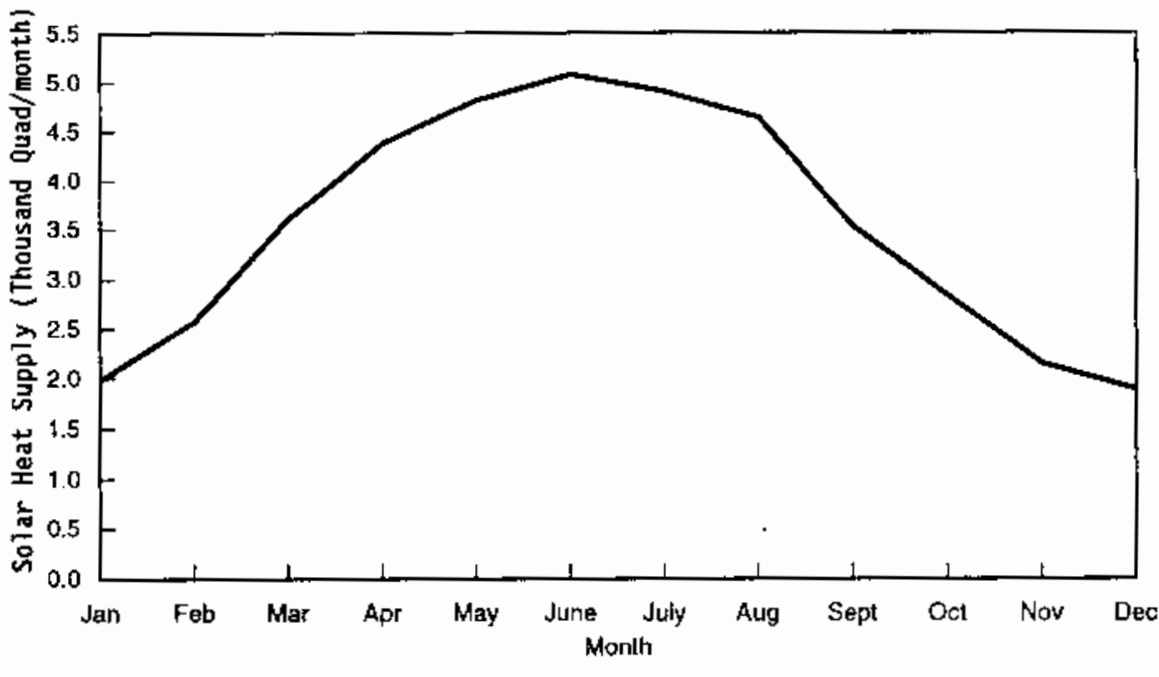

$\$ 8204050.49$

\section{FIGURE 4.25. Seasonal Solar Heat Supply (U.S. excluding Alaska)}

Shown: This graph illustrates the amount of solar radiation incident upon the United States (excluding Alaska) in thousands of quad per month. It is based on mid-latitude of the contiguous United States. The peak solar radiation occurring in June is 5,080 quad/month, and the minimum solar radiation of 1,890 quad/month occurs in December. 


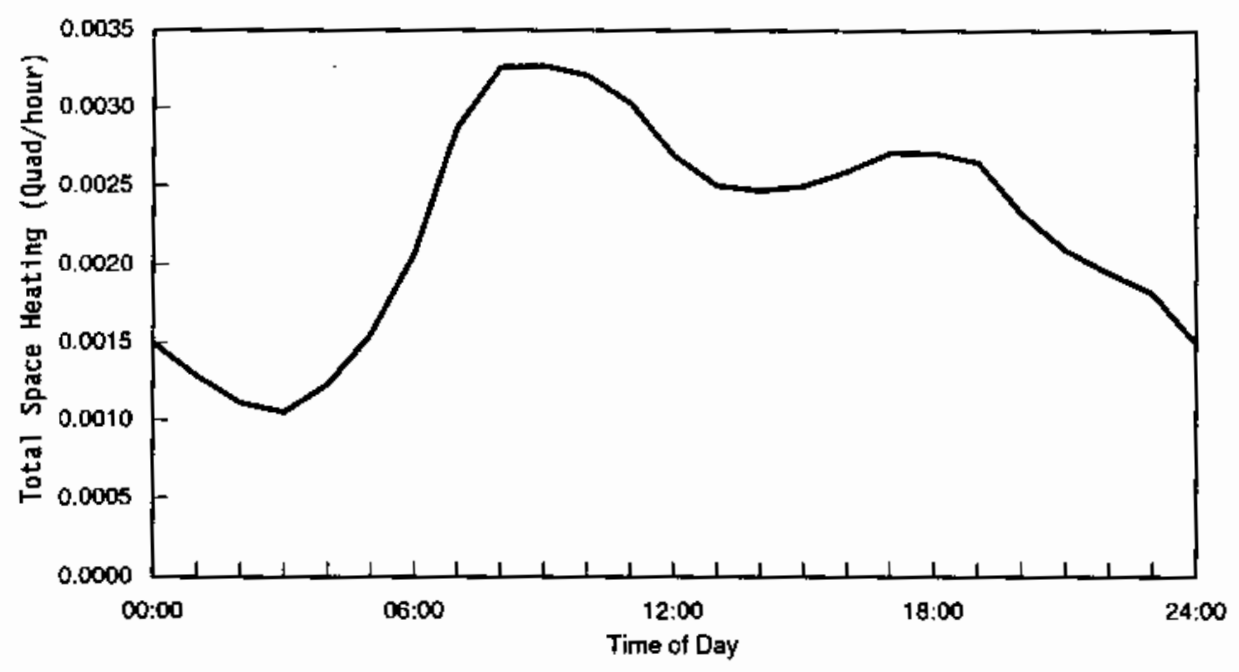

FIGURE 4.26. Building Sector Heating: Diurnal Thermal Primary Power Demand for January

Shown: This graph illustrates the amount of primary energy in quad per hour used for space heating in the building sector during a peak dernand month of January in 1990 . There are two peaks occurring within each diurnal cycle. The first peak occurs at $9: 00 \mathrm{a} . \mathrm{m}$. with a value of 0.00327 quad/hr and the second occurs at approximately 6:00p.m. with a value of 0.00271 quad/hr. The effect of having two peaks occurring each dav is largely due to the influence of the space heating in the residential sector. The misimum space heating value of 0.00105 quad $/ \mathrm{hr}$ occurs at $3: 00 \mathrm{a} . \mathrm{m}$. 


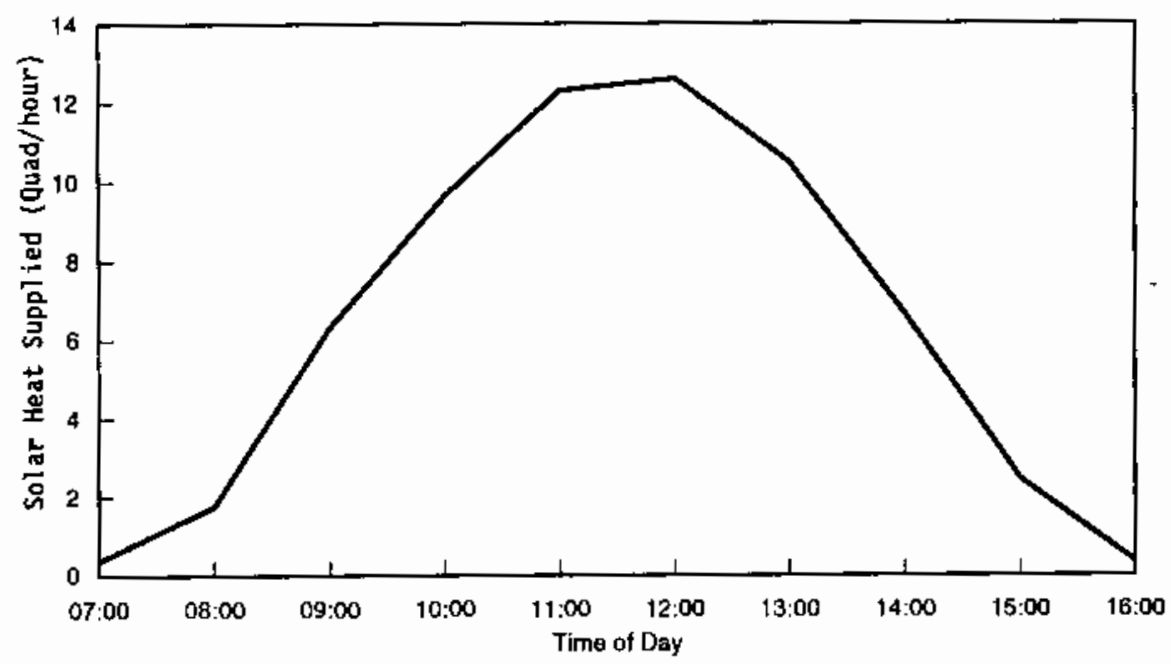

59204050.53

\section{FIGURE 4.27. Diurnal Solar Heat Supply: December (U.S. excluding Alaska)}

Shown: This graph illustrates the amount of solar radiation incident upon the United States (excluding Alaska) in thousands of quad per hour for the month of December. It is based on mid-latitude of the contiguous United States. The peak solar radiation occurring at 12:00 noon is 12.6 quad/hr. With some of the shortest days of the year falling in December, incident radiation is limited to hours approximately between 7;00a.m. and 4:00p.m.

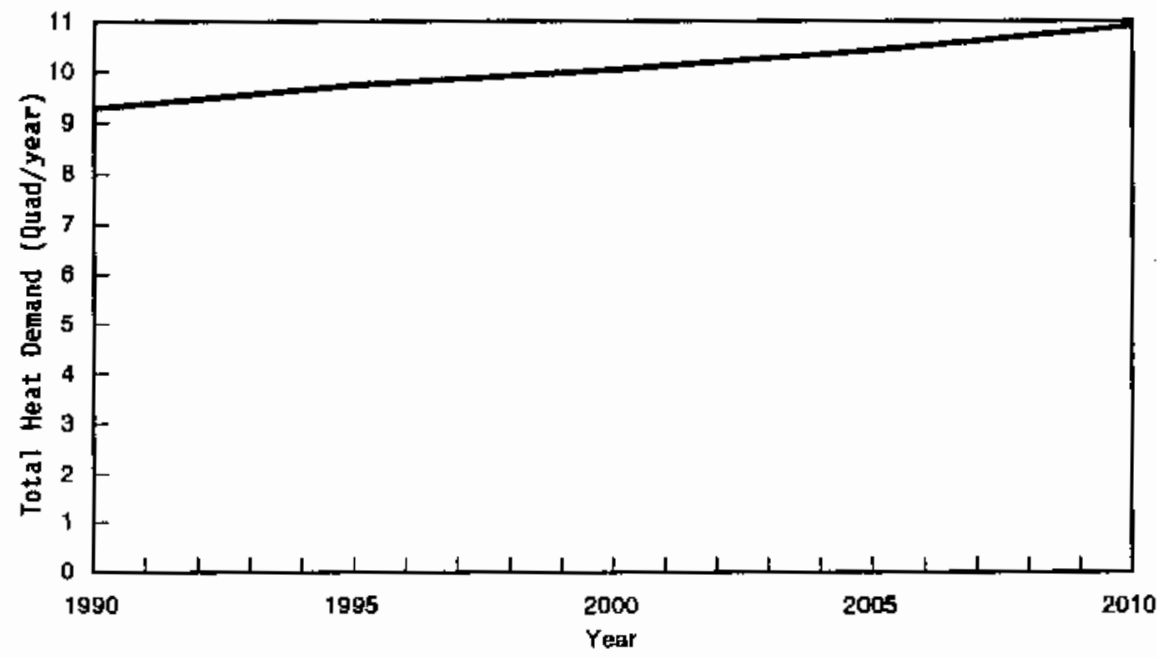

sq204050.55

\section{FIGURE 4.28. Building Sector Heating: Total Primary Energy Heat Demand}

Shown: This graph illustrates how the total amount of primary energy will increase between 1990 and 2010 for space heating. Starting in 1990, 9.28 quad/yr will be required, and this need will increase in a linear fashion to a demand of 10.91 quad/yr in 2010. 


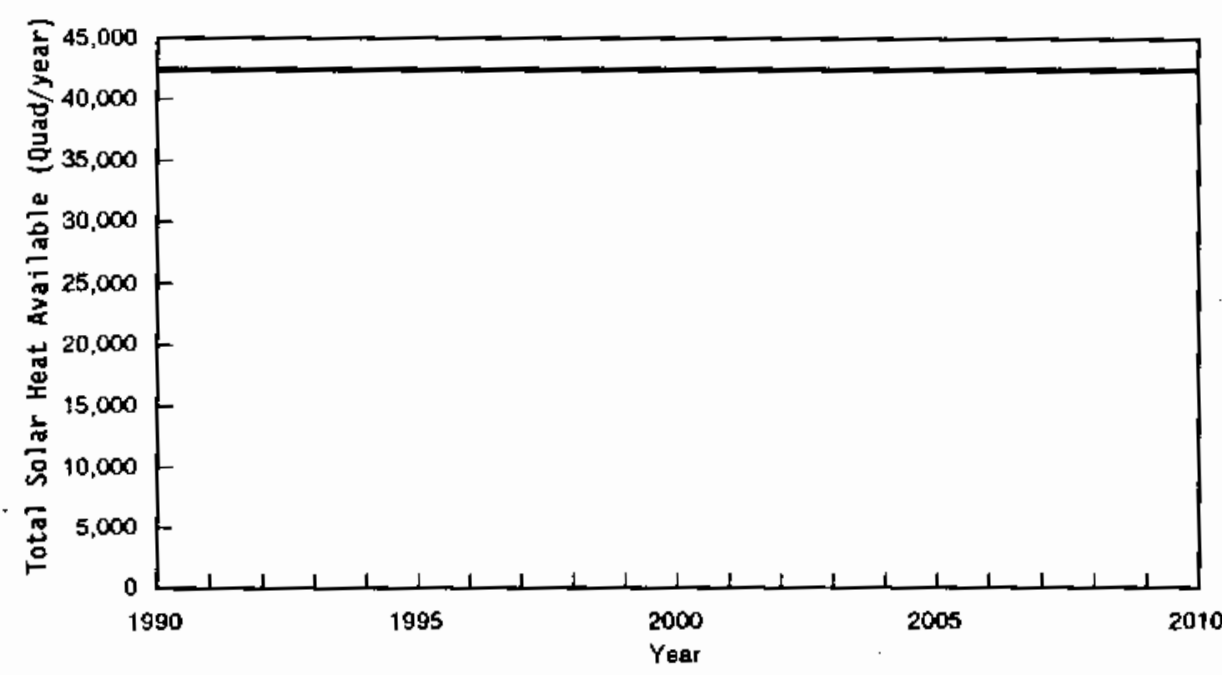

S\$201050.57

FIGURE 4.29. Total Solar Heat Available: (U.S. excluding Alaska)

Shown: This graph illustrates the total amount of solar radiation incident upon the United States (excluding Alaska) aver the period of 1990 to 2010 . This constant value of 42,400 quad/yr is based on total global radiation data calculated for each state.

\subsubsection{Building Sector Cooling}

The following graphs provide background information in support of the graphs for the building cooling sector showing TES research program benefits. 


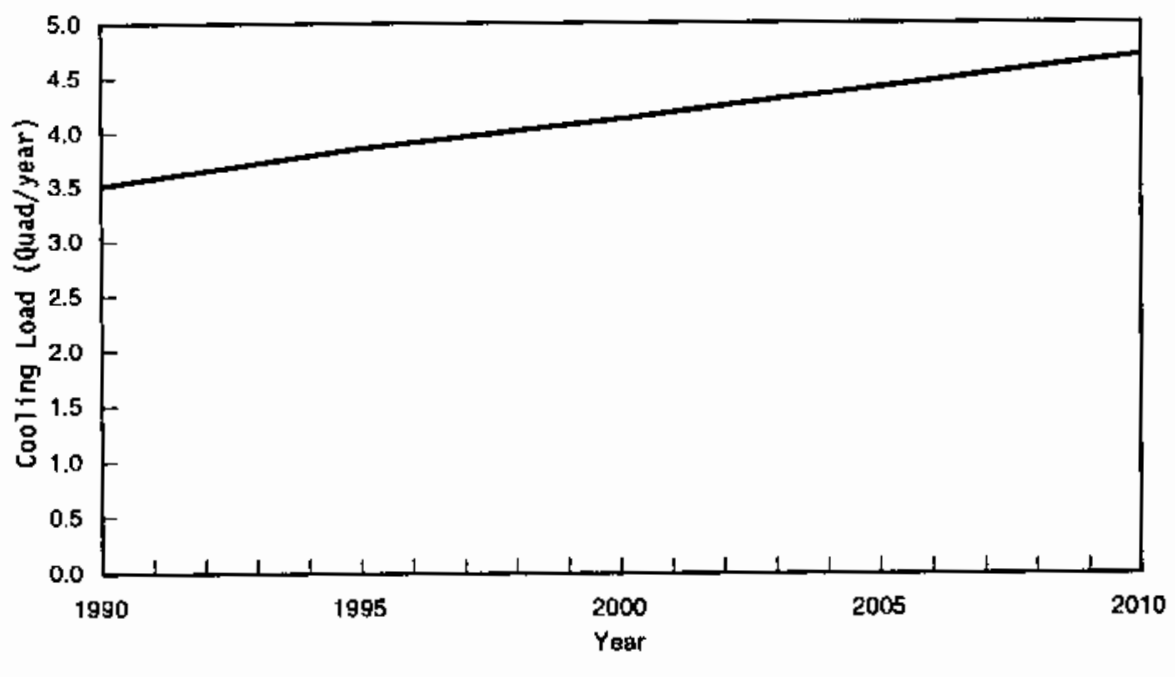

FIGURE 4.30. Building Sector Cooling: Annual Cooling Load (Primary Energy)

Shown: This graph illustrates the annual cooling load in quads for the building sector over the period spanning 1990 to 2010 . The value ranges from 3.5 quads/yr in 1990 to 4.5 quads/yr in 2010 .

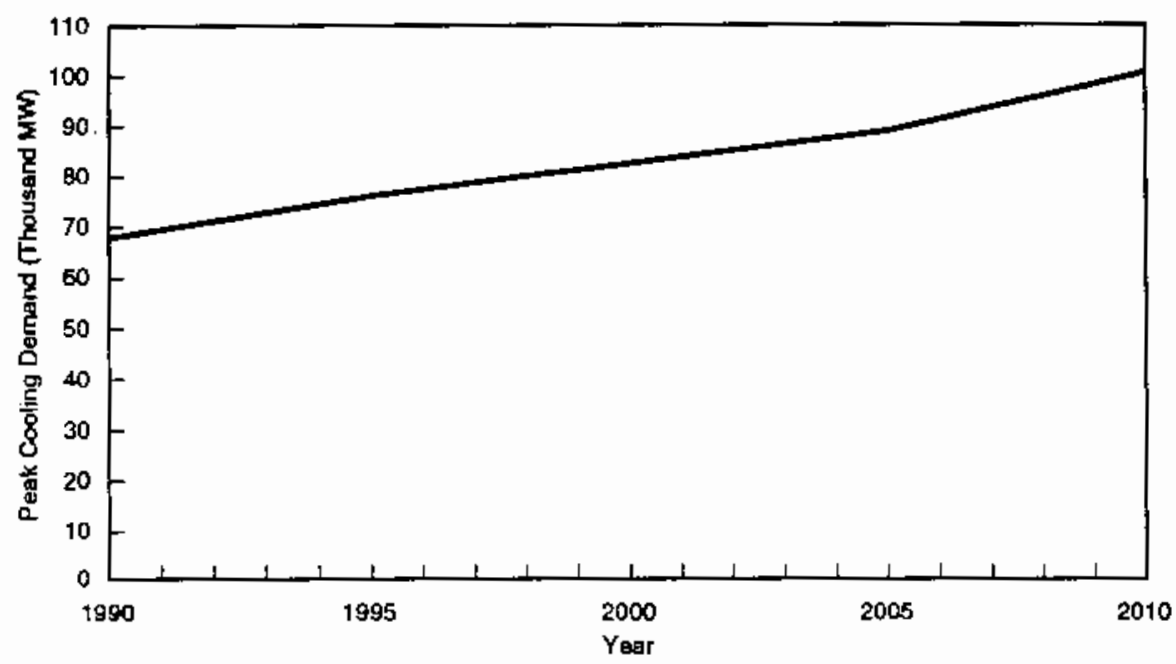

\section{FIGURE 4.31. Building Sector Cooling: Peak Electric Cooling Demand}

Shown: This graph illustrates the peak electric cooling demand for cooling in the building sector over the 20-year period between 1990 and 2010. The values for this graph range between $68,000 \mathrm{MWe}$ in 1990 and $100,000 \mathrm{MWe}$ in 2010 . 


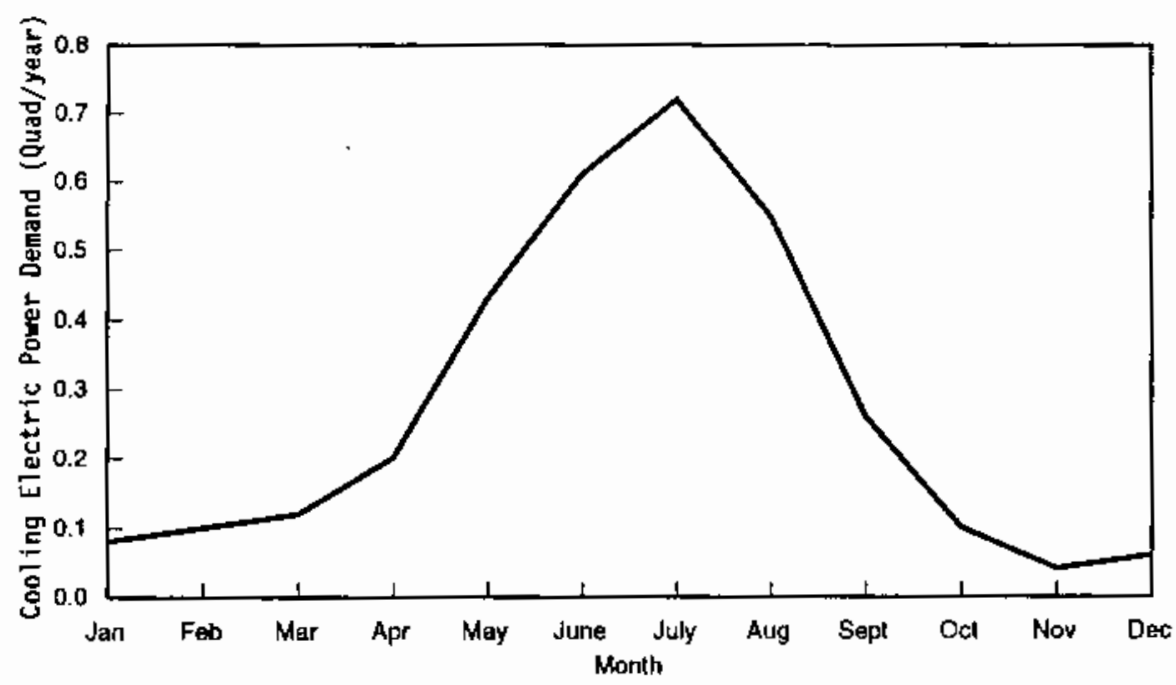

\section{FIGURE 4.32. Building Sector Cooling: Seasonal Primary Electric Energy Demand}

Shown: The seasonal electric energy demand by month over the course of a year is illustrated in this graph. The values for this parameter range between 0.06 quads for Novernber to 0.7 quads for July.

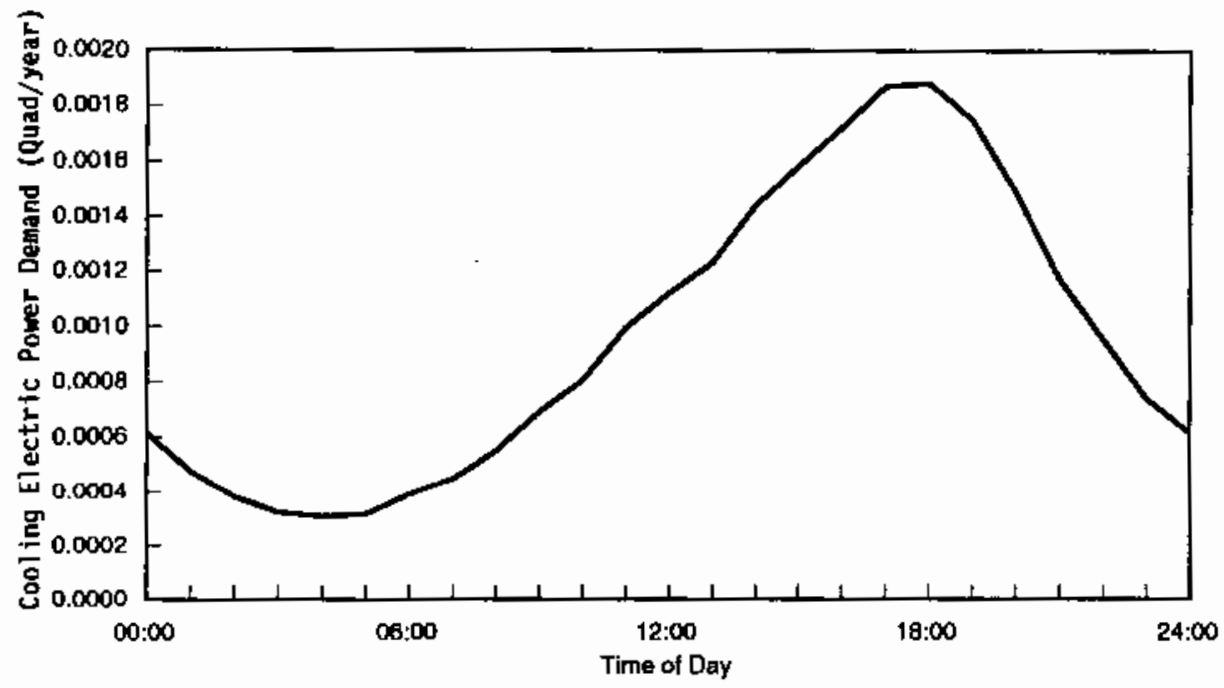

S9rososo, B5

\section{FIGURE 4.33. Building Sector Cooling: Diurnal Cooling Primary Energy Demand for July}

Shown: This graph indicates the quantity of primary energy dernanded in July broken down by time of day. The values range between 0.0003 quads at 4:00a.m. to .0018 quads at $6: 00 \mathrm{p} . \mathrm{m}$.. 


\subsubsection{Utility Sector}

The following graphs provide background information in support of the graphs for the utility sector showing TES research program benefits.

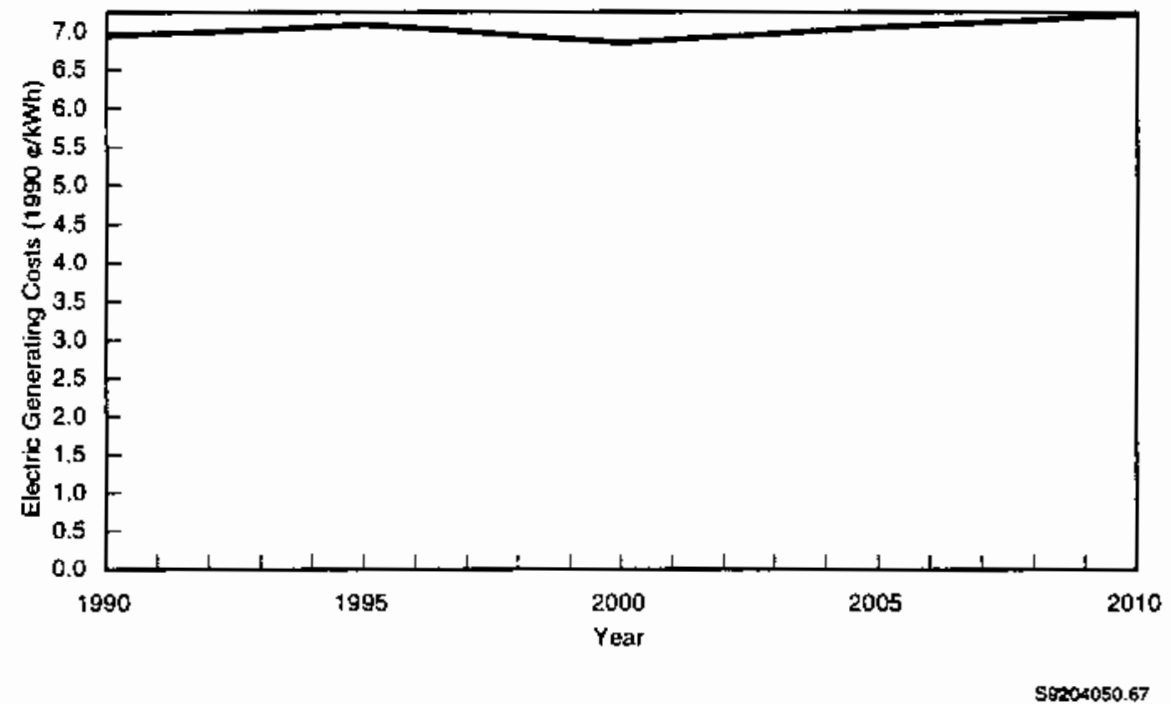

FIGURE 4.34. Utility Sector: Electricity Generating Costs

Shown: This graph illustrates the projected price of electricity for the utility sector between 1990 and 2010 . The generating values are given in 1990 cents per kilowatt-hour.

\subsubsection{Industrial Sector}

The following graphs provide background information in support of the graphs for the industrial sector showing TES research program benefits. 


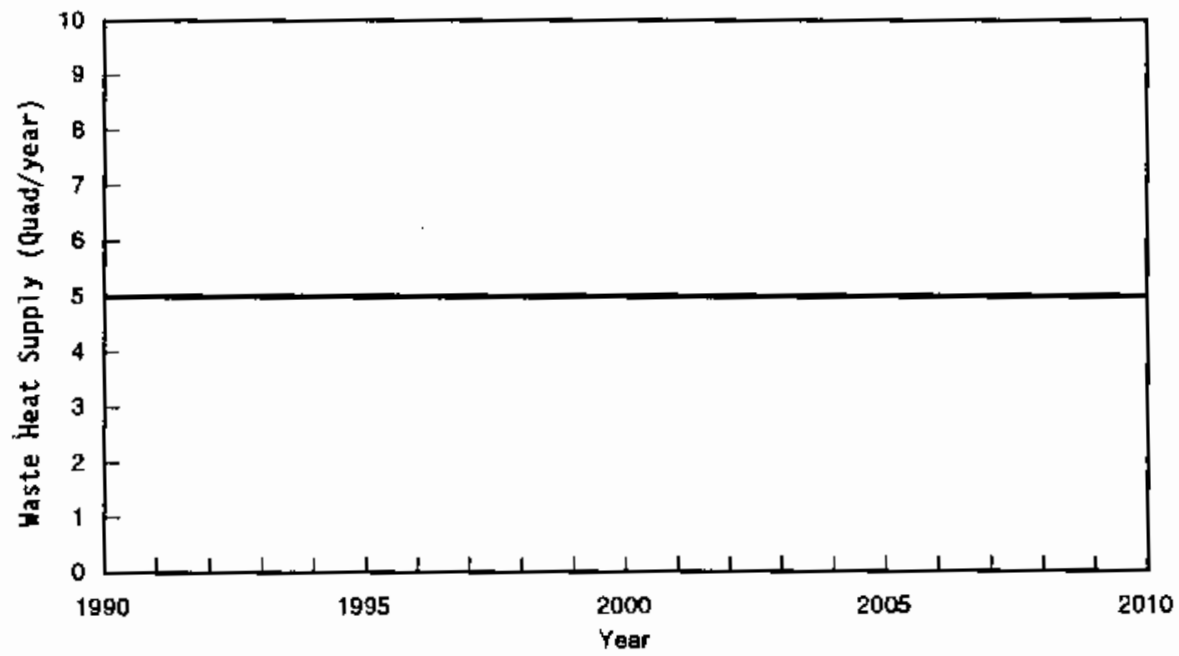

FIGURE 4.35. Industrial Sector: Total Waste Heat Supply

Shown: This graph indicates the total projected supply of waste heat generated by the industrial sector between 1990 and 2010. The supply is projected to remain constant at 5 quads/yr over this period.

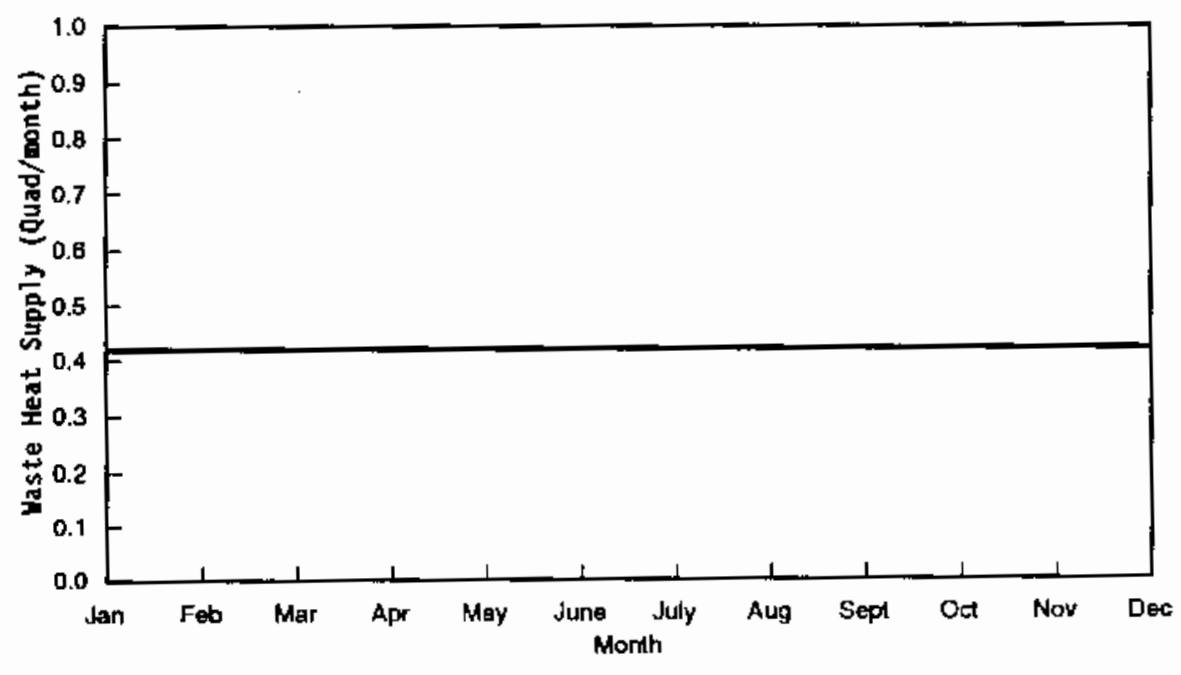

FIGURE 4.36. Industrial Sector: Seasonal Waste Heat Supply

Shown: This graph delineates the supply of industrial waste heat on a seasonal basis. The supply remains constant throughout the year at a level of 0.4 quads/month. 


\subsection{REFERENCES}

40 CFR 86.090. July 1991. U.S. Environmental Protection Agency, "Emission Standards for 1990 and Later Model Year Light-duty Vehicles." U.S. Code of Federal Regulations.

Avallone, E. A., and T. Baumeister III. 1978. Mark's Standard Handbook for Mechanical Engineers, Ninth Edition. McGraw-Hill Book Company, New York.

Bass, F. M. 1969. "A New Product Growth Model for Consumer Durables". Management Science 15(5):215-227.

Brookhaven Nationa 7 Laboratory (BNL). 1991. Analys is and Technology Transfer Report, 1989 and 1990 - Building Technologies. BNL 46559, Brookhaven National Laboratory, Upton, New York.

Brown, D. R., S. M. Garrett, and J. M. Sedgewick. 1991. Electric Rate Structure for Thermal Energy Storage Evaluation. PNL-7697, Pacific Northwest Laboratory, Richland, Washington.

Duffie, J. A., and W. A. Bechman. 1974. Solar Energy Thermal Processes, p.39. John Wiley and Sons, New York.

Edison Electric Institute (EEI). 1991. Statistical Yearbook of the Electric Industry (EEI)/1990. Edison Electric Institute, Washington, D.C.

Energy Information Agency (EIA) 1991a. Annual Energy Review - 1990. Energy Information Agency, Washington, D.C.

Energy Information Agency (EIA). 1991b. 1991 Annual Energy Outlook with Projections to 2010. DOE/EIA-0383(91), Energy Information Agency, Washington, D.C.

EPA. (See U.S. Environmental Protection Agency.)

Fourt, L. A., and J. W. Woodlock. 1960. "Early Prediction of Market Success for New Grocery Products." Journal of Marketing 25:31-38.

Mahajan, V., E. Muller, and F. M. Bass. 1990. "New Product Diffusion Models in Marketing: A Review and Directions for Future Research." Journal of Marketing 54:1-26.

Mansfield, E. 1961. "Technical Change and the Rate of Imitation." Econometrica 29(4):741-746.

Motor Vehicle Manufacturers Association of the United States, Inc. (MVMA). 1991. MVMA Facts and Figures, Annual Statistical Yearbook, 1991 Edition, p.28. MVMA, Detroit Michigan. 
Pratt, R. G., C. C. Conner, E. E. Richman, K. G. Ritland, W. F. Sandusky, and M. E. Taylor. 1989. Description of Electric Energy Use in Single-Family Residences in the Pacific Northwest: End-Use Land and Consumer Assessment Program (ELCAP). DOE/BP-13795-21, Bonneville Power Administration, Portiand, Oregon.

Rand McNally \& Company. 1984. Rand McNally Commercial Atlas and Marketing Guide - I15th Edition. Rand McNally \& Company, Chicago.

Rogers, E. M. 1962. The Diffusion of Innovation. The Free Press, New York. Rogers, E. M., and F. F. Shoemaker. 1971. Communication of Innovations: A Cross-Cultural Approach. The Free Press, New York.

Solar Energy Research Center (SERI). 1990. Insolation Data Manual and Direct Normal Solar Radiation Data Manual. SERI/TP-220-3880, Solar Energy Research Center, Golden, Colorado.

Sorensen, H. A. 1983. Energy Conversion Systems. John Wiley and Sons, New York.

Taylor, Z. T., and R. G. Pratt. 1989. Description of Electric Energy Use in Commercial Buildings in the Pacific Northwest: End-Use Land and Consumer Assessment Program (ELCAP). DOE/BP-13795-22, Bonneville Power Administration, Portiand, Oregon.

Teotia, A. P. S., and P. S. Raju. 1986. "Forecasting the Market Penetration of New Technologies Using a Combination of Economic Cost and Diffusion Models." Journal of Product Innovation Management 4:225-237.

Teotja, A. P. S., Y. L. Klein, and F. R. Wyant. 1981. "Estimating Market Penetration of New Energy Products: A Case Example of New Energy-Efficient Electric Motors, Modeling and Simulation." In Proceedings of the 12th Annual University of Pittsburgh Modeling and Simulation Conference, Pittsburgh.

U.S. Department of Energy (DOE). 1991. National Energy Strategy, First Edition 1991/1992. DOE/S-0082P, U.S. Department of Energy, Hashington, D.C.

U.S. Department of Transportation (DOT). August 1991. I990 Nationalwide Personal Transportation Study (NPTS). August 1991. Office of Highway Information Management, U.S. Department of Transportation, Washington, D.C.

U.S. Environmental Protection Agency (EPA). 1985. AP-42: Compilation of Air Pollutant Emission Factors, Volume 1: Stationary Point and Area Sources, Fourth Edition. U.S. Environmental Protection Agency, Research Triangle Park, North Carolina.

Warren, E. H., Jr. 1980. "Solar Energy Market Penetration Mode1s: Science ur Number Mysticism?" Technological Forecasting and Social Change 16:105-118. 
Weijo, R. 0., and D. R. Brown. 1988. Estimating the Market Penetration of Residential Cool Storage Technology Using Economic Cost Modeling. PNL-6561, Pacific Northwest Laboratory, Richi and, Washington.

Wilfert, G. L., H. D. Huber, R. E. Dodge, B. A. Garrett-Price, L. L. Fassbender, E. A. Griffin, D. R. Brown, and N. L. Moore. 1984.

Characterization of Industrial Process Waste Heat and Input Heat Systems.

PNL-4912, Pacific Northwest Laboratory, Richland, Washington. 



\subsection{BIBLIOGRAPHY}

Davis, L. B. 1990. Dry Low NO Combustion for GE Heavy-Duty Gas Turbines. GER 3568A, General Electric Power Generation, Schenectady, New York.

Electric Power Research Center (EPRI). 1989. TAG: Technical Assessment Guide, Electrical Supply - 1989, Vol. 6, Rev. 6, pp. 7.2, 7.63. EPRI-6587-L, Electric Power Research Center, Palo Alto, California.

Kendal1, D. L. and S. C. Cates 1991. Market Penetration of New Technologies, Programs, and Services. Final Report. EPRI CU-7011, Electric Power Research Institute, Palo Alto, California.

Lawrence, K. D. and W. H. Lawton. 1981. "Applications of Diffusion Models: Some Empirical Results." In New Product Forecasting, eds. Y. Wind, V. Mahajan, and R. N. Cardozo, pp. 20-60. D.C. Heath, Lexington, Massachusetts.

National Energy Strategy (NES) - Powerful Ideas for America, First Edition 1991/1992. February 1991. U.S. Department of Energy, Washington, D.C.

"Total Population (U.S.A.)." 1990. CENDATA Database from DIALOG. U.S. Department of Commerce, Bureau of Census, Washington, D.C. 

APPENDIX A

KEY ASSUMPTIONS AND DATA SOURCES FOR THE BENEFITS GRAPHS 
APPENDIX A

KEY ASSUMPTIONS AND DATA SOURCES FOR THE BENEFITS GRAPHS

This appendix contains a listing of the key assumptions as we 11 as limitations and sources of information used in developing each graph appearing in Sections 4.1 and 4.2 of Chapter 4.0. Certain blanket assumptions that appear in Chapter 2.0 and 3.0 of the report have been made in the development of all the graphs.

A. 1 


\section{TOTAL BENEFITS GRAPHS}

\section{FIGURE 4.1 - KEY ASSUMPTIONS:}

- The total potential primary energy savings that would result from using thermal energy storage (TES) technologies is the aggregate of the potential primary energy displaced in the building sector for heating (by allowing greater use of industrial waste heat and solar thermal energy for space heating, see Figure 4.8) and in the building sector for cooling (by allowing greater use of winter chill for space cooling. see Figure 4.14).

- Eventual $28 \%$ residential and $42 \%$ commercial penetration by TES by 2010 based on estimates provided by Weijo and Brown (1988)

- Remaining technical issues resolved by 1995

- Linearly increasing econoric fractions between 1990 and 2010

- Economic Market Ratio (EMR) (2010) without TES equaled EMR (1995) with TES

- Solar applications assumed to be $10 \%$ of waste heat applications

- Logistic diffusion growth

- Rate parameter $\alpha=4.0$

- Diffusion half- 7 ife $h=12$ years

- Binary diffusion based on value of Economic Cost Ratio (ECR)

- No repeat adoptions.

\section{FIGURE 4.2 - KEY ASSUMPTIONS:}

- The total potential reduction in $\mathrm{CO}_{2}$ emissions that would result from TES technologies is the aggregate of the potential $\mathrm{CO}_{2}$ emissions reduction in the building sector heating (see Figure 4.11) and the building sector cooling (see Figure 4.16).

- Eventual $28 \%$ residential and commercial penetration by TES in building sector heating (based on market penetration estimates by Weijo and Brown ([1988])

- Commercial applications 1.5 times as numerous as residential applications in building sector heating

- Linearly increasing economic fractions between 1990 and 2010 
- EMR (2010) without TES equaled EMR (1995) with TES

- Solar applications assumed to be $10 \%$ of waste heat applications in building sector heating

- 1/6 of the U.S. economically attractive (for near-surface ice and snow ponds) by 2010 (e.g., EMR $[2010]=1 / 6$ ) in building sector cooling

- $\operatorname{EMR}(1990)=5 \%$ in building sector cooling

- EMR for residential sector equals that of commercial sector in building sector cooling

- Without a DOE-funded research program, the EMR will be one-half that achievable with a fully-funded program in building sector cooling

- Logistic diffusion growth

- Rate parameter $\alpha=4.0$

- Diffusion half-life $h=12$ years

- Binary diffusion based on value of ECR

- No repeat adoptions.

\section{FIGURE 4.3 - KEY ASSUMPTIONS:}

- The total potential reduction in SO emissions that would result from TES technologies is the aggregate of the potential $\mathrm{SO}_{\mathrm{x}}$ emissions reduction in the building sector heating (see Figure 4.12) and the building sector cooling (see Figure 4.17).

- Eventual $28 \%$ residential and comnercial penetration by TES in building sector heating, based on market penetration estimates by Weijo and Brown (1988)

- Commercial applications 1.5 times as numerous as residential applications in building sector heating

- Linearly increasing economic fractions between 1990 and 2010

- EMR (2010) without TES equaled EMR (1995) with TES

- Solar applications assumed to be $10 \%$ of waste heat applications in building sector heating

- 1/6 of the U.S. economically attractive (for near-surface ice and snow ponds) by 2010 (e.g., EMR [2010] = 1/6) in building sector cooling 
- $\operatorname{EMR}(1990)=5 \%$ in building sector cooling

- EMR for residential sector equals that of commercial sector in building sector cooling

- Without a DOE-funded research program, the EMR will be one-half that achievable with a fully-funded program in building sector cooling

- Logistic diffusion growth

- Rate parameter $\alpha=4.0$

- Diffusion half-life $h=12$ years

- Binary diffusion based on value of ECR

- No repeat adoptions.

\section{FIGURE 4.4 KEY ASSUMPTIONS:}

- The total potential reduction in NOx emissions that would result from TES technologies is the aggregate of the potential NO emissions reduction in the building sector heating (see figure 4.13), the building sector cooling (see Figure 4.18), and the transportation sector (see Figure 4.23).

- Eventual $28 \%$ residential and commercial penetration by TES in building sector heating based on market penetration estimates by Weijo and Brown (1988)

- Commercial applications 1.5 times as numerous as residential applications in building sector heating

- Linearly increasing economic fractions between 1990 and 2010

- EMR (2010) without TES equaled EMR (1995) with TES

- Solar applications assumed to be $10 \%$ of waste heat applications in building sector heating

- Power plant $\mathrm{NO}_{x}$ emissions meet EPA requirements.

- 1/6 of the U.S. economically attractive (for near-surface ice and snow ponds) by 2010 (e.g., EMR [2010] $=1 / 6$ ) in building sector cooling

- $\operatorname{EMR}(1990)=5 \%$ in building sector cooling

- EMR for residential sector equals that of commercial sector in building sector cooling 
- Without a DOE-funded research program, the EMR will be one-haif that achievable with a fully-funded program in building sector cooling

- Federal mandate requiring catalytic preheating for $\mathrm{NO}_{x}$ reduction effective in 1995 in transportation sector

- All new vehicles in the U.S. will be equipped with this device thereafter (transportation sector)

- Catalytic preheating technology unavailable until 2005 without DOEfunded TES research (transportation sector)

- Total potential market for this technology is a 11 new cars produced in 1995 and subsequent years (transportation sector)

- Logistic diffusion growth

- Rate parameter $\alpha=4.0$

- Diffusion half-life $h=12$ years

- Binary diffusion based on value of ECR

- No repeat adoptions.

\section{FIGURE 4.5 - KEY ASSUMPTIONS:}

- The top curve shows the maximum predicted potential peak electric cooling capacity reduction and is the aggregate of the avoided generating capacity by diurnal TES in the building sector cooling and utility sector (see Figures 4.15 and 4.22 ). It is based on an annual electric load factor of 61.6\% (EEI 1991) and the total electric energy used for space cooling projected for 1990 to 2010 in the (EIA 1991b).

- Unit cost of a cooling storage system assumed to be cut in half with a TES program

- The fraction of utilities offering rate structure incentives assumed to be $100 \%$ by 2010 with a TES program

- No improvement in unit cost assumed without a TES program

- The fraction of utilities offering rate structure incentives assumed to be $50 \%$ by 2010 without a TES program

- Logistic diffusion growth

- Rate parameter $\alpha=4.0$

- Diffusion half-life $h=12$ years 
- Binary diffusion based on value of ECR

- No repeat adoptions.

\section{FIGURE 4.6 - KEY ASSUMPTIONS:}

- The total potential displacement of expensive fuels (oil and gas) by cheaper fuels (coal) is indicated in the figures' top curve as the total projected demand for $0 i l$ and gas (in equivalent million bbl crude oil per day) for the 20-year period from 1990 to 2010 for electricity generation (EIA 1991b).

- The total potential market for retrofitted coal-fired power plants is 100,000 MW based on available excess capacity in existing coal-fired power plants. Retrofitting is assumed to be economically attractive for $50 \%$ of all existing coal-fired plants, resulting in a total retrofit market for utility TES of 50,000 $\mathrm{MW}$.

- Retrofitting of coal-fired plants economical at an additional $5,000 \mathrm{MW} / \mathrm{yr}$, beginning with zero in 1990

- Retrofitting economically attractive on $50 \%$ of existing coal-fired plants

- Starting in 2000 , new integrated, gasification combined-cycle coa] plants will be replaced by TES at 5,000 MW/yr

- In 2005 , an additional 5,000 MW/yr of gas turbine capacity displaced by advanced TES technologies

- Without TES research, the aforementioned advanced technologies will not be available

- Logistic diffusion growth

- Rate parameter $\alpha=4.0$

- Diffusion half-life $h=12$ years

- Binary diffusion based on value of ECR

- No repeat adoptions.

\section{FIGURE 4.7 - KEY ASSUMPTIONS:}

- The top curve indicates the maximum predicted potential electric energy reduction by TES and is the aggregate of the electricity components of building sector heating (derived from data used for Figure 4.8) and building sector cooling (derived from data used for Figure 4.14) 
- $1 / 6$ of the U.S. economically attractive by 2010 (e.g., EMR $[2010]=1 / 6$ ) (building sector cooling)

- $\operatorname{EMR}(1990)=5 \%$ (building sector cooling)

- Linear EMR growth between 1990 and 2010 (building sector cooling)

- EMR for residential sector equals that of cormercial sector (building sector cooling)

- Without a DOE-funded research program, the EMR will be one-half that achievable with a fully-funded program (building sector cooling)

- Eventual $28 \%$ residential and commercial penetration by TES (building sector heating)

- Commercial applications 1.5 times as numerous as residential applications (building sector heating)

- Remaining technical issues resolved by 1995 (building sector heating)

- Linearly increasing economic fractions between 1990 and 2010 (building sector heating)

- EMR (2010) without TES equaled EMR (1995) with TES (building sector heating)

- Solar applications assumed to be $10 \%$ of waste heat applications (building sector heating)

- Logistic diffusion growth

- Rate parameter $\alpha=4.0$

- Diffusion half-life $h=12$ years

- Binary diffusion based on value of ECR

- No repeat adoptions. 


\section{BUILDING SECTOR HEATING GRAPHS}

\section{FIGURE $4.8 \mathrm{KEY}$ ASSUMPTIONS:}

- Current funding level for TES research is $\$ 5 \mathrm{miltion} / \mathrm{yr}$.

- The maximum potential primary energy savings from building space heating resulting from the use of STES technologies is the aggregate of the potentiai primary energy consumption for building space heating displaced in the residential and commercial bujlding sectors. These projections are based on data in EIA (1991b), the National Energy Strategy (NES) (DOE 1991), and Analys is and Technology Transfer Report, 1989 and 1990 - Building Technologies (BNL 1991).

- Primary energy is derived from fuels including coal, natural gas, and distillate fuel oil. The primary energy for electricity production was determined using an overall power plant conversion efficiency of $30 \%$ and the following breakdown of electricity: coal - $55.4 \%$, natural gas $9.4 \%$, oil - 4.2\%, nuclear - $20.6 \%$, hydro - $10.0 \%$, and other $-0.4 \%$ Annual Energy Review - 1990) (EIA 1991a).

- Eventual $28 \%$ residential and commercial penetration by TES based on market penetration estimates by Weijo and Brown (1988)

- Commercial applications 1.5 times as numerous as residential applications

- Remaining technical issues resolved by 1995

- Linearly increasing economic fractions between 1990 and 2010

- EMR (2010) without TES equaled EMR (1995) with TES

- Solar applications assumed to be $10 \%$ of waste heat applications

- Logistic diffusion growth

- Rate parameter $\alpha=4.0$

- Diffusion half-life $h=12$ years

- Binary diffusion based on value of ECR

- No repeat adoptions.

\section{FIGURE 4.9 - KEY ASSUMPTIONS:}

- Growth in manufacturing primary energy use will increase slowly, and any increase in energy consumption will be offset by increases in energy 
efficiency; therefore, it is assumed that the total waste heat available for manufacturing operations $w i 11$ remain at a constant 5 quad/yr during the 20-year period between 1990 and 2010 (Wilfert et al. 1984); see

Figure 4.35 .

- Eventual $28 \%$ residential and commercial penetration by TES

- Commercial applications 1.5 times as numerous as residential applications

- Linearly increasing economic fractions between 1990 and 2010

- EMR (2010) without TES equaled EMR (1995) with TES

- Solar applications assumed to be $10 \%$ of waste heat applications

- Logistic diffusion growth

- Rate parameter $\alpha=4.0$

- Diffusion half-life $h=12$ years

- Binary diffusion based on value of ECR

- No repeat adoptions.

\section{FIGURE 4.10 - KEY ASSUMPTIONS:}

- Because the amount of solar heat available to the U.S. (see Figure 4.29) far exceeds the amount of primary energy used in the building sector heating, the potential for energy savings is simply the total building sector heating energy.

- Eventual $28 \%$ residential and commercial penetration by TES

- Commercial applications 1.5 times as numerous as residential applications

- Linearly increasing economic fractions between 1990 and 2010

- EMR (2010) without TES equaled EMR (1995) with TES

- Solar applications assumed to be $10 \%$ of waste heat applications

- Logistic diffusion growth

- Rate parameter $\alpha=4.0$

- Diffusion half-life $h=12$ years 
- Binary diffusion based on value of ECR

- No repeat adoptions.

\section{FIGURE 4.11 - KEY ASSUMPTIONS:}

- The potential reduction in $\mathrm{CO}_{2}$ emissions is based on the following assumptions:

- $\mathrm{CO}_{2}$ emissions will not be controlled for the 20-year period from 1990 to 2010

- Coal-fired Power Plants:

* Based on the stoichiometry of burning carbon, $3.667 \mathrm{Tbm} \mathrm{CO}_{2}$ wi11 be produced for each ibm of carbon

* The average coal consists of $66.6 \mathrm{wt} \%$ carbon (C) and has a higher heating value (HHV) of $11,428 \mathrm{Btu} / 1 \mathrm{bm}$ (Avallone and Baumeister 1978)

* $97.0 \mathrm{~kg} \mathrm{CO} 2$ will be produced during the combustion of each MMBtu of coal.

- 0i]-fired Power Plants:

* The primary oil fuel burned in oil-fired power plants is distillate fuel (fuel $0 i 1$ \#2) and it consists of 85 wt\% carbon and has an HHV of $0.1388 \mathrm{MMBtu} / \mathrm{gal}$. Its density is $7.41 \mathrm{lbm} / \mathrm{gal}$ (Avallone and Baumeister 1978).

* $75.4 \mathrm{~kg} \mathrm{CO}_{2}$ will be produced during the combustion of each MMBtu of fuel.

- Natural Gas-fired Power Plants:

* Natural gas is mostly methane $\left(\mathrm{CH}_{4}\right)$ and, based on stoichiometric relationships, $2.75 \mathrm{lbm} \mathrm{CO}_{2}$ will be produced for each $1 \mathrm{bm}$ of $\mathrm{CH}_{4}$.

* The density of natural gas at $101.325 \mathrm{kPa}$ and $288.9 \mathrm{~K}$ is 0.6767 $\mathrm{kg} / \mathrm{m}^{3}$.

* $50.1 \mathrm{~kg} \mathrm{CO} \mathrm{C}_{2}$ will be produced during the combustion of each MMBtu of fuel.

- Eventual $28 \%$ residential and commercial penetration by TES

- Commercial applications 1.5 times as numerous as residential applications 
- Linearly increasing economic fractions between 1990 and 2010

- EMR (2010) without TES equaled EMR (1995) with TES

- Solar applications assumed to be $10 \%$ of waste heat applications

- Logistic diffusion growth

- Rate parameter $\alpha=4.0$

- Diffusion half-life $h=12$ years

- Binary diffusion based on value of ECR

- No repeat adoptions.

\section{FIGURE 4.12 - KEY ASSUMPTIONS:}

- The potential reduction in SO emissions is based on the following assumptions:

- Coal-fired Power Plants:

* SO emissions are controlled with $90 \%$ of the SO being captured by flue gas desulfurization (FGD) equipment (EPA 19B5).

* The average coal consists of $1.3 \mathrm{wt} \%$ sulfur and has an HHV of $11,248 \mathrm{Btu} / 1 \mathrm{bm}$ (Avallone and Baumeister 1978).

* $0.1006 \mathrm{~kg} \mathrm{SO}$ will be produced during the combustion of each MMBtu of coal (EPA 1985).

- 0i1-fired Power Plants:

* SO emissions are controlled with $90 \%$ of the S0 being captured by flue gas desulfurization (FGD) equipment (EPA 1985).

* The primary oil fuel burned in oil-fired power plants is distillate fuel (fuel 011 \#2) and consists of $0.35 \mathrm{wt} \%$ sulfur and has an HHV of $0.138 \mathrm{MMBtu} /$ gal (Avallone and Baumeister 1978).

* $0.0183 \mathrm{~kg} \mathrm{SO}$ will be produced during the combustion of each MMBtu of 011 (EPA 1985).

- Natural Gas-fired Power Plants:

* The size of the utility boilers used for electricity generation is $100 \mathrm{MMBtu} / \mathrm{hr}$ (EPA 1985). 
* Sulfur is added to natural gas as a "mercaptan" so the gas can be detected by smell (EPA 1985).

* SO emissions are small and uncontrolled. 2.59E-05 kg SO will be produced during the combustion of each MMBtu of natural gas (EPA 1985).

- Eventual $28 \%$ residential and commercial penetration by TES

- Comnercial applications 1.5 times as numerous as residential applications

- Linearly increasing economic fractions between 1990 and 2010

- ECR (2010) without TES equaled ECR (1995) with TES

- Solar applications assumed to be $10 \%$ of waste heat applications

- Logistic diffusion growth

- Rate parameter $\alpha=4.0$

- Diffusion half-7ife $h=12$ years

- Binary diffusion based on value of ECR

- No repeat adoptions.

\section{FIGURE 4.13 KEY ASSUMPTIONS:}

- The potential reduction in $\mathrm{NO}_{x}$ is based on the following assumptions:

- Coal-fired Power Plants:

* The average coal has an HHV of 11,248 Btu/lbm (Avallone and Baumeister 1978).

* NO emissions are controlled with $35 \%$ of the $\mathrm{NO}_{x}$ being captured (EPA 1985).

* $0.2877 \mathrm{~kg} \mathrm{NO}$ will be produced during the combustion of each MMBtu of coal (EPA 1985$)$.

- Oil-fired Power Plants:

* The primary fuel burned in oil-fired power plants is distillate fuel (fuel 011 \#2) and has an HHV of $0.1388 \mathrm{MMBtu} / \mathrm{gal}$ (Avallone and Baumeister 1978). 
* NO emissions are controlled with $40 \%$ of the $\mathrm{NO}_{x}$ being captured (EPA 1985).

* $0.1314 \mathrm{~kg} \mathrm{NO}$ will be produced during the combustion of each MMBtu of 011 (EPA 1985).

- Natural Gas-fired Power Plants:

* NO emissions are controlled with $80 \%$ of the $\mathrm{NO}_{\mathrm{x}}$ being captured (EPA 1985).

* $0.0475 \mathrm{~kg} \mathrm{~N} 0$ will be produced during the combustion of each MMBtu of natura 1 gas (EPA 1985).

- Eventual $28 \%$ residential and commercial penetration by TES

- Commercial applications 1.5 times as numerous as residential applications

- Linearly increasing economic fractions between 1990 and 2010

- ECR (2010) without TES equaled ECR (1995) with TES

- Solar applications assumed to be $10 \%$ of waste heat applications

- Logistic diffusion growth

- Rate parameter $\alpha=4.0$

- Diffusion half-7ife $h=12$ years

- Binary diffusion based on value of ECR

- No repeat adoptions. 


\section{BUILDING SECTOR COOLING GRAPHS}

\section{FIGURE 4.14 - KEY ASSUMPTIONS:}

- The maximum potential primary energy savings from bujlding space cooling resulting from the use of STES technologies is the aggregate of the potential primary energy consumption for building space cooling displaced in the residential and commercial building sectors. These projections are based on data in EIA (1991b), the NES (DOE 1991), and Analysis and Technology Transfer Report, 1989 and 1990 - Building Technologies (BNL 1991).

- Primary energy is derived from fuels including coa7, natural gas, and distillate fuel $0 i 1$. The primary energy for electricity production was determined using an overall power plant conversion efficiency of $30 \%$ and the following breakdown of electricity: coal - $55.4 \%$, natural gas $9.4 \%, 0 i]-4.2 \%$, nuclear - $20.6 \%$, hydro - $10.0 \%$, and other $-0.4 \%$ Annual Energy Review - 1990 (EIA 1991a)

- $1 / 6$ of the U.S. economically attractive by 2010 (e.g., EMR [2010] = 1/6)

- $\operatorname{EMR}(1990)=5 \%$

- Linear EMR growth between 1990 and 2010

- EMR for residential sector equals that of commercial sector

- Without a DOE-funded research program, the EMR will be one-half that achieved such a program

- Logistic diffusion growth

- Rate parameter $\alpha=4.0$

- Diffusion half-1ife $h=12$ years

- Binary diffusion based on value of ECR

- No repeat adoptions.

\section{FIGURE 4.15 - KEY ASSUMPTIONS:}

- The top curve (see also Figure 4.31) shows the maximum predicted potential peak electric cooling capacity reduction and is based on an annual electric load factor of $61.6 \%$. An annual load factor is equal to the total energy produced divided by the peak energy demanded. This is the average load factor based on peak load for the 20-year period from 1970 to 1990 for the electric utility industry (EEI 1991). It is 
assumed this load factor will remain constant through 2010 . The load factor was applied to the total projected electric energy demand for space cooling projected for 1990 to 2010 in EIA (1991b).

- Penetration of diurnal TES technologies depended on a number of factors including: state population, cooling degree days (CDD) by state, timeof-day peak and off-peak rate differentials, varying levels of rebates offered by DOE, and in what sector the technology is being applied (commercial or residential). The diurnal TES technology was assumed to apply only to central air conditioning use, not room units (Weijo and Brown 1988; Brown, Garrett, and Sedgwick 1991).

- DOE-funded TES research reduced the unit cost of a cool storage system by $50 \%$.

- Unit cost of a cool storage system assumed to be cut in half with a TES program

- The fraction of utilities offering rate structure incentives assumed to be $100 \%$ by 2010 with a TES program

- No improvenent in unit cost assumed without a TES program

- The fraction of utilities offering rate structure incentives assumed to be $50 \%$ by 2010 without a TES program

- Logistic diffusion growth

- Rate parameter $\alpha=4.0$

- Diffusion half-life $h=12$ years

- Binary diffusion based on value of ECR

- No repeat adoptions.

\section{FIGURE 4.16 - KEY ASSUMPIIONS:}

- The potential reduction in $\mathrm{CO}_{2}$ emissions is based on the following as sumptions:

- $\mathrm{CO}_{2}$ enissions will not be controlled for the 20-year period from 1990 to 2010 .

- Coa]-fired Power Plants:

* Based on the stoichiometry of burning carbon, $3.667 \mathrm{lbm} \mathrm{CO}_{2}$ will be produced for each $1 \mathrm{bm}$ of carbon. 
* The average coal consists of $66.6 \mathrm{wt} \%$ carbon (C) and has an HHV of $11,428 \mathrm{Btu} / 1 \mathrm{bm}$ (Avallone and Baumeister 1978).

* $97.0 \mathrm{~kg} \mathrm{CO}$, will be produced during the combustion of each MMBtu of coal.

- 0il-fired Power Plants:

* The primary oil fuel burned in oil-fired power plants is distillate fuel (fuel $0 i 1$ \#2) and it consists of $85 \mathrm{wt} \%$ carbon and has an HHV of $0.1388 \mathrm{MMBtu} / \mathrm{gal}$. Its density is $7.41 \mathrm{lbm} / \mathrm{gal}$ (Avallone and Baumeister 1978).

* $75.4 \mathrm{~kg} \mathrm{CO}_{2}$ will be produced during the combustion of each MMBtu of fuel.

- Natural Gas-fired Power Plants:

* Natural gas is mostly methane $\left(\mathrm{CH}_{4}\right)$ and, based on stoichiometric relationships, $2.75 \mathrm{lbm} \mathrm{CO}$ will be produced for each $1 \mathrm{bm}$ of $\mathrm{CH}_{4}$.

* The density of natural gas at $101.325 \mathrm{kPa}$ and $288.9 \mathrm{~K}$ is $0.6767 \mathrm{~kg} / \mathrm{m}^{3}$.

* $50.1 \mathrm{~kg} \mathrm{CO} \mathrm{C}_{2}$ will be produced during the combustion of each MMBtu of fuel.

- $1 / 6$ of the U.S. economically attractive (for near-surface ice and snow ponds) by 2010 (e.g., EMR $[2010]=1 / 6$ )

- $\operatorname{EMR}(1990)=5 \%$

- Linear EMR growth between 1990 and 20107

- EMR for residential sector equals that of commercial sector

- Without a DOE-funded research program, the EMR will be one-half that achievable with a fully-funded program

- Logistic diffusion growth

- Rate parameter $\alpha=4.0$

- Diffusion halflife $h=12$ years

- Binary diffusion based on value of ECR

- No repeat adoptions. 


\section{FIGURE 4.17 - KEY ASSUMPTIONS:}

- The potential reduction in $\mathrm{SO}_{x}$ emissions is based on the following assumptions:

- Coal-fired Power Plants:

* So emissions are controlled with $90 \%$ of the SO being captured by flue gas desulfurization (FGD) equipment (EPA 1985).

* The average coal consists of $1.3 \mathrm{wt} \%$ sulfur and has an HHV of $11,248 \mathrm{Btu} / 1 \mathrm{bm}$ (Avallone and Baumeister 1978).

* $0.1006 \mathrm{~kg} \mathrm{SO}$ will be produced during the combustion of each MMBtu of coal (EPA 1985$)$.

- 0i]-fired Power Plants:

* SO emissions are controlled with $90 \%$ of the SO being captured by flue gas desulfurization (FGD) equipment (EPA 1985).

* The primary oil fuel burned in oil-fired power plants is distillate fuel (fuel oil \#2) and consists of $0.35 \mathrm{wt} \%$ sulfur and has an HHV of $0.138 \mathrm{MMBtu} / \mathrm{gal}$ (Avallone and Baumeister 1978).

* $0.0183 \mathrm{~kg} \mathrm{SO}$ will be produced during the combustion of each MMBtu of 0 il (EPA 1985).

- Natural Gas-fired Power Plants:

* The size of the utility boilers used for electricity generation is $100 \mathrm{MMBtu} / \mathrm{hr}$ (EPA 1985).

* Sulfur is added to natural gas as a "mercaptan" so the gas can be detected by smell (EPA 1985).

* SO emissions are small and uncontrolled. 2.59E-05 $\mathrm{kg} \mathrm{SO}$ will be produced during the combustion of each MMBtu of natural gas (EPA 1985).

- 1/6 of the U.S. economically attractive (for near surface ice and snow ponds) by 2010 (e.g., EMR $[2010]=1 / 6$ )

- $\operatorname{EMR}(1990)=5 \%$

- Linear EMR growth between 1990 and 2010

- EMR for residential sector equals that of the cormercial sector

- Without a DOE-funded research program, the EMR will be one-half that achievable with a fully-funded program 
- Logistic diffusion growth

- Rate parameter $\alpha=4.0$

- Diffusion half-life $h=12$ years

- Binary diffusion based on value of ECR

- No repeat adoptions.

\section{FIGURE 4.18 - KEY ASSUMPTIONS:}

- The potential reduction in $\mathrm{NO}_{x}$ is based on the following assumptions:

- Coal-fired Power Plants:

* The average coal has an HHV of 11,248 Btu/lbm (Aval)one and Baume ister 1978).

* NO emissions are controlled with $35 \%$ of the $\mathrm{NO}_{x}$ being captured (EPA 1985).

* $0.2877 \mathrm{~kg} \mathrm{NO} \times$ will be produced during the combustion of each MMBtu of coal (EPA 1985 ).

- 0i1-fired Power Plants:

* The primary fuel burned in oil-fired power plants is distillate fuel (fuel oil \#2) and has an HHV of $0.1388 \mathrm{MMBtu} / \mathrm{ga}$ ) (Avallone and Baumejster 1978).

* No emissions are controlled with $40 \%$ of the NO ${ }_{x}$ being captured (EPA 1985).

* $0.1314 \mathrm{~kg} \mathrm{NO}$ will be produced during the combustion of each MMBtu of 011 (EPA 1985).

- Natural Gas-fired Power Plants:

* No emissions are controlled with $80 \%$ of the NO ${ }_{x}$ being captured (EPA 1985).

* $0.0475 \mathrm{~kg} \mathrm{NO}_{\mathrm{x}}$ will be produced during the combustion of each MMBtu of natural gâs (EPA 1985).

- $1 / 6$ of the U.S. economically attractive (for near surface ice and snow ponds) by 2010 (e.g., EMR $[2010]=1 / 6$ )

- $\operatorname{EMR}(1990)=5 \%$ 
- Linear EMR growth between 1990 and 2010

- EMR for residential sector equals that of commercial sector

- Without a DOE-funded research program, the EMR will be one-half that achievable with a fully-funded program

- Logistic diffusion growth

- Rate parameter $\alpha=4.0$

- Diffusion half-1ife $h=12$ years

- Binary diffusion based on value of ECR

- No repeat adoptions. 


\section{UTILITY SECTOR GRAPHS}

\section{FIGURE 4.19 - KEY ASSUMPTIONS:}

- The total potential displacement of expensive fuels (oil and gas) by cheaper fuels (coal) is indicated in the figures' top curve as the total projected demand for $0 i 1$ and gas (in equivalent million bbl crude oil per day) for the 20-year period from 1990 to 2010 for electricity generation (EIA 1991).

- Total consumption of oil and natural gas for power generation forms the potential displacement (savings) that could be realized by implementing coal-fired TES technology.

- The total potential market for retrofitted coal-fired power plants is $100,000 \mathrm{MW}$ based on available excess capacity in existing coal-fired power plants. Retrofitting is assumed to be economically attractive for $50 \%$ of all existing coal-fired plants, resulting in a total retrofit market for utility TES of 50,000 MH.

- Total economic potential for retrofitted coal-fired power plants is $50,000 \mathrm{MN}$.

- Retrofitting of coal-fired plants economical at an additional $5000 \mathrm{MW} / \mathrm{yr}$, beginning with zero in 1990.

- Retrofitting economically attractive on $50 \%$ of existing coal-fired plants.

- Starting in 2000, new integrated, gasification combined-cycle plants will be replaced by TES at $5,000 \mathrm{MW} / \mathrm{yr}$.

- In 2005, an additional 5,000 MW/yr of gas turbine capacity displaced by advanced TES technologies.

- Without TES research, the aforementioned advanced technologies will not be available.

- Logistic diffusion growth

- Rate parameter $\alpha=4.0$

- Diffusion half-life $h=12$ years

- Binary diffusion based on value of ECR

- No repeat adoptions. 


\section{FIGURE 4.20 - KEY ASSUMPTIONS:}

- The top curve (see also Figure 4.31) shows the maximum predicted potential peak electric cooling capacity reduction and is based on an annuai electric load factor of $61.6 \%$. An annual load factor is equal to the total energy produced divided by the peak energy demanded. This is the average load factor based on peak load for the 20-year period from 1970 to 1990 for the electric utility industry (EEI 1991). It is assumed this load factor will remain constant through 2010. The load factor was applied to the total projected electric energy demand for space cooling projected for 1990 to 2010 in EIA (1991b).

- The annual electric load factor remained constant between 1990 and 2010 .

- Nationally, increased gas turbine inlet temperatures during peak demand periods reduce the total installed capacity of all gas turbines in the U.S. by approximately 8,200 WWe. With a predicted annual installation rate of new gas turbines and combined-cycle power plants of 10,000 MWe/yr and assuming a 15\% decrease in capacity between summer and winter conditions, the annual potential for increasing gas turbine output by inlet air cooling will be 1,500 MWe.

- It is assumed that a DOE-funded program in utility TES will advance the technique sufficiently to make it economically feasible to capture $60 \%$ of the potential for increasing summer capacity with gas turbine inlet cooling.

\section{FIGURE 4.21 - KEY ASSUMPTIONS:}

- The top curve (see also Figure 4.31) shows the maximum predicted potential peak electric cooling capacity reduction and is based on an annual electric load factor of $61.6 \%$. An annual load factor is equal to the total energy produced divided by the peak energy demanded. This is the average load factor based on peak load for the 20-year period from 1970 to 1990 for the electric utility industry (EEI 1991). It is assumed this load factor will remain constant through 2010 . The load factor was applied to the total projected electric energy demand for space cooling projected for 1990 to 2010 in EIA (1991b).

- The annual electric load factor remained constant between 1990 and 2010 .

- Nationally, approximately 30,000 MWe of cogeneration are installed with a predicted annual increase of $3,500 \mathrm{MWe} / \mathrm{yr}$. It is assumed that a DOEfunded program will result in TES being economical for installation at $25 \%$ of all cogeneration facilities and that a TES installation will increase the peak capacity of the facility by a factor of 3 . 


\section{FIGURE 4.22 - KEY ASSUMPTIONS:}

- The top curve (see also Figure 4.31) shows the maximum predicted potential peak electric cooling capacity reduction and is based on an annual electric load factor of $61.6 \%$. An annual load factor is equal to the total energy produced divided by the peak energy denanded. This is the average load factor based on peak load for the 20-year period from 1970 to 1990 for the electric utility industry (EEI 1991). It is assumed this load factor will remain constant through 2010 . The load factor was applied to the total projected electric energy demand for space cooling projected for 1990 to 2010 in EIA (1991b).

- The annual electric load factor remained constant between 1990 and 2010 .

- Nationa1ly, increased gas turbine inlet temperatures during peak demand periods reduce the total installed capacity of all gas turbines in the U.S. by approximately 8,200 MWe. With a predicted annual installation rate of new gas turbines and combined-cycle power plants of 10,000 MWe/yr and assuming a 15\% decrease in capacity between summer and winter conditions, the annual potential for increasing gas turbine output by inlet air cooling will be 1,500 MWe.

- It is assumed that a DOE-funded program in utility TES will advance the technique sufficiently to make it economically feasible to capture $60 \%$ of the potential for increasing sumer capacity with gas turbine inlet cooling.

- Nationally, approximately 30,000 MWe of cogeneration are installed with a predicted annual increase of $3,500 \mathrm{MWe} / \mathrm{yr}$. It is assumed that a DOEfunded program will result in TES being economical for installation at $25 \%$ of a 17 cogeneration facilities and that a TES installation will increase the peak capacity of the facility by a factor of 3 . 


\section{TRANSPORTATION SECTOR GRAPHS}

\section{FIGURE 4.23 - KEY ASSUMPTIONS:}

- $43 \%$ of car engine starts are cold. A $75 \%$ reduction in $\mathrm{NO}_{\mathrm{x}}$ emissions is possible with catalytic preheating.

- The technology will only be applied to new automobiles, and it will not be used to retrofit old automobiles.

- Between 1983 and 1990, an average of $5.5 \%$ of the cars on the road were from the latest model year according to R. L. Polk \& Co. (MVMA 1991). From this, it is assumed that $5.5 \%$ of the person trips (i.e., the number of starts) in the years between 1983 and 1990 were made with new cars and that this rate will continue for 1990 through 2010 .

- Between 1983 and 1990 , the number of person trips escalated at $1.6 \%$ per year (DOT 1991). It is assumed that this escalation rate will continue from 1990 through 2010.

- The average vehicle trip distance was $9.2 \mathrm{mi} /$ trip for 1991 (DOT 1991). It is assumed that this will remain constant from 1990 through 2010.

- $S O_{x}$ and $\mathrm{NO}_{\mathrm{x}}$ automobile emissions are not regulated by the EPA. $\mathrm{NO}_{\mathrm{x}}$ is controlled to $1.0 \mathrm{~g} / \mathrm{mi}$ for light-duty vehicles (40 CFR 86 ).

- By 1995 , Federal mandate will require catalytic preheaters for $\mathrm{NO}_{\mathrm{x}}$ emission reduction.

- Catalytic preheating technology unavailable until 1995 with D0E-funded TES research. EPA mandate will result in $\mathrm{NO}_{x}$ reduction being equivalant to the potential of this technology.

- All new vehicles in the U.S. will be equipped with this device thereafter.

- Catalytic preheating technology unavailable until 2005 without DOEfunded TES research.

- Total potential market for this technology is all new cars produced in 1995 and subsequent years.

(a) Personal communication with Steve Poulos (Staff Engineer, Advanced Production Engineering) at General Motors, October 7, 1991. 



\section{APPENDIX B}

KEY ASSUMPTIONS AND DATA SOURCES FOR THE SUPPORTING GRAPHS 


\section{APPENDIX B}

\section{KEY ASSUMPTIONS AND DATA SOURCES FOR THE SUPPORTING GRAPHS}

This appendix contains a listing of the key assumptions as well as limitations and sources of information empioyed in the development of each graph appearing in Section 4.3, chapter 4.0. 


\section{BUILDING SECTOR HEATING}

\section{FIGURE 4.24 - KEY ASSUMPTIONS:}

- The total 1990 building sector heating primary energy potential savings value of 9.28 quad/yr (see Figure 4.8 ) was broken down with 5.47 quad/yr (58.9\%) being used in the residentia] sector and 3.81 quad/yr being used in the commercial sector (41.1\%) (EIA 1991b).

- By applying the results of metered End-Use Load and Consumer Assessment Program (ELCAP) data (Taylor and Pratt 1989; Pratt et al. 1989) to the residential and commercia] sectors, the thermal primary power demand was further broken down into increments of months. In the case of the residential sector, single- family residences were used as a proxy for all residential buildings while in the commercial sector, the restaurant was used as a proxy for all commercial buildings.

\section{FIGURE 4.25 - KEY ASSUMPTIONS:}

- The total solar heat available $(42,400$ quad/yr, see figure 4.29) was broken down into increments of months by applying the monthly fractions over a period of a year of the clear day solar radiation on a horizontal plane at 39.N Latitude (Duffie and Beckman 1974).

\section{FIGURE 4.26 - KEY ASSUMPTIONS:}

- From the data used in Figure 4.24 , the total thermal primary power demand for January 1990 was 1.69 quad/mo. Broken down further, approximately $5.45 \mathrm{E}+13 \mathrm{Btu}$ would be demanded in one day for January 1990. By applying residential and commercial metered data for the winter months (Taylor and Pratt 1989; Pratt et al. 1989) to the appropriate sector diurnal thermal, primary power demand was determined.

\section{FIGURE_4.27 - KEY ASSUMPTIONS:}

- Fron the data used in Figure 4.25 , the total solar heat supply for December is $1.89 \mathrm{E}+18 \mathrm{Btu} / \mathrm{mo}$. Broken down further, approximately $6.30 E+16 \mathrm{Btu} /$ day is available. The diurnal variation of this amount was determined by applying hourly fractions of the typical clear day solar radiation on a horizontal plane at $43^{\circ} \mathrm{N}$ Latitude (Sorenson 1983). 
FIGURE 4.28 - KEY ASSUMPTIONS:

- This is the aggregate of the potential primary energy consumption for building space heating displaced in the residential and commercial building sectors. These projections are based on data in EIA (1991b), the NES (DOE 1991), and Analysis and Technology Transfer Report, 1989 and 1990 - Building Technologies (BNL 1991).

- Primary energy is derived from fuels inciuding coal, natural gas, and distillate fuel $0 i 1$. The primary energy for electricity production was determined using an overall power plant conversion efficiency of $30 \%$ and the following breakdown of electricity: coal - $55.4 \%$, natural gas $9.4 \%$, $011-4.2 \%$, nuclear - $20.6 \%$, hydro $-10.0 \%$, and other $-0.4 \%$ Annual Energy Review - 1990 (EIA 1991a).

\section{FIGURE 4.29 - KEY ASSUMPTIONS:}

- This line was developed by averaging the daily global radiation of the cities in a given state (SERI 1990) and multiplying it by the state's area (Rand McNally 1984). The sum of the states' solar radiation (excluding Alaska) is 42,400 quad/yr. 


\section{BUILDING SECTOR COOLING}

\section{FIGURE 4.30 - KEY ASSUMPTIONS:}

- This is the aggregate of the potential primary energy consumption for building space cooling displaced in the residential and commercial building sectors. These projections are based on data in EIA (1991b), the NES, (DOE 1991), and Analysis and Technology Transfer Report, 1989 and 1990 - Building Technologies (BNL 1991).

- Primary energy is derived from fuels including coal, natural gas, and distillate fuel oil. The primary energy for electricity product ion was determined using an overall power plant conversion efficiency of $30 \%$ and the following breakdown of electricity: coal - $55.4 \%$, natural gas $9.4 \%$, oil - $4.2 \%$, nuclear - $20.6 \%$, hydro - $10.0 \%$, and other - $0.4 \%$ Annual Energy Review - 1990 (EIA 1991a).

\section{FIGURE 4.31 - KEY ASSUMPTIONS:}

- This curve shows the maximum predicted potential peak electric cooling capacity reduction and is based on an annual electric load factor of $61.6 \%$. An annual load factor is equal to the tota] energy produced divided by the peak energy demanded. This is the average load factor based on peak load for the 20-year period from 1970 to 1990 for the electric utility industry (EEI 1991). It is assumed this load factor will remain constant through 2010 . The load factor was applied to the total projected electric energy demand for space cooling projected for 1990 to 2010 in EIA (1991b).

\section{FIGURE 4.32 - KEY ASSUMPTIONS:}

- The total 1990 building sector cooling primary electric energy potential savings value of 3.28 quad/yr (see Figure 4.14) was broken down with 1.35 quad/yr (41.2\%) being used in the residential sector and 1.93 quad/yr being used in the commercial sector (58.8\%) (EIA 1991b).

- By applying the results of metered ELCAP data (Taylor and Pratt 1989; Pratt et a1. 1989) to the residential and comercial sectors, the cooling primary electric energy demand was further broken down into increments of months. In the case of the residential sector, singlefamily residences were used as a proxy for all residential buildings, while in the commercial sector the restaurant was used as a proxy for all commercial buildings. 


\section{FIGURE 4.33 - KEY ASSUMPTIONS:}

- From the data used in Figure 4.32 , the total cooling primary energy demand for July 1990 was 0.72 quad/month. Broken down further, approximately $2.32 \mathrm{E}+13 \mathrm{Btu}$ would be demanded in one day for July 1990. By applying residential and commercial metered ELCAP data for the winter months (Taylor and Pratt 1989; Pratt et al. 1989) to the appropriate sector diurnal cooling, primary energy demand was determined. 


\section{UTILITY SECTOR}

\section{FIGURE 4.34 - KEY ASSUMPTIONS:}

- This curve was developed with EIA projections for the 20-year period between 1990 and 2010 (EIA 1991b). 


\section{INDUSTRIAL SECTOR}

\section{FIGURE 4.35 - KEY ASSUMPTIONS:}

- Growth in manufacturing primary energy use will increase slowly and any increase in energy consumption will be offset by increases in energy efficiency; therefore, it is assumed that the total waste heat available for manufacturing operations will remain at a constant 5 quad Btu/yr during the 20-year period between 1990 and 2010 (Wilfert et a]. 1984); see Figure 4.35 .

\section{FIGURE 4.36 - KEY ASSUMPTIONS:}

- The seasonal waste supply curve assumes that the 5 quad/yr is evenly divided between the 12 months in a year $(0.42$ quad/mo). 



\section{DISTRIBUTION}

No. of

Copies

\section{OFFSITE}

R. Eaton

U.S. Department of Energy Office of Energy Management Forrestal B]dg., CE-142 5F-064

Washington, DC 20585

K. W. Klunder

U.S. Department of Energy

Office of Energy Management

Forrestal Bldg., CE-142 5F-064

Washington, DC 20585

E. Reimers

U.S. Department of Energy

Office of Energy Management

Forresta1 B1dg., CE-142 5F-064

Washington, DC 20585

12 DOE/Office of Scientific and Technical Information

\section{Rabl}

Electric Power Research Inst itute

P.0. Box 10412

Palo Alto, CA 94303

J. Hurwitch

Energetics, Inc.

9210 Route 108

Co7umbia, MD 21045

J. 0'Sullivan

Institute of Gas Technology

3424 S. State

Chicago, IL 60612

H. Jaehne

3290 Warrenville Center Rd.

Cleveland, $\mathrm{OH} 44122$
No. of

Copies

M. Wahlig

Lawrence Berke]ey Laboratory

University of California

B1dg., 90-2024

1 Cyclotron Road

Berkeley, CA 94720

C. F. Meyer

1141 Cima Linda Lane

Santa Barbara, CA 93108

G. Walmet

New York State Energy Research and Development Agency

Rockefeller Plaza

Albany, NY 12223

J. Tomlinson

Oak Ridge Nationa] Laboratory

Building 9204-1, MS 8045

$Y-12$ Plant, Box 2009

0ak Ridge, TN 37831-8045

Office of Congressman

Sid Morrison

1330 Longworth B7dg.

Washington, DC 20515

Office of Congressman

Tom Bevil

2302 Rayburn B1dg.

Washington, DC 20515

M. Spurr

Resource Efficiency, Inc.

340 Daly Street

St. Paul, MN 55102

National Renewable Energy Laboratory

1536 Cole Blvd.

Golden, CD 80401

ATTN: B. Gupta

T. A. Williams

Distr.1 
No. of

Copies

K. Vakhshoorzaden

Southern Company Service, Inc. P.0. Box 2625

Birmingham, AL 35202

E. Brett

University of Alabama

School of Mines and Energy Development

Box 870164

Tusca7oosa, AL 35487-0164

J. E. Sunderland

University of Massachusetts at Amherst

Dept. of Mechanical Eng.

Amherst, MA 01003

C. W. Sohn

U.S. Army Corps of Engineers

Construction Engineering Research Laboratory

P.0. Box 4005

Champaign, IL 61820-1305

U.S. Department of Interior

Serials 8ranch (G/E)

Washington, DC 20240

ATTN: Natura] Resources

Library

\section{FOREIGN}

A. Boysen

Bengt Hidemark Gosta Danielson Arkitekter SAR

Jarntorget 78

S-11 29 Stockholm

SWEDEN

P. Zegers

Comission of European

Communities

DG XII, E3

200 Weststraat

Brussels

BELGIUM
No. of

Copies

\section{Becker}

DFVLR

Bereich Projekttragerschaften

Linder Hohe

5000 Koeln 90

GEPMANY

C. Streuber

DIDIER Berke

Lessingstrasse 16-18

D-6200 Wiesbaden 1

GEPMANY

P. Lund

Helsinki University of

Technology

Otakaari 3

SF-02150 Espoo

FINLAND

P. Vainio

Helsinki University of

Technology

Otakaari 3

SF-02150 Espoo

FINLAND

B. Saugy

I.E.N.E.R.

EPF-Ecublens

1015 Lausanne

SWITZERLAND

A. Snijders

IF Technology

Frombregstraat 1

6814 RE Arnhem

THE NETHERLANDS

M. Groll

Institut fur Kernenergetik and Energiesystems

Universitat Stuttgart

Pfaffenwaldring 31

Postfach 801140

7000 Stuttgart 80

GERMANY 
No. of Copies

U. Gross

Institut fur Thermodynamik and Waermetechnik

Universitat Stuttgart

Pfaffenwaldring 6

7000 Stuttgart 80

GERMANY

V. Lottner

KFA Julich, PLE

P.0. Box 1913

D-5170 Julich

GERMANY

S. Lundin

K. M. Kjessier \& Mannerstrale $A B$

P.0. Box 7124

S-171 07 Solna

SWEDEN

B. Qvale

Laboratory for Energetics

Technical University of Denmark

DTH Building 403

DK-2800 Lyngby

DENMARK

Lambrecht Industrial Consultants

Max-Ruttgers-Str 29

D-8021 Irschenhausen GERMANY

\section{B. Matthey}

Consulting-Engineers Ltd.

$\mathrm{CH}-2205$ Montezillon-Neuchatel

SWITZERLAND

Pirjo-Liisa Vainio

Ministry of Trade and Industry

Energy Department

Pohjoinen Makasi ininkatu 6

00130 Hels inki

FINLAND
No. of

Copies

G. J. van Mourik

NOVEM

P.0. $80 \times 8242$

3503 RE Utrecht

THE NETHERLANDS

E. L. Morofsky

Public Works Canada

C456 Sir Charles Tupper 81dg.

Riverside $\mathrm{Dr}$. and Heron Rd.

Ottawa, Ontario

K1A OM2

CANADA

P. L. Christensen

Riso National Laboratory

DK-4000 Roskilde

DENMARK

B. T. Sellberg

Swedish Council for Building Research

Sankt Goransgatan 66

S-11233 Stockholm

SWEDEN

Rudolf Giebe

Universitat Stuttgart

Pfaffenwaldring 6

7000 Stuttgart 80

GERMANY

\section{ONSITE}

DOE Richland Field office

D. R. Segna, A5-90

Westinghouse Hanford Company

K. A. Corcoran 
No. of

Copies

2 Battelle Washington Operations
R. D. Rapoport

R. D. Sands

42 Pacific Northwest Laboratory

Z. I, Antoniak, K7-15

D. B. Belzer, K6-57

D. R. Brown, K6-61

K. K. Daell enbach, K6-6l (2)

D. E. Deonigi, K6-54

J. A. Dirks, K6-61

M. K. Drost, K5-19
No. of

Copies

R. L. Eckert, K6-54

M. P. Hattrup, K6-54

K. R. Hughes, K6-54 (2)

K. K. Humphreys, K6-61

L. D. Kannberg, K5-2l (15)

S. A. Shankle, K6-54

G. E. Spanner, K6-61 (5)

G. P. Sullivan, K6-61

G. L. Wilfert, K6-54 Publishing Coordination Technical Report Files (5) 